\title{
AN INVESTIGATION OF CARDIAC INDICES IN NORMAL SLEEPERS AND THOSE WITH INSOMNIA DISORDER \\ by
}

Angela M. Lachowski

Master of Arts, Ryerson University, 2012

\author{
A dissertation \\ presented to Ryerson University \\ in partial fulfillment of the \\ requirements for the degree of \\ Doctor of Philosophy \\ in the program of \\ Psychology \\ Toronto, Ontario, Canada, 2017 \\ (C) Angela M. Lachowski 2017
}


Author's Declaration

\section{AUTHOR'S DECLARATION FOR ELECTRONIC SUBMISSION OF A DISSERTATION}

I hereby declare that I am the sole author of this dissertation. This is a true copy of the dissertation, including any required final revisions, as accepted by my examiners.

I authorize Ryerson University to lend this dissertation to other institutions or individuals for the purpose of scholarly research.

I further authorize Ryerson University to reproduce this dissertation by photocopying or by other means, in total or in part, at the request of other institutions or individuals for the purpose of scholarly research.

I understand that my dissertation may be made electronically available to the public. 


\begin{abstract}
An Investigation of Cardiac Indices in Normal Sleepers and those with Insomnia Disorder Doctor of Philosophy, Fall 2017

Angela Lachowski

Psychology, Ryerson University
\end{abstract}

Cardiovascular disease (CVD) is the world's leading cause of death. Insomnia, a prevalent disorder among Canadian adults, has been identified in some studies as an independent risk factor for CVD. Heart rate variability (HRV), often used as a proxy for autonomic activity in the body, has been demonstrated to be impaired in individuals with insomnia. Scientists have suggested that results implicate exaggerated sympathetic activation in people with insomnia, which can lead to impaired cardiac reactivity and poorer heart health. Much of the research in this field has been with poorly classified clinical groups and potentially confounding comorbid disorders, making the results difficult to interpret. Findings of the present study extend our understanding of the relationship between insomnia and CVD by addressing the weaknesses of prior research and by utilizing contemporary statistical methods. A well-classified clinical group meeting Research Diagnostic Criteria for Insomnia Disorder (ID; $\mathrm{N}=26$ ) was compared to normal sleepers $(\mathrm{NS} ; \mathrm{N}=23$ ) on two well-validated indices of cardiovascular health and autonomic activity, cardiac output (CO) and pre-ejection period (PEP). Values of these indices were derived from an acoustic challenge paradigm that allowed the heart to adapt to the environment via autonomic influence. A multi-level modeling (MLM) approach was used to evaluate both the within-person and between-person differences in autonomic activation and cardiac functioning using a group of predictors that are known to be associated with insomnia and/or CVD. Results of the level two MLM analyses revealed that sleep variables are not 
significantly predictive of cardiac reactivity indices. A post-hoc linear regression analysis using the same predictor variables to predict HRV revealed that insomnia was significantly predictive of HRV. These conflicting results raise important questions about research methodology, validity of chosen indices, and statistical techniques. 


\section{Acknowledgments}

Sincerest thanks to my graduate mentor, Dr. Colleen Carney. The stars aligned when you took a chance on me at a time when I didn't know much at all about sleep but was willing to learn. You taught me to be a scientist, but also that it is important to love what you do. Thanks also to my examination committee, Drs. Kristin Vickers, Alexandra Fiocco, Catherine Fichten, and Suzanne Fredericks, who provided not only helpful feedback but contributed to an overall quite pleasant and thought-provoking dissertation defense experience.

My labmates past and present, who became friends and kept me sane, especially Olya, lab manager and gentle spirit - I needed you all to complete this project and I'm indebted to you. Thanks to my friends who never questioned why I undertook this very long degree (though I've been the butt of many jokes - good thing I have a sense of humour!) - your support means more than you know. Innumerable thanks to my partner Ben, who tolerated many hours of tearful complaints about statistics, papers littered everywhere, and for generally just holding my hand and being my home base until I got it done. My family has been neverendingly supportive, especially my \#1 fan, my mom - I couldn't have finished this dissertation and degree without the limitless love and support you and Dad provided. You will never know how thankful I am to have had you both. Special thanks to my Babci, who taught me that girls who exercise their brains can grow up to be anything they want to be.

Finally, to all the incredibly bright, determined, and generous young women who volunteered their time to help me with this project: I'm grateful and honoured to have worked with all of you, and I'm excited to see where you will go in your own careers. The future is female! 


\section{Dedication}

For my dad, my knight in shining armour, who was there at the beginning of this project but not the end. He taught me to never give up. 


\section{TABLE OF CONTENTS}

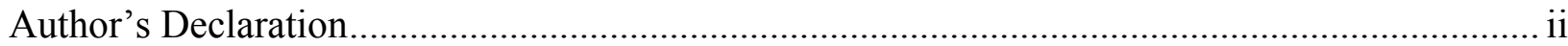

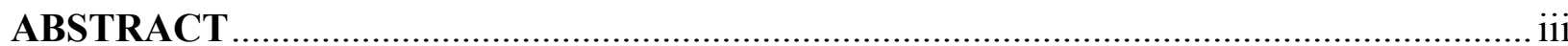

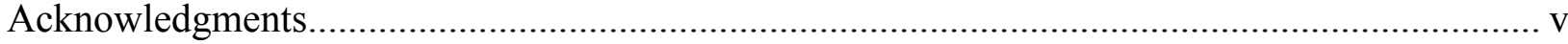

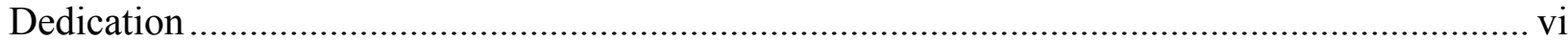

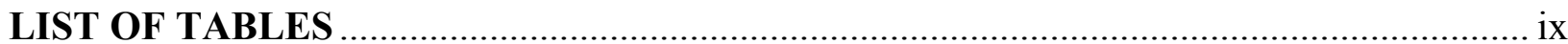

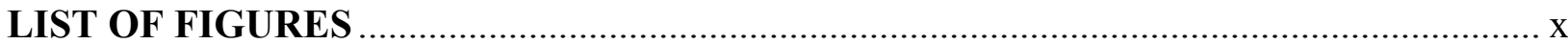

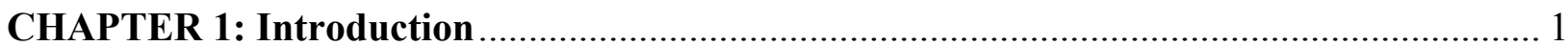

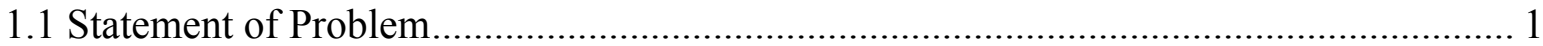

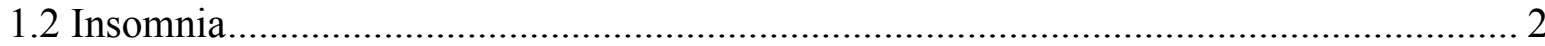

1.3 Insomnia and Cardiovascular Disease ………………............................................ 3

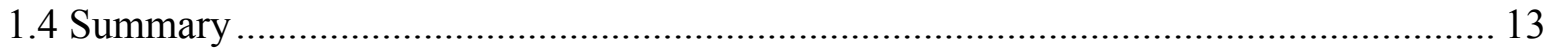

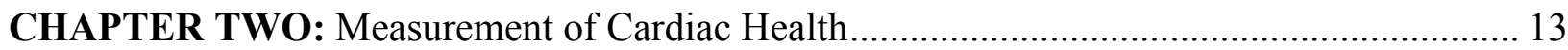

2.1 Role of the Autonomic Nervous System in Organ Function .......................................... 13

2.2 Evaluation of Cardiac Health: Impedance Cardiography ……………............................ 15

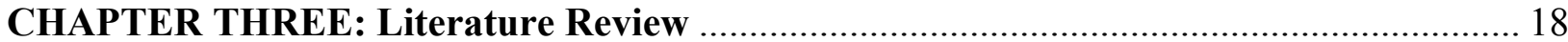

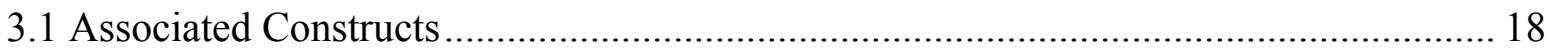

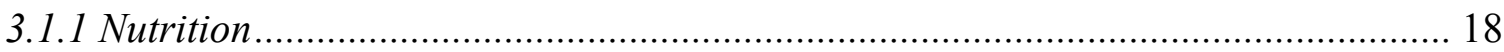

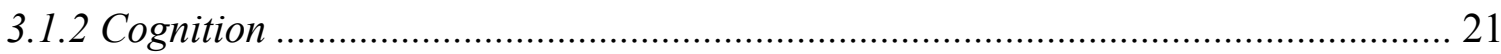

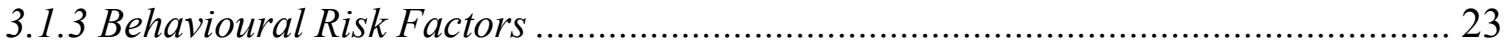

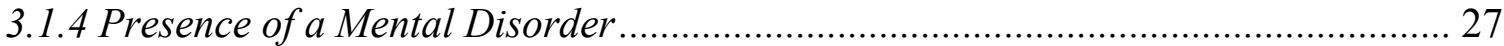

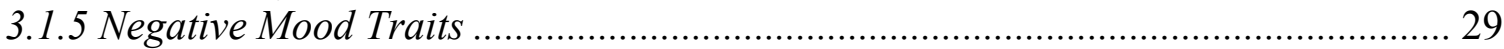

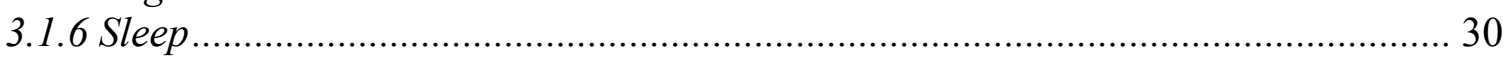

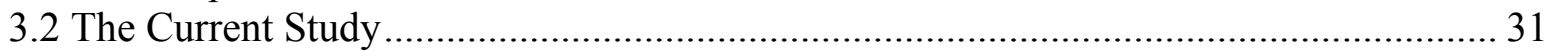

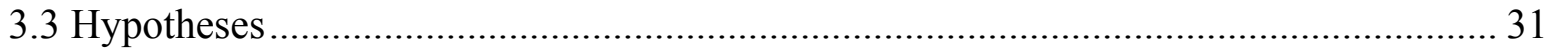

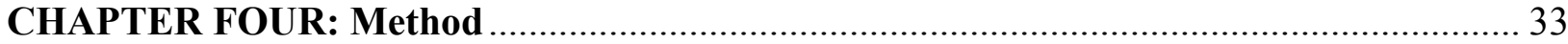

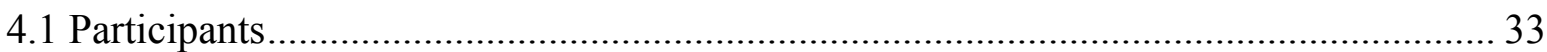

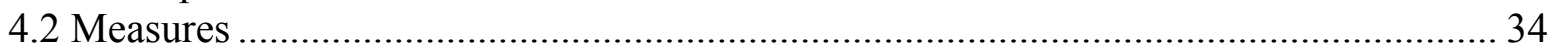

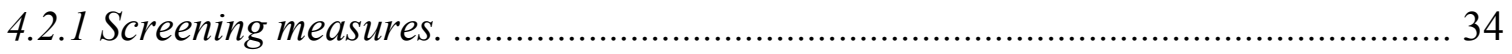

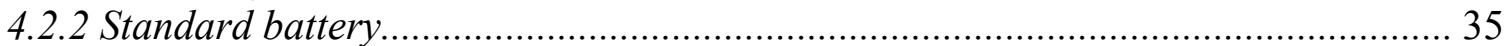

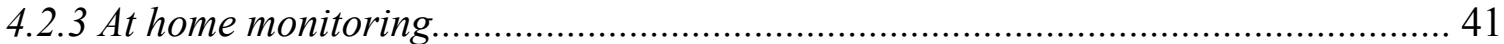

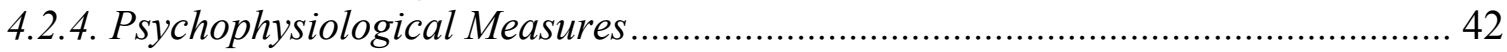

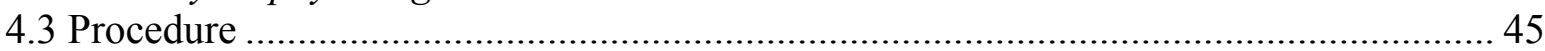

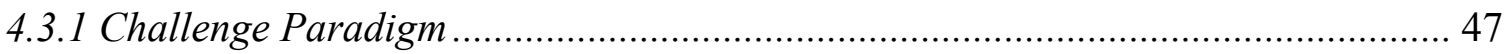

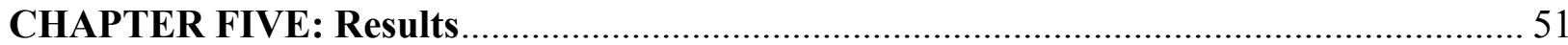

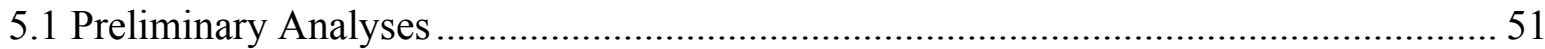

5.2 Demographic Characteristics of the Sample ............................................................... 51

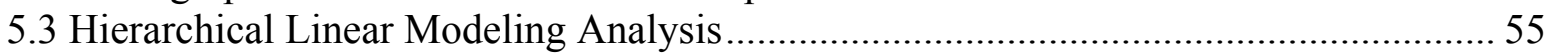

5.3.1 HLM Data Preparation............................................................................... 56

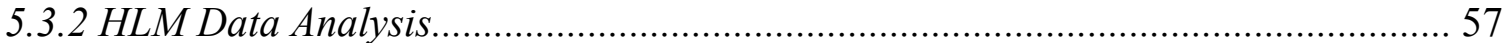

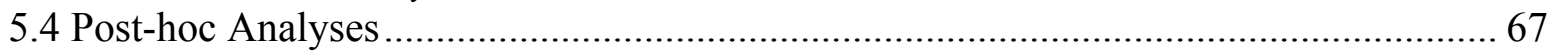

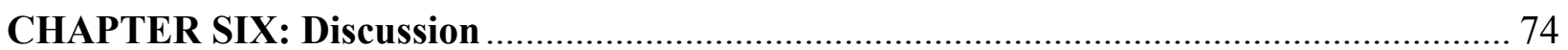

6.1 Synthesis of the Literature and Findings from the Current Study ................................. 74 
6.2 Consideration of Characteristics of the Sample.

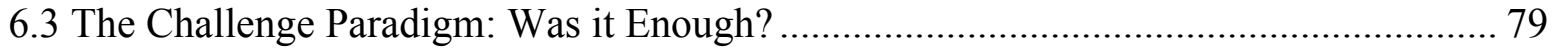

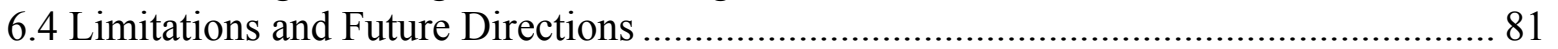

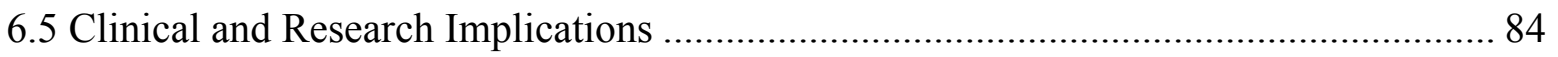

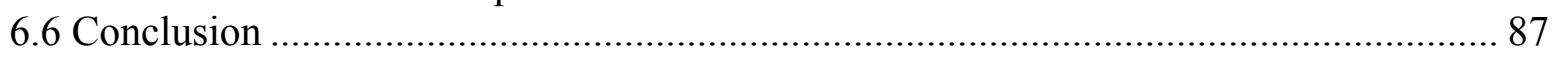

REFERENCES

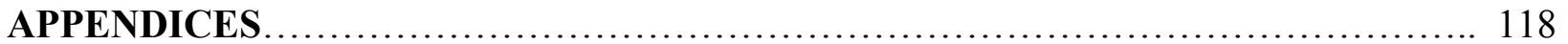

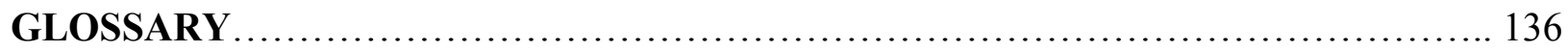




\section{LIST OF TABLES}

Table 1: Participant Demographics

Table 2: Group Comparison of Sleep Variables and Self-Report Dependent Variables

Table 3: Unconditional Model for CO and PEP

Table 4: Conditional Model For CO Including Theoretical Predictors

Table 5: Conditional Model for PEP Including Theoretical Predictors

Table 6: Conditional Model for CO Including Percent of Variance Explained by Phase

Table 7: Conditional Model for PEP Including Percent of Variance Explained by Phase

Table 8: Mean CO and PEP values by Phase

Table 9: Mean HF HRV (normalized unit) values by Phase

Table 10: Hierarchical Multiple Regression Analysis Predicting HF HRV in Dark Phase 2

Table 11: Hierarchical Multiple Regression Analysis Predicting HF HRV in Recovery Phase 


\section{LIST OF FIGURES}

Figure 1: BIOPAC Lead II Einthoven Configuration

Figure 2: The Startle Paradigm, Randomized by Group

Figure 3: CO for Each Participant Across Paradigm Phases

Figure 4: PEP for Each Participant Across Paradigm Phases 


\section{LIST OF APPENDICES}

Appendix A: Participant Demographic Information, Duke Structured Interview for Sleep

Disorders

Appendix B: Insomnia Severity Index

Appendix C: Depression Anxiety Stress Scale-21

Appendix D: Daytime Insomnia Symptom Rumination Scale

Appendix E: Semi-Quantitative Food Frequency Questionnaire

Appendix F: Medication Quantification Scale

Appendix G: Consensus Sleep Diary 
An Investigation of Cardiac Indices in Normal Sleepers and those with Insomnia Disorder

\section{CHAPTER 1}

\subsection{Statement of Problem}

\section{Introduction}

Among Canadian adults, heart disease is the second leading cause of death, accounting for almost $30 \%$ of all deaths (Government of Canada, 2014a). According to the world's leading cardiovascular research organizations, the World Heart Federation and the American Heart Association, cardiovascular disease (CVD) is now the leading cause of death globally, and the number of deaths per year due to CVD is expected to exceed 23 million by 2030 (Smith et al., 2012). Identifiable risk factors are urgently needed to ameliorate this statistic. Insomnia has been identified in some studies as an independent risk factor of heart disease, even in the absence of respiratory pathologies (Schwartz et al., 1999; Sofi et al., 2014). Population-based studies indicate that insomnia is a common disorder, affecting about $30 \%$ of the adult population intermittently and 10-15\% chronically (Buysse, Ancoli-lsrael, Edinger, Lichstein, \& Morin, 2006; Ohayon, 2002; Roth, 2007). Taking a moment to Google "consequences of insomnia" reveals a glimpse into the frightening public archive of this relationship; even the Mayo Clinic writes that insomnia may lead to: "increased risk and severity of long-term diseases or conditions, such as high blood pressure, heart diseases, and diabetes" (MayoClinic.org, 2014). The high prevalence of insomnia and its purported link to increased risk for heart disease make the relationship between insomnia and heart health an important scientific target of study. However, due to mixed evidence and studies with questionable methodology, it is unclear if having insomnia increases risk for cardiovascular disease. Addressing this question is imperative in order for researchers and healthcare advocates to potentially target risk factors for heart disease prevention among the Canadian adult population. 
The following sections will provide an overview of the status of the literature on the relationship between insomnia and CVD. Such a review is necessary to provide a sound rationale for why a number of constructs are identified herein as important predictor variables included in the analyses that further evaluated this relationship. As both insomnia and CVD are influenced by a number of constructs, including sleep, personal characteristics, and modifiable health behaviours, several constructs were carefully selected to be measured and included in the analyses. The inclusion of these variables in this study, often neglected or poorly characterized in previous work, contributes to its methodological strength.

\subsection{Insomnia}

According to the Diagnostic and Statistical Manual of Mental Disorders $5^{\text {th }}$ edition, insomnia is a subjective disorder that is characterized by difficulty falling asleep, staying asleep, waking too early, or feeling unrefreshed, and is accompanied by daytime impairment for at least a three month duration (American Psychiatric Association, 2013). The widespread prevalence of insomnia and its association with deleterious personal and societal consequences make it an important public health concern (Daley, Morin, LeBlanc, Grégoire, \& Savard, 2009; Ford \& Kamerow, 1989; Morin, LeBlanc, Daley, Gregoire, \& Mérette, 2006; Ohayon, 2002). Personal and societal costs include reduced quality of life, higher rates of work absenteeism, greater utilization of healthcare resources, decreased attention and memory, and increased traffic and work-related accidents (Daley et al., 2009; Edinger \& Wohlgemuth, 1999; Roth, 2007). Presence of insomnia also increases the risk of other psychiatric disorders, such as depression or anxiety disorders (Riedel \& Lichstein, 2000). Economically, insomnia costs Canadians approximately $\$ 970.6$ million for insomnia-related absenteeism and $\$ 5.0$ billion for decreased 
worked productivity (Daley et al., 2009). Clearly, insomnia bestows a significant burden on both general health and the Canadian economy, warranting continued scientific attention.

\subsection{Insomnia and Cardiovascular Disease}

The relationship between insomnia and CVD has been investigated from various angles, leaving a somewhat murky literature with no sound consensus about either strength of relationship or direction of causality. Like many other disorders with biological, psychological, and social influences, there are numerous reasons for the complexity of the relationship between insomnia and CVD. In itself, CVD is multifarious; it is actually an umbrella term for a class of diseases that involves the heart and/or blood vessels of the body. Coronary artery disease, hypertension, and heart failure are just a few of the many conditions that are contained under the umbrella of CVD. Insomnia is also a multidimensional disorder; its many social and psychological influences preclude discovery of any simple biomarker that would allow for rapid and simple diagnosis. To add to these complications, over time, insomnia has been evaluated in a number of different ways, using a number of different operational definitions that leaves comparison or aggregation of studies difficult. For example, some epidemiologic research has indicated that insomnia may be an independent risk factor for heart disease and cardiovascular mortality even in the absence of respiratory pathology such as sleep apnea-hypopnea syndrome (Schwartz et al., 1999). Schwartz and colleagues published a review of epidemiologic studies to clarify the status of the literature on the association between sleep complaints and coronary events. They reported that higher-quality studies showed risk ratios of 1.47-3.90 between difficulty falling asleep and coronary events, even after adjusting for age and other coronary risk factors. A later prospective trial found that symptoms of insomnia that included waking up repeatedly and awakening tired and fatigued predicted a slightly elevated risk for CVD but not 
hypertension, while endorsement of difficulty falling asleep or waking repeatedly predicted increased risk for hypertension (Phillips \& Mannino, 2007). Some other large prospective epidemiological studies have failed to replicate these results, showing that symptoms of insomnia do not predict cardiovascular mortality in the absence of other non-respiratory pathology (Kripke, Garfinkel, Wingard, Klauber, \& Marler, 2002; Phillips \& Mannino, 2005, 2007). A 2013 meta-analysis of 11 prospective trials that assessed the association between insomnia and hypertension incidence in normotensive adults found that the pooled effect estimates for difficulty falling asleep were in the direction of increased risk for hypertension incidence, but this association was not significant (Meng, Zheng, \& Hui, 2013). Analyses included evaluation of publication bias, which was not found to have an influence on these results. Additionally, the subgroup of included studies that adjusted for psychological factors (e.g. depression) had a greater effect than the subgroup of studies that did not make such adjustments. The authors speculated that the effect of insomnia variables on hypertension incidence is partially accounted for by the presence of psychological factors, or the existence of psychological factors might underestimate the effect of insomnia symptoms on hypertension.

Findings from the above studies indicate that there may be increased risk for CVD among individuals with insomnia. Unfortunately, epidemiological studies investigating insomnia have several methodological limitations. For example, these studies often include only one variable to assess "insomnia", which may have poor specificity for a diagnosis of insomnia disorder. Additionally, the varying definitions of insomnia used in these studies make the results difficult to compare. Other methodological drawbacks include poor characterization of occult sleep disorders such as apnea or periodic limb movement disorder; thus, the "insomnia" evaluated in many of the studies may actually be a sleep disorder other than insomnia. Though 
epidemiological studies are often referenced due to their considerably larger sample size than most randomized controlled trials, their frequently poor classification of variables of interest renders their construct validity quite low. Thus, studies with different methodological design are considered to try and clarify this relationship.

One large community-based prospective cohort study evaluated the relationship between persistent (i.e. insomnia persisting between two survey periods of five years) and intermittent (i.e., insomnia existing in only one of the two survey periods) insomnia and all-cause mortality (Parthasarathy et al., 2015). Consistent with national statistics, heart disease was the leading cause of death after the 5-year period. Results indicated that only persistent insomnia was associated with mortality risk; this relationship was independent of the use of hypnotics, sex, age, systemic inflammation, and other common confounding factors. Importantly, even when the sample was restricted to individuals reclining for at least 7 hours per day (i.e., opportunity for normal sleep duration), the association between persistent insomnia and mortality risk remained. Secondary analyses revealed that this relationship was largely explained by heart disease and cardiopulmonary mortality rather than cancer mortality. Unfortunately, this study evaluated insomnia only via survey method, which negatively impacts the validity of an actual insomnia diagnosis: primary insomnia cannot be distinguished from other occult disorders. Thus, firm conclusions cannot be drawn about the nature of this relationship.

Regardless of its limitations, this last study identifies an important potentially confounding issue when evaluating the cardiovascular consequences of insomnia. In the past five to ten years, there has been considerable interest in the relationship between insomnia with short sleep duration and hypertension/CVD. Short sleep duration (the definition of which can vary by study, but is often objectively derived $<5-6$ hours of sleep per night), though it can 
coexist with insomnia, is actually a separate phenomenon (Vgontzas, Fernandez-Mendoza, Liao, \& Bixler, 2013). More recently, some researchers have recommended differentiating between insomnia with and without objective short sleep duration, as they have been empirically shown to have unique characteristics (Bathgate, Edinger, Wyatt, \& Krystal, 2016). Short sleep is also different from sleep curtailment, which occurs when people purposely shorten their sleep period (e.g., when someone has a demanding work schedule or new baby). In short sleep duration studies, the population of short sleepers often includes both individuals who purposely curtail their sleep and those who would like to sleep more, but their bodies are not able to produce more sleep (Meng et al., 2013). Thus, results do not allow for differentiation between biologically short sleepers and those with sleep curtailment, which may be an important distinction.

Sleep duration was evaluated in another large prospective insomnia study that assessed risk for mortality (not necessarily due to CVD). Unfortunately, this study employed survey methods to assess for the presence of insomnia and sleep duration. Researchers found that mortality risk was significantly increased in male participants with insomnia who slept for less than 6 hours compared to the "normal sleep duration, no insomnia" group, even after adjusting for diabetes, hypertension, and other confounders (Vgontzas et al., 2010). Interestingly, in women, insomnia with short sleep duration was not associated with increased mortality. Another large epidemiological study found that only long and short sleep duration (i.e., longer than 8 hours and less than 6 hours) were associated with increased mortality (Kripke et al., 2002). Thus, it appears that sleep duration may be an important factor to consider when assessing for the relationship between insomnia and CVD. Some limitations of this dichotomization approach are reviewed in the discussion. 
Many of the aforementioned studies failed to use well-validated classification methods for insomnia and/or sleep duration, which leaves questions about the validity of the results. The following study employed stronger methodology by objectively assessing sleep via two nights of polysomnography in a large population-based study. Researchers found that chronic insomnia (duration $>1$ year, assessed via telephone questionnaire) with objective short sleep duration was associated with physiological hyperarousal as assessed by blood pressure. The researchers hypothesized that this activation of the stress system leads to subsequent medical sequelae, including increased mortality (Fernandez-Mendoza et al., 2011). Chronic insomnia that was not associated with objective short sleep duration was characterized by lack of physiological hyperarousal, which they hypothesized leads to normal activation of the stress system. In these cases, the researchers hypothesized that insomnia was possibly due to sleep-state misperception (that is, the individual is sleeping, but perceives wakefulness). It was evidently the short sleep duration in addition to insomnia that was associated with physiological hyperarousal.

Further evidence for the importance of sleep duration when assessing for cardiovascular risk comes from a recent cross-sectional study that evaluated risk for hypertension by insomnia symptoms both with and without short sleep duration (Bathgate et al., 2016). These researchers found that the short sleep duration group (defined as $<6$ hours of sleep) was associated with a threefold significantly greater risk for hypertension after adjusting for covariates (age, depression, BMI, medical disorders, alcohol, smoking, caffeine). Interestingly, this relationship was found only when short sleep duration was derived objectively (i.e. with overnight polysomnography) versus subjectively (i.e. via two week subjective sleep diaries). The authors argue that the association between CVD and insomnia may be best accounted for with short objective sleep duration. 
Given the implications for treatment, insomnia and cardiovascular health researchers are currently seeking to understand the mechanisms behind the potential relationship between insomnia and CVD. Several models of insomnia propose that a chronic condition of cognitive and physiological hyperarousal underlies the disorder (De Zambotti, Covassin, De Min Tona, Sarlo, \& Stegagno, 2011). Evidence of this hyperactivation in insomnia has been demonstrated by numerous studies; physiologically, insomnia has been linked to decreased nocturnal production of melatonin (Riemann et al., 2002), high levels of cortisol and ACTH (Rodenbeck, Huether, Rüther, \& Hajak, 2002; Vgontzas et al., 2010), increased metabolic rate (Bonnet \& Arand, 1995; Nofzinger et al., 2004), basal temperature (Monroe, 1967), muscle tone (Freedman \& Sattler, 1982), electrodermal activity (Monroe, 1967), and higher sympathetic activation across all stages of sleep according to heart rate variability analysis (Bonnet \& Arand, 1998). Cognitively, individuals with insomnia more frequently report intrusive thoughts about sleep onset than normal sleepers (Carney, Edinger, Meyer, Lindman, \& Istre, 2006; Harvey, 2002; Morin, Rodrigue, \& Ivers, 2003) and report higher subjective scores of hyperactivation on selfreport questionnaires (Jansson-Fröjmark \& Linton, 2008; Szelenberger \& Niemcewicz, 2000). Taken together, these findings implicate chronic hyperactivation in both physiological and cognitive domains among individuals with insomnia. It has been hypothesized that this chronic hyperactivation may be the physiological link that leads to an increased risk for chronic cardiac conditions among individuals with insomnia (Brosschot, Van Dijk, \& Thayer, 2007).

\subsubsection{Heart Rate Variability as a Measure of Sympathetic Hyperactivation}

Some researchers have investigated the idea that increased CV risk among those with insomnia comes from a state of chronic sympathetic activation. In the past decade, there has been a surge of interest in investigating heart rate variability (HRV) in individuals with insomnia 
as a method of evaluating cardiovascular health in this population (e.g. Bonnet \& Arand, 1998; Bonnet \& Arand, 1996; Busek, Vanková, Opavský, Salinger, \& Nevsímalová, 2005; Fang, Huang, Yang, \& Tsai, 2008; Hall et al., 2004; Jurysta et al., 2009). Measures of HRV assess the temporal variation of the interval between consecutive heartbeats as well as oscillations between consecutive instantaneous heart rates (Task Force of the European Society of Cardiology and The North American Society of Pacing and Electrophysiology, 1996). As HRV reflects continuous changes in the sympathetic/parasympathetic balance of the autonomic nervous system, researchers have used HRV as an indicator of sympathetic hyperarousal (Karim, Hasan, \& Sanowar, 2011). Further, HRV has been demonstrated to be a strong independent predictor of mortality following acute myocardial infarction (Bigger et al., 1992; Kleiger, Miller, Bigger Jr., \& Moss, 1987). Low HRV in particular has been found to be a risk factor for cardiovascular disease and overall morbidity and mortality (Friedman \& Thayer, 1998; Thayer \& Brosschot, 2005; Thayer, Smith, Rossy, Sollers, \& Friedman, 1998; Yeragani et al., 2002). HRV is also simple and inexpensive to assess, which may also help to explain its surge in popularity in CVD risk investigations.

Several other insomnia-specific studies have also investigated HRV as a mechanistic link for chronic sympathetic hyperactivation. In a frequently cited paper, Bonnet and Arand (1998) matched individuals with psychophysiological insomnia (individuals who display elevated heart rate, body temperature, and whole body metabolic rate) and no other sleep or psychiatric disorders with individuals with normal sleep for a 36-hour laboratory sleep study. Individuals with insomnia displayed significantly lower overall HRV compared with controls across all stages of sleep (Bonnet \& Arand, 1998). The authors postulated that insomnia is associated with chronic sympathetic hyperactivity indicated by the increase in sympathovagal balance (decreased 
HRV) in the insomnia group. Moreover, they added that since increased sympathetic activity is related to many risk factors for coronary heart disease (e.g., increases in circulating triglycerides and cholesterol), this insomnia/SNS connection could be contributing to the increased risk for cardiovascular mortality in individuals with insomnia. This theory is supported by more recent research investigating a sample of individuals with chronic fatigue syndrome (CFS) that found that HRV parameters were the best predictors of subjective sleep measures (Burton, Rahman, Kadota, Lloyd, \& Vollmer-Conna, 2010). The authors of this paper purport that this finding suggests a pervasive state of nocturnal sympathetic hyperarousal in individuals with CFS. Bonnet and Arand's theory might suggest that it is this state of sympathetic hyperarousal that leads to increased cardiovascular mortality. However, as stated above, other studies have failed to replicate these results (e.g., Jurysta et al., 2009), and evaluation of cardiac functioning using solely HRV may not provide a comprehensive view of cardiac function, specifically with respect to sympathetic hyperactivation. For example, one study investigated changes in activation of the nervous system among individuals who had undergone cognitive behavioural therapy for insomnia (CBT-I; Jarrin et al., 2016). HRV was assessed via ECG during three consecutive nights pretreatment and two nights at posttreatment. Their results were contrary to their hypothesis: interestingly, sleep improvements following CBT-I were found to be associated with dampened rather than increased parasympathetic nervous system activation and an overall increased sympathovagal balance, reflecting increased sympathetic hyperarousal after treatment. The authors postulated that perhaps the additional stress of sleeping in a strange environment (the sleep laboratory) led to the increased activation, and recommended that the study be replicated in a naturalistic setting and with a control group. An alternate hypothesis could be that immediately posttreatment, participants are still adhering to a stricter sleep schedule and their 
time in bed is low, possibly leading to some sympathetic hyperarousal that may diminish with time and adjustment to the sleep schedule. Nonetheless, it seems that the evidence regarding physiological sympathetic hyperarousal among those with insomnia is mixed. Additional research using more sophisticated techniques to ascertain sympathetic and parasympathetic influence to cardiac reactivity is needed to understand how insomnia may or may not influence cardiac function.

\subsubsection{Critical Analysis of Heart Rate Variability}

Though many hundreds of researchers have employed HRV as an index of central nervous system activation, critics of HRV analysis argue that it provides an incomplete picture of cardiac function that relies heavily on external validation of autonomic system activation (e.g. Goldstein, Bentho, Park, \& Sharabi, 2011; Heathers, 2012, 2014). This difficulty in ascertaining the specific autonomic influences on the various oscillation frequencies of short-term HRV recordings is due in large part to the myriad of autonomic outflows that affect HRV (e.g. the sinoatrial node, body vasculature, endothelial and endocrine factors; Heathers, 2014). Though HRV has been demonstrated to provide a representative view of parasympathetic activation (Task Force, 1996), it has equally been demonstrated to provide an incomplete and even erroneous assessment of sympathetic activation (Goldstein et al., 2011). Spectral power in the low frequency portion of the heart period variability is commonly used to assess sympathetic activation of the heart; unfortunately, this index is misleading as both sympathetic and parasympathetic activity contribute to the low frequency spectrum of cardiac activation (Quigley \& Stifter, 2006). The commonly used LF/HF HRV ratio is equally flawed, as it assumes that the parasympathetic contribution to low frequency power varies in some predictable way to the sympathetic contribution. This harmonious relationship may not occur, as both autonomic 
branches have been shown to vary independently of one another (Berntson, Cacioppo, \& Quigley, 1991; Cacioppo et al., 1994).

Based on the existing literature, the question of whether or not those with insomnia exhibit sympathetic hyperactivation remains unknown. Some studies that have investigated this hypothesis have largely relied on LF HRV or the LF/HF HRV ratio as the physiological correlate of sympathetic activation (e.g. Bonnet \& Arand, 1998; Jurysta et al., 2003). As a result of these dubious claims, strong conclusions about the meaning of these associations cannot be established. Another study investigated the relationship between degree of sleep disruption in both REM and non-REM (NREM) periods of sleep via the coefficient of variation for HRV, a frequency-domain parameter that does not rely on external validation with other autonomic system activation measures (Krystal, Edinger, Wohlgemuth, \& Marsh, 2002; Lachowski, 2012). Findings indicated that HRV was not associated with sleep index total wake time across all stages of sleep, which was in contrast to the study's hypotheses. Interestingly, a somewhat baffling finding of this study involved the comparison of participants with and without a current anxiety disorder diagnosis; individuals with a current anxiety disorder were found to have a significantly higher coefficient of variation (indicative of decreased sympathetic activation) across REM sleep only. In fact, the current literature surrounding worry and HRV would suggest the opposite; that anxiety would be associated with increased sympathetic activation (Brosschot et al., 2007). It is possible that the inherent measurement flaws of HRV itself may have erroneously influenced these findings. Fortunately, though, other physiological measures have been well-validated to specifically evaluate sympathetic hyperarousal and overall cardiac function, specifically, pre-ejection period (PEP) and cardiac output (CO). These indices are described in detail in later sections. 


\subsection{Summary}

Clearly, the literature is murky when it comes to the relationship between insomnia and CVD. It remains unclear as to why, in some investigations, individuals with insomnia might have an increased risk for cardiovascular disease. Much of the research so far comes from epidemiological studies with poor classification of insomnia, or the chosen measures of heart health do not provide a comprehensive view of cardiac functioning. Some researchers have argued that short sleep duration is a mechanistic link to CVD (e.g. Bathgate et al., 2016). Other scientists have postulated that sympathetic hyperarousal, which leads to hyperactivation of the heart, may be a mechanism through which CVD may develop (Zambotti et al., 2012). The primary aim of this study was to test the hypothesis that individuals with insomnia demonstrate higher levels of sympathetic activation through a thoroughly classified sample with a normal sleeper comparison group, well-validated cardiac indices, and more contemporary statistical methods. Heart rate variability was assessed only as part of a more thorough investigation of cardiac function through a method called impedance cardiography, described in detail below.

\section{CHAPTER 2}

\section{MEASUREMENT OF CARDIAC HEALTH}

\subsection{Role of the Autonomic Nervous System in Organ Function}

The autonomic nervous system (ANS) controls the involuntary regulation of the body's internal organs. It operates via a homeostatic regulatory system involving both an activating side (the sympathetic nervous system, or SNS) and complementary deactivating side (the parasympathetic nervous system, or PNS). The sympathetic branch of the ANS performs 
catabolic functions; it modulates physiological activation throughout the body. The parasympathetic branch is involved in anabolic functions and thus acts as the deactivating partner to the sympathetic system. As sleep is an automatic bodily function, the ANS plays a vital role in its regulation. Traditionally, sympathetic control prevails during wakefulness, and parasympathetic dominance takes over during sleep (with the exception of rapid eye movement sleep stages; Somers, Dyken, Mark, \& Abboud, 1993).

A healthy individual's ANS is able to initiate both the SNS and PNS when required by either internal or external environmental circumstances. For example, with respect to the heart, both systems exert a regulatory effect on heart rate by influencing the sinoatrial (SA) node, the primary pacemaker for the heart. The sympathetic branch of the ANS increases heart rate by sending an excitatory signal to the SA node. In contrast, the parasympathetic branch of the ANS provides a regulatory balance to the sympathetic branch by exerting an inhibitory effect on the SA node, resulting in decreased heart rate (Appelhans \& Luecken, 2006). In someone with a healthy heart, these two branches work together in homeostatic harmony within the ANS to allow the body to respond and adapt quickly and appropriately to stress and environmental stimuli.

Though the human body has evolved to contain a usually seamlessly responsive ANS, there are times when this elegant complementary system falls out of sync, and one branch overshadows another. Low parasympathetic activity results in sympathetic dominance, which can cause autonomic behaviour that, when sustained over long periods of time, has been hypothesized to be somatically and psychologically pathogenic (Brosschot et al., 2007). Psychopathological conditions such as depression, anxiety, post-traumatic stress disorder, and schizophrenia are all associated with a lack of inhibitory neural processes from the PNS, 
resulting in sympathetic dominance (Friedman \& Thayer, 1998; Thayer, Hansen, Saus-Rose, \& Johnsen, 2009). It has been hypothesized that increased risk for chronic cardiac conditions among individuals with psychopathology may result from a dysfunctional ANS (Brosschot et al., 2007).

\subsection{Evaluation of Cardiac Health: Impedance Cardiography}

Measurement of such an intricate and elegant organ such as the heart requires sophisticated technology. Impedance cardiography (ICG), originally developed by NASA in the 1960 's, is a non-invasive method to assess an individual's hemodynamic status (i.e., the heart's ability to generate enough force to pump blood through the circulatory system). In essence, it is a technology that converts changes in thoracic impedance that occur during the heart cycle to changes in volume over time. Previous noninvasive methods used for this purpose include magnetic resonance imaging and radionuclide angiography, which are unfortunately both complicated and expensive alternatives. With recent advances in hardware and software, ICG has offered a new standard of treatment for evaluation of hemodynamic state (Sodolski \& Kutarski, 2007). A fall in basic chest resistance that can result in the aggravation of heart failure is easily detected via ICG technology.

The methodology of ICG is based on changes in electrical resistance of the thorax during heartbeat. Through the placement of eight electrodes on an individual's neck and thorax, a constant electrical current is transmitted through the chest. Like all electricity, the current seeks the path of least resistance, which in this case is through the blood-filled aorta. At this point, baseline impedance (interruption) to the current is measured. With each heartbeat, blood volume and velocity in the aorta change; ECG is used as part of ICG to assess corresponding changes in impedance. Ohm's law states that changes in voltage are directly proportional to changes in 
resistance under conditions of constant electrical intensity. The basic resistance, known as $Z_{O}$, is calculated as the sum of the resistance of all of the components of the chest (i.e., the adipose tissue, muscles, lungs, vessels, bones, and air; Sodolski \& Kutarski, 2007). Changes in the basic resistance of the chest $\left(Z_{O}\right)$ result from changes in both the volume of the lungs during respiration and changes in the volume and blood velocity of large vessels during the stages of a heartbeat. Impedance cardiography uses electronic filters to mathematically eliminate changes in resistance caused by breathing, which allows for the calculation of changes in resistance associated with outflow of blood (known as $\Delta Z$ ). With the addition of ECG tracing, graphs of derivative changes in impedance can be distinguished and it is possible to monitor the hemodynamic parameters of the chest from beat to beat of the heart. A number of hemodynamic parameters are calculated by ICG; together, these parameters indicate a measure for evaluation of the mechanical efficiency of the heart.

There are many parameters assessed by ICG: stroke volume (SV), cardiac output (CO), systemic vascular resistance index (SVRI), velocity index (VI), acceleration index (AI), thoracic fluid content (TFC), pre-ejection period (PEP), left ventricular ejection time (LVET), systolic time ratio (STR), left cardiac work (LCW), and heart rate variability (HRV). For the purposes of the proposed study, CO and PEP will be the primary variables of interest, as these provide a comprehensive overview of overall heart function and sympathetic activation of the heart, and have been evaluated previously in sleep studies (De Zambotti et al., 2011). With respect to autonomic influence, PEP is the most well-validated measure of cardiac sympathetic activity (Sherwood et al., 1990). Physiologically, PEP is a measure of the time interval in which the left ventricle (primarily innervated by $\beta$-adrenergic sympathetic fibers) contracts while both the aortic and mitral valves are closed (Burgess, Penev, Schneider, \& Van Cauter, 2004). The use of 
PEP as a proxy for cardiac sympathetic activity has been supported by sophisticated pharmacological blockade studies (Cacioppo et al., 1994; Schächinger, Weinbacher, Kiss, Ritz, \& Langewitz, 2001). With increased sympathetic activity, PEP (measured in milliseconds) shortens (DeCaro, 2016). Stroke volume is an important parameter when characterizing the mechanical activity of the heart as a pump. It indicates the amount of blood that the left ventricle pumps out in one beat, measured in milliliters per beat (mL/beat). Cardiac output represents the overall function of the heart; it indicates the amount of blood that the left ventricle emits into the circulatory system in one minute, measured in liters per minute $(\mathrm{L} / \mathrm{min})$. It is simply calculated by multiplying SV by HR. Both CO and PEP have been used to evaluate cardiac sympathetic activation across a wide variety of studies, from evaluating effects of exercise on cardiac function to changes in sympathetic activation during cold pressor tasks (e.g. Hjemdahl, Freyschuss, Juhlin-Dannfelt, \& Linde, 1984; Kelsey, 2012; Licht, Penninx, \& de Geus, 2012; Ogoh et al., 2005; Zambotti et al., 2012)

Though not the most well-validated correlate, HRV has been the most frequently used measure to infer sympathetic hyperactivation in insomnia studies. Consequently, though PEP and $\mathrm{CO}$ were used as primary dependent variables to assess for cardiac sympathetic activity, LF HRV (validated for estimating parasympathetic activity) was examined in post-hoc analyses in order to place the results of this study within the current literature. Together, these three indices will provide a sophisticated view of cardiac functioning as a whole as well as the individual influences of both sympathetic and parasympathetic cardiac activity. 


\section{CHAPTER THREE}

\section{LITERATURE REVIEW}

\subsection{Associated Constructs}

Both sleep and cardiovascular health can be affected by a number of biological, psychological, and behavioural factors. In order to directly address some of the limitations of previous research in this area, this study has attempted to take the multifarious nature of both sleep and cardiovascular health into consideration. A detailed description of these broad constructs and their relationship to sleep and cardiovascular health is provided below.

\subsubsection{Nutrition}

Caloric intake and nutritional content of food is well-established in the literature to be associated with both sleep and cardiac health. Studies evaluating short sleep duration have consistently demonstrated that shorter sleep is associated with increased caloric intake (BosyWestphal et al., 2008; Brondel, Romer, Nougues, Touyarou, \& Davenne, 2010; Shechter et al., 2012; St-Onge et al., 2011) and consumption of more calories and percentage of calories derived from fat (Spaeth, Dinges, \& Goel, 2013) and carbohydrates (Nedeltcheva et al., 2009). Studies have also linked short sleep duration with changes in neuroendocrine function, particularly with respect to leptin, which chemically signifies satiety, and ghrelin, an appetite-stimulating hormone. An experimental sleep deprivation study which investigated two nights of sleep restriction (four hour time in bed) with controlled energy intake via continuous intravenous glucose infusion found increased levels of ghrelin and decreased levels of leptin (Spiegel, Leproult, \& Van Cauter, 1999). In addition, the sleep deprived subjects reported significant increases in self-reported ratings of hunger and appetite, specifically for foods high in carbohydrate content. However, other sleep deprivation studies that allowed for food access that 
mimics the natural environment replicated the findings related to increased caloric intake but did not find the same neuroendocrine changes (e.g. Omisade, Buxton, \& Rusak, 2010; Simpson, Banks, \& Dinges, 2010). Some scientists have hypothesized that the conflicting results from these studies can be explained by activation of the stress system; intravenous glucose infusion and the 60 hour bed rest in the Spiegel study were likely stress-inducing; results also indicated a 24-hour increase in sympathovagal balance and late afternoon and evening cortisol in sleepdeprived participants. The contrasting studies did not find similar indications of increased stress (Pejovic et al., 2010).

Nutrition has also been linked to cardiovascular health. A prospective large-scale epidemiological cohort study found an inverse association between fruit and vegetable intake and risk of CVD and all-cause mortality in a sample of American adults (Bazzano et al., 2002). Importantly, statistical adjustments were made for other important potential confounders, such as alcohol use, smoking status, physical activity, age, race, sex, and education level. The authors assert that the association between fruit and vegetable intake and decreased risk for cardiovascular disease may not be a result of other confounding health habits (Bazzano et al., 2002). Unfortunately, however, though this study collected information about frequency of fruit and vegetable intake (ranging from 0 to 8 times per day), it did not collect information about portion size or differentiate the form in which the food was consumed (e.g., raw vegetable versus juice).

The Health Professionals Follow-up Study is a prospective cohort study started in 1986 of 51529 American male health professionals to study the dietary etiologies of cancer and CVD. Risk for CVD was calculated through presence of several biomarkers of CVD, including HDL and LDL cholesterol, insulin, leptin, and lipoproteins, among others. Food frequency 
questionnaires (FFQs) were used to assess frequency of 130 types of foods every 4 years. Other potentially confounding variables such as BMI, physical activity, smoking, and alcohol use were also assessed every 2 years and entered as covariates in the statistical analyses. A factor analyses revealed 2 types of dietary patterns: the first, labeled "prudent" by the investigators, was characterized by higher consumption of fruit, vegetables, poultry, legumes, whole grains, and fish. The second pattern, labeled "Western", was characterized by higher consumption of red and processed meats, French fries, sweets, eggs, high fat dairy products, beer and liquor, and refined grains. Dietary category was also correlated with lifestyle behaviours; those who consumed more a more "prudent" diet were also more likely to engage in healthy lifestyle behaviours. As expected, results indicated that a Western dietary pattern was significantly correlated with a less favourable biomarker profile reflective of increased risk for CVD (Fung et al., 2001).

Several studies have investigated whether a "Mediterranean"-style diet that contains dietary or nondietary (i.e., supplemental) $\Omega-3$ polyunsaturated fatty acids (PUFA) reduces the risk of coronary artery disease (de Lorgeril et al., 1994; GISSI-Prevenzione Investigators, 2000). Mediterranean diets contain higher consumption of fish and soybean, flaxseed, and canola oils, all of which contain PUFAs that have been shown to have a protective effect on the heart through several mechanisms (e.g., Billman, Kang, \& Leaf, 1997; Connor, 2000; Leaf, Kang, Xiao, \& Billman, 2003; Tagawa et al., 1999). A meta-analysis of several studies investigating the protective effects of $\Omega-3$ PUFAs concluded that dietary and nondietary intake of these acids reduces overall mortality, mortality due to MI, and sudden death in coronary artery disease (Bucher, Hengstler, Schindler, \& Meier, 2002). 
Clearly, dietary pattern is an important contributory factor to the development of CVD. Researchers have hypothesized several reasons for this association, including the importance of antioxidants, dietary fibers, polyphenols, vitamins, and minerals to a heart health (Ignarro, Balestrieri, \& Napoli, 2007). Regardless of the exact mechanisms, it is important to consider nutritional habits in order to more carefully investigate the influence of sleeper status on cardiovascular health.

\subsubsection{Cognition}

While some variables, like nutrition, are more intuitively linked to insomnia and/or CVD, various other less obvious variables have been demonstrated to be important when evaluating these relationships. One of these such variables is cognition, or the tendency to demonstrate consistent cognitive patterns. Research has indicated that cognition is associated with both insomnia and cardiovascular health. The mechanisms by which cognition may influence these variables is reviewed in the following paragraphs.

For decades, research has shown that mental events prevent people with insomnia from sleeping (Espie, Brooks, \& Lindsay, 1989; Harvey, 2000; Harvey \& Greenall, 2003; Lichstein \& Rosenthal, 1980). These mental events can include rumination, intrusive thoughts, uncontrollable worry, and dysfunctional beliefs about sleep. As sleep is a relatively unconscious process that can be disrupted by will, deliberately thinking about sleep or attempting to control the process of falling asleep can lead to unintentional effects of poorer sleep. For example, the belief that "I need to catch up on lost sleep" might lead to increased sleep effort and cognitive arousal that consequently serves as a perpetuating factor of poor sleep.

The failure to "de-arouse" among individuals with insomnia has been proposed by other sleep experts in slightly different cognitive models of insomnia than the one proposed by Morin. 
Espie and colleagues argue that the loss of automaticity (i.e. the effortless process of sleep onset) and plasticity (i.e. that sleep is flexible) are central to maintenance of insomnia (Espie, 2007). Cognitively, according to this model, those with insomnia have selective attention for sleeprelated cues and increased intention and effort to sleep compared to normal sleepers. Espie argues that these cognitions and behaviours are maladaptive, leading to a failure to de-arouse at night and subsequently inhibits the natural homeostatic and circadian processes that regulate sleep. Harvey's cognitive model of insomnia is similar in that it emphasizes both daytime and nighttime cognitive processes that could contribute to increased arousal and poor sleep (Harvey, 2002). These cognitive processes include worry, unhelpful beliefs, misperception of sleep and fatigue, selective attention, and safety behaviours. Importantly, Harvey argues that these processes can occur with or without actual deficits in sleep; it is the cognitions themselves that lead to increased arousal and subsequent actual sleep deficits (Ong, Ulmer, \& Manber, 2012).

While Harvey's cognitive model of insomnia emphasizes worry (i.e., "what if" questions that focus on future consequences of sleep disruption), Carney's work emphasizes the role of rumination (i.e., repetitive "why" questions that focus on attributions for daytime symptoms of insomnia such as disturbed mood or fatigue; Carney et al., 2006). The research of Carney and colleagues has demonstrated that insomnia and worry are distinct cognitive processes within insomnia, and in fact it is rumination that is more strongly associated with sleep indices such as sleep efficiency, sleep quality, and wakefulness after sleep onset than worry (Carney, Harris, Moss, \& Edinger, 2010). Thus, when investigating cognitive processes that may influence sympathetic hyperarousal, it is important to consider both worry and rumination as separate constructs. 
Specific consistent cognitive patterns have been shown to be related to heart health in addition to insomnia. Research into the mechanisms behind the association of perseverative cognition and heart health have revealed that a physiological sequelae from this cognitive style leads directly to negative health consequences, including to the heart. Brosschott and colleagues (2006) theorize that perseverative cognition serves to prolong a stressor in a form that continues to activate the organism. This prolonged state of cognitive activation corresponds to prolonged physiological activation, including the cardiovascular and neuroendocrine systems. It has been theorized that this excessive physiological activation may lead to disease (Brosschot, Gerin, \& Thayer, 2006). After a thorough review of the literature on the somatic link between perseverative worry (including worry and rumination) and cardiac health, a group of experts concluded that perseverative cognition is associated with decreased parasympathetic activity and increased sympathetic activity. This sympathetic dominance is potentially pathogenic and makes the tendency to worry or ruminate an independent risk factor for CVD (Brosschot et al., 2006)

Due to the association of cognitions with both sleep and cardiovascular health, the perseverative cognitive style of rumination was assessed and considered in the analyses as a covariate.

\subsubsection{Behavioural Risk Factors}

According to the Global Atlas on Cardiovascular Disease Prevention and Control, a publication produced by the World Heart Federation, a large proportion of CVDs are preventable through the reduction of behavioural risk factors (Mendis, Puska, \& Norrving, 2011). The American Heart Association, a leading global institution in the identification and reduction of risk factors for CVD, has identified smoking, physical inactivity, obesity, poor nutrition (discussed above), and excessive alcohol consumption as predisposing behavioural risk factors 
for CVD (Yusuf, Reddy, Ôunpuu, \& Anand, 2001). Some of these behavioural factors are presumed to increase risk for CVD by influencing other risk factors that are presumed to act directly. For example, obesity raises blood pressure and causes dyslipidemia, which have direct effects on CVD. As these modifiable behavioural risk factors remain common today, an evaluation of these behaviours among participants is essential in a study investigating cardiovascular health.

As CVD often progresses slowly over time, longitudinal studies are the best design to evaluate risk factors for the development of this disease. The Framingham Heart Study was initiated in 1948 as a joint collaboration between Boston University and the National Heart, Blood, and Lung Institute to investigate risk factors for CVD and stroke among presently healthy men and women (Dawber, Meadors, \& Moore, 1951). In this trial, manifestations of CVD are coronary heart disease, congestive heart failure, stroke, and intermittent claudication. At the time, little was known about risk factors for heart disease and stroke, which was alarming considering the steadily rising death rates from CVD. To date, it is the largest, most comprehensive longitudinal trial to investigate the epidemic of CVD in the developed world. Participants were 2252 men and 2818 women from Framingham, Massachusetts aged 28-62 years who were free of clinically recognizable CVD at the first study examination timepoint. To the present day, participants continue to be followed biannually; a detailed medical exam, blood and genome tests, and a battery of questionnaires are administered.

It is relevant to mention the Framingham study here because it is the most comprehensive longitudinal trial to date that has systematically evaluated a myriad of risk factors for CVD. Though the modifiable behavioural risk factors mentioned below are now considered to be common knowledge as risk factors for CVD, it is the results of the Framingham study that first 
indicated the impact of these factors. One of the very first published papers from the over 1,200 generated from this trial identifies tobacco use as a major risk factor for CVD (Kannel, Dawber, Kagan, Revotskie, \& Stokes, 1961). Tobacco, either smoked or chewed, is estimated to cause nearly $10 \%$ of CVD (World Health Organization, 2009). According to the World Heart Federation, harm from tobacco use is higher among women, if use is heavy, or if it was initiated at a young age (World Heart Federation website). Second-hand or passive smoking has also been identified as a risk factor for CVD (Dunbar, Gotsis, \& Frishman, 2013). Further evidence for the association between tobacco and CVD comes from studies that evaluate the association between smoking cessation and CVD. A 50-year follow-up study of British doctors found that those who quit between 35 and 44 years old matched the same survival rates of those who had never smoked at all. As smoking evidently influences heart health, smoking habits of the participants were assessed and considered as a covariate in the present study.

In the mid-1960's, results of the Framingham study also pointed to physical inactivity as a risk factor for CVD, and increasing level of habitual physical activity as protective against CVD (Kannel, 1967). The World Health Organization asserts that approximately $60 \%$ of the world's population is not sufficiently active. Alarmingly, physical inactivity (defined as less than 5 times per week of 30 minutes or more of moderate activity or less than 3 times of 20 minutes of strenuous activity per week) is the fourth leading risk factor for adult mortality globally (Mendis et al., 2011). Similarly, the links between physical measures such as obesity, body mass index and waist circumference and cardiovascular health are well-established. At the 26-year follow-up, degree of obesity in the Framingham men and women was an important predictor of CVD incidence, particularly among younger cohort participants (Hubert, Feinleib, McNamara, \& Castelli, 1983). Specifically, the risk of death in the 26 years increased by $1 \%$ 
with each extra pound of weight. Among both sexes, obesity exerted an influence on CVD that was partially independent of other coexisting risk factors such as glucose intolerance and smoking (Hubert et al., 1983).

Another common vice in our society is excessive alcohol consumption. Globally, 5.9\% of all deaths and $5.1 \%$ of the world's burden of disease is attributable to alcohol (as measured in disability-adjusted life years; World Health Organization, 2014). Disturbingly, though alcohol is the most common global substance of abuse, it has been identified as a component cause of over 200 diseases, injuries, and other health conditions associated with International Classification of Disease (ICD) codes (Rehm et al., 2009). In addition, a dose-response relationship exists for most diseases that are causally impacted by alcohol. For example, for all cancers related to alcohol consumption, the higher the consumption, the larger the risk for these cancers (IARC, 2010; Shield et al., 2013). With respect to CVD, a 2009 meta-analysis that analyzed the doseresponse relationship between average daily alcohol consumption and risk of hypertension found that risk for hypertension increases linearly with alcohol consumption (Taylor et al., 2009).

There is an ongoing debate in the literature about whether low to moderate alcohol consumption actually has a cardioprotective protective effect against CVD. Another metaanalysis investigated this question by analyzing longitudinal cohort data comparing alcohol drinkers with non-drinkers on outcomes of overall mortality from CVD, incident coronary heart disease, mortality from coronary heart disease, incident from stroke, and overall mortality from stroke (Ronksley, Brien, Turner, Mukamal, \& Ghali, 2011). Using strict quality inclusion criteria, 84 studies were included in this analysis. Alcohol consumption at $2.5-14 \mathrm{~g} /$ day (the equivalent of less than one drink) was consistently associated with a $14-25 \%$ reduction in risk for all assessed outcomes in comparison to abstaining from alcohol. Higher alcohol consumption 
was associated with higher risk for stroke incidence and mortality in a J-shaped curve. At high doses, the authors reported that alcohol consumption has an adverse association with blood pressure that may account in part for the increased risk for hemorrhagic stroke associated with heavier drinking (Ronksley et al., 2011). In a companion paper, the authors argue for a causal relationship between alcohol and the apparent cardioprotective effect against CVD using various biomarkers (Brien, Ronksley, Turner, Mukamal, \& Ghali, 2011). However, more recent population-based genetic research has challenged these results, indicating that individuals with a genetic disposition to consume less alcohol had lower odds of developing later coronary events regardless of whether consumption was light, moderate, or heavy (Holmes et al., 2014). In light of this body of research, alcohol was considered an important covariate in order to assess for the relationship between sleep and cardiovascular health.

\subsubsection{Presence of a Mental Disorder}

Psychological factors have also been implicated as important to the development and expression of CVD. For example, the presence of depressive symptoms has been associated with an increased risk for cardiovascular events (Anda et al., 1993). Several studies also support the relationship between the magnitude of depression symptoms and future cardiac events (Aromaa et al., 1994; Pratt et al., 1996). This association is hypothesized to be due to both behavioural and direct pathophysiological effects (Rozanski, Blumenthal, \& Kaplan, 1999). Behaviourally, depression is often associated with unhealthy lifestyle behaviours such as those discussed above (e.g., smoking or physical inactivity; Glassman et al., 1990). The direct physiological effects linking depression and CVD involve various mechanisms, including increased cortisol production (Gold et al., 1986), impairments in platelet function (Musselman et al., 1996), and reduced heart rate variability (Carney et al., 1995). Anxiety has also been linked to the 
development of cardiac events, particularly sudden cardiac death, among the general population (Rozanski et al., 1999). Like depression, anxiety has been linked to reduced heart rate variability, which may implicate a pathological cardiac autonomic tone due to increased sympathetic activation or reduced vagal control (Kawachi, Sparrow, Vokonas, \& Weiss, 1995; Kubzansky et al., 1997). Interestingly, unlike with depression, research investigation behavioural changes related to anxiety disorders has not implicated increased frequency of unhealthy behaviours as the likely cause of increased cardiac events associated with anxiety (Rozanski et al., 1999).

There is an abundance of literature that points to a link between insomnia and depression. Previously, insomnia was considered a symptom of depression, but more recent research has pointed to insomnia as a comorbidity of depression that warrants its own diagnosis. Longitudinal studies have indicated that individuals with clinically significant insomnia are at increased risk of developing depression (Buysse et al., 2008) or exacerbating depression symptoms (Pigeon et al., 2008). Studies evaluating treatment for comorbid depression and insomnia have found that adding an insomnia-focused cognitive-behavioural therapy (CBT-I) enhances depression outcomes (Manber et al., 2008). Interestingly, acute sleep deprivation has been found to have antidepressant effects (Wu \& Bunney, 1990). The accumulation of research clearly points to a relationship between insomnia and depression; thus, the proposed study will include an evaluation of depression symptoms.

The relationship between insomnia and anxiety has been long established (Buysse et al., 2006; Uhde, Cortese, \& Vedeniapin, 2009). This relationship is complex, as anxiety can worsen sleep, and experiencing poor sleep can contribute to anxiety (Carney, Moss, Harris, Edinger, \& Krystal, 2011). Experimental research has shown that inducing anxiety in participants (by telling 
them that they have to deliver a speech the next morning) lengthens sleep onset latencies and results in an increase in intrusive and worrisome thoughts (Gross \& Borkovec, 1982; Hall, Buysse, Reynolds, Kupfer, \& Baum, 1996). Similarly, manipulating poor sleep in participants increases anxiety symptoms (Bonnet \& Arand, 1992; Talbot, McGlinchey, Kaplan, Dahl, \& Harvey, 2010). Insomnia is the most common co-occurring disorder among individuals with insomnia (Ford \& Kamerow, 1989). As insomnia and anxiety disorders have overlapping symptoms (e.g. reduced sleep, catastrophizing, muscle tension), it was important to assess for anxiety in a study that attempted to evaluate the psychophysiological effects of insomnia.

\subsubsection{Negative Mood Traits}

In addition to the presence of other psychiatric illness as important to the development of CVD, some negative mood dispositions have also been demonstrated to be associated with risk for CVD. Interest in anger as a predictor for CVD began with work by Friedman and Rosenman, who initiated investigation into the association of CVD with "Type A" personality (Rosenman, Brand, Sholtz, \& Friedman, 1976). This personality type is characterized by consistent patterns of anger, impatience, and irritation. Subsequent studies found inconsistent support for the association between CVD and Type A personality, but did find some support for a relationship between CVD and sub-categories of the Type A personality, including hostility, anger, and anger expression (Suls \& Bunde, 2005). The mechanism behind this association of these negative mood traits and CVD is not yet clearly elucidated, but some researchers have hypothesized that they are associated with elevated SNS and HPA activation (Cohen \& Rodriguez, 1995; Smith \& Ruiz, 2002; Troxler, Sprague, Albanese, Fuchs, \& Thompson, 1977)

With respect to insomnia, the role of anger and its associated constructs remains understudied. One trial found that anger was significantly associated with longer sleep onset 
latencies and longer periods of wakefulness after sleep onset (Waters, Adams, Binks, \& Varnado, 1993). A subsequent large Korean study found that trait anger was associated with nonrestorative sleep and excessive daytime sleepiness (Shin et al., 2005). The authors concluded that after adjusting for other important risk factors, high and/or moderate scores of trait anger were associated with a $40 \%-70 \%$ increase in the odds for sleep disturbance. The support for the association between CVD, insomnia, and these negative mood variables points to the importance of including their assessment in this study.

\subsubsection{Sleep}

The relationship between commonly assessed sleep variables (e.g., total wake time, total sleep time) and insomnia is not straightforward. It seems intuitive to assume that insomnia is caused by poor sleep manifested as longer sleep onset latencies, poor sleep maintenance, early morning awakenings, and overall reduced total sleep times. However, investigation of brain activity during sleep using polysomnograph technology has indicated that individuals with insomnia do not necessarily exhibit poorer PSG scores on these sleep variables (Edinger et al., 2000). In addition, it has also been demonstrated that individuals with insomnia tend to underestimate the time spent asleep and overestimate time spent awake during the night (Perlis, Smith, Andrews, Orff, \& Giles, 2001). Thus, insomnia is best conceptualized as a subjective disorder based on self-report of symptoms and duration (at least three months according to the DSM-5 (American Psychiatric Association, 2013). In addition to traditionally-assessed insomnia variables total wake time (TWT) and total sleep time (TST) from two-week prospective sleep logs, a subjective self-report scale (the Insomnia Severity Index; ISI) was assessed and included in the study analyses. The links between sleep duration (TST) and CVD has already been described in previous sections. 


\subsection{The Current Study}

The current study extends the existing body of literature that suggests a relationship between poor sleep and cardiovascular health (e.g. Spiegelhalder et al., 2011; Zambotti et al., 2012). Specifically, participants (categorized by research diagnostic criteria as either normal sleepers or having ID) all underwent an experimental challenge paradigm that provided an opportunity for the autonomic nervous system to exert its influence on the heart in an effort to adjust to the external stimuli. To date, studies that have assessed cardiac health among individuals with insomnia have either poorly defined the insomnia syndrome, failed to use a normal sleeper comparison group, or failed to assess for important behavioural or trait variables that are known to have an important influence on either sleep or cardiovascular health. Importantly, with the addition of an experimental challenge, the heart was given an opportunity to demonstrate its reactivity under tightly controlled conditions. With this challenge paradigm, continuous psychophysiological data were collected over time, which provided a unique opportunity to assess for longitudinal cardiac changes. This continuous longitudinal design also allowed for the use of more advanced statistical techniques that can account for within-person influences on the dependent variables. Previous research in this area has primarily employed statistical methods (e.g., repeated measures ANOVA) that fail to take into account both withinand between-person variance. The outcome of this study will contribute to the growing body of literature evaluating sympathetic hyperactivation as a mechanistic link between insomnia and increased risk for cardiovascular disease.

\subsection{Hypotheses}

It was hypothesized that in a hierarchical linear modeling analysis, sleep variables would emerge as important level two between-group predictors of cardiac indices CO and PEP, above 
and beyond the chosen relevant cognitive and behavioural variables. In addition, those in the ID groups would demonstrate that they continue to show sympathetic hyperactivation (via higher CO and lower PEP variables) throughout a stress paradigm, while normal sleeperss show CO and PEP values that normalize throughout the paradigm as assessed by comparison of time periods.

- Primary: Sleep variables TWT, TST, and ISI will be significant between-groups predictors of $\mathrm{CO}$ and PEP in a multilevel modeling analysis that includes established predictors age, nutrition score, physical activity, BMI, smoking, alcohol, rumination, mood, and trait anger

- Secondary: Dummy-coded challenge phases Dark Phase 1, Dark Phase 2, and Recovery will be significant predictors of $\mathrm{CO}$ and PEP among the predictors established to be significant in the previous longitudinal model,

Follow-up analyses will determine that PEP and CO values for Dark Phase 1 (DP1) will not be significantly different between both NS and the ID group; however, NS mean PEP value for Dark Phase 2 (DP2) will be significantly lower than the ID group mean PEP value for DP2 (i.e., increased sympathetic activation in the ID group during the challenge)

NS mean CO value for Dark Phase 2 (DP2) will be significantly lower than the ID group mean $\mathrm{CO}$ value for DP2 (i.e., increased sympathetic activation in the ID group during the challenge) 


\section{CHAPTER FOUR}

\section{METHOD}

\subsection{Participants}

Study participants $(\mathrm{N}=49)$ included men and women aged 18-79 years. They were recruited by the Ryerson Sleep and Depression Laboratory over approximately two years, and included both normal sleeper and poor sleeper volunteers from the Greater Toronto Area. Insomnia diagnosis was determined via Research Diagnostic Criteria for Insomnia Disorder (RDC-I; Edinger et al., 2004) by assessment with a validated sleep interview (Duke Structured Interview for Sleep Disorders (DSISD; see Measures section). Normal sleepers (NS) met RDC for normal sleepers (Edinger et al., 2004) and did not have self-reported histories of insomnia. As this study is part of a larger CIHR-funded CBT- I clinical trial, recruitment was based on both clinic referrals and individuals solicited from other ongoing research studies and media advertisements. Given that insomnia often presents as comorbid with other Axis I disorders, those with comorbid disorders that would not confound results were permitted to participate, thus making our findings more generalizable. Eligibility criteria for all participants were as follows: 1) between 18 and 79 years old, 2) fluency in English. Exclusion criteria were as follows: 1) met criteria for a mental health disorder that could interfere with sleep and is a contraindication for CBT-I (as per the parent study), such as Bipolar Disorder, Substance Dependence, any Psychotic Disorder, or endorses current suicidal ideation, as per the Structured Clinical Interview for DSMIV-TR Disorders (SCID-IV-TR; First, Spitzer, Robert, Gibbon, \& Williams, 2002), 2) met criteria for a sleep disorder that could confound results, such as moderate to severe apnea, hypersomnia, or a circadian rhythm disorder, as per the validated DSISD, 3) had a current medical diagnosis of CVD, including hypertension, atherosclerosis, history of myocardial 
infarction or stroke, thrombosis, 4) currently taking heart medication or beta-blockers, and 5) currently pregnant.

\subsection{Measures}

\subsubsection{Screening measures.}

Duke Structured Interview for Sleep Disorders (DSISD; Edinger et al., 2004).

The DSISD is a structured diagnostic interview designed to assist in the diagnosis of sleep disorders in accordance with both the DSM-IV-TR and the International Classification of Sleep Disorders (ICSD-2; American Academy of Sleep Medicine, 2005) sleep disorder nosologies. This diagnostic interview was used in the proposed study to determine an insomnia diagnosis and to rule out apnea, hypersomnia, and other sleep disorders. The DSISD is divided into four modules: 1) sleep disorders associated with insomnia complaints; 2) sleep disorders associated with complaints of excessive daytime sleepiness-hypersomnia; 3 ) circadian rhythm sleep disorders; and 4) sleep disorders associated with parasomnias. The DSISD has both acceptable inter-rater reliability for an insomnia diagnosis $(r=.46$ across DSM-IV-TR \& ICSD-2 categories; Carney, Edinger, Olsen, Stechuchak, \& Krystal, 2008) and discriminant validity (Carney, Ulmer, Edinger, Krystal, \& Knauss, 2009). Likewise, this measure has moderate to good inter-rater reliability for the exclusion criteria apnea $(r=.74)$ and a circadian rhythm disorder ( $r=.44$; Carney et al., 2008). Moreover, the DSISD is a commonly used assessment interview in sleep research (e.g., Carney, Moss, Harris, Edinger, \& Krystal, 2011; Talbot et al., 2012).

Structured Clinical Interview for DSM-IV Disorders (SCID; First, Spitzer, Gibbon, \& Williams, 2012). The SCID is a commonly used semi-structured interview used for making the major DSM-IV-TR Axis I diagnoses. This instrument is considered the gold standard semi- 
structured interview for the assessment of clinical disorders (Lobbestael, Leurgans, \& Arntz, 2011). In the proposed study, the SCID was used to assess and exclude participants with an Axis I disorder that could interfere with sleep, such as Bipolar Disorder, Substance Use Disorder, a Psychotic Disorder, or current suicidal ideation that could interfere with safety of the participant. In a mixed sample of inpatients, outpatients, and non-patient controls, Lobbestael and colleagues (2011) assessed the inter-rater reliability of the SCID-IV-TR and demonstrated fair to excellent inter-rater agreement of Axis I disorders, with kappa values ranging from .61 to .83 . Given the wide use of SCID methodology in various research applications over the past several decades, the SCID-IV-TR has a strong history of being utilized in research, which further supports its reliability, validity, and utility for screening and diagnosing patients. As this study was initiated before the laboratory acquired a copy of the most updated SCID, the previous version was retained.

\subsubsection{Standard battery}

\section{Demographics}

All participants were asked standard demographic information, such as age, sex, education level, employment, and relationship status. Participants were also asked about alcohol intake, smoking, and exercise. If participants indicated that they consumed alcohol regularly even in small doses OR engaged in binge drinking ( 5 or more drinks on one occasion) either currently or in the past, they were coded as "1", indicating current or past alcohol consumption. Likewise, participants were asked if they smoked cigarettes currently or in the past, and were coded as a " 1 " if either of these responses was "yes". Possible responses were kept as simple as possible on the demographics form in order to reduce participant burden. Current average 
exercise habits were coded on a Likert scale, which ranged from 0 ("never break a sweat") to 4 ("break a sweat 4 or more times per week").

Insomnia Severity Index (ISI; Morin, 1993).

The ISI is a 7-item self-report questionnaire that provides an index of the global severity of insomnia by assessing the nature, severity, and impact of insomnia (Bastien, Vallières, \& Morin, 2001; Morin et al., 2011). The ISI was used to evaluate the severity of sleep onset, sleep maintenance, early morning awakening problems, sleep dissatisfaction, interference of sleep difficulties with daytime functioning, noticeability of sleep problems by others, and distress caused by the sleep difficulties. Each item is rated on a 5-point Likert scale, ranging from " $0=$ no problem" to " 4 = very severe problem," yielding a total score between 0 and 28 . A cutoff score of 10 is optimal for detecting insomnia in a community sample (Morin et al., 2011), and this cutoff score was employed for the present study. The ISI is increasingly being used as a measurement of treatment response in clinical research (Morin et al., 2011).

The ISI has been found to be a reliable and valid instrument to measure self-reported insomnia severity (Bastien et al., 2001; Morin et al., 2011). Bastien and colleagues (2001) investigated the psychometric properties of the ISI in a clinical sample of young and older adults and found adequate internal consistency (Cronbach $\alpha=0.74)$ and significant correlation coefficients (at the 0.01 level) between the ISI individual items and corresponding variables on the sleep diary. Likewise, Morin and colleagues (2011) further investigated the internal consistency of the ISI in both a community and clinical sample and found high internal consistency for the ISI in both samples (Cronbach $\alpha=0.90$ and 0.91).

Depression and Anxiety Stress Scale (DASS-21; Lovibond \& Lovibond, 1995). 
The DASS-21 is a shortened version of the original DASS-42. It is a 21-item self-report questionnaire that assesses three negative states (depression, anxiety, and stress) from the past week. This measure was used in the proposed study to primarily evaluate depression and anxiety severity, as presence of a comorbid mental disorder will be this score will be entered into the model in the statistical analysis of the primary hypothesis. The Depression scale includes items that measure symptoms often related to dysphoric mood (e.g., sadness or worthlessness). The Anxiety scale includes items that are primarily associated with symptoms of physical arousal, panic attacks, and fear (e.g., trembling). Finally, the Stress scale includes items that assess for symptoms such as tension, irritability, and a tendency to overreact to stressful events (Antony, Bieling, Cox, Enns, \& Swinson, 1998). Each item is rated on a 4-point scale ranging from $0=$ "Did not apply to me at all" to 3 = "Applied to me very much or most of the time." Scores from each subscale are summed and multiplied by two, which yields a total subscale score ranging from 0 to 42. On the Depression subscale, optimal cutoff scores for detecting the degree of depression are the following: 10-13 (mild), 14-20 (moderate), 21-27 (severe), and 28+ (extremely severe). On the Anxiety subscale, the following are optimal cutoff scores for detecting the degree of anxiety: 8-9 (mild), 10-14 (moderate), 15-19 (severe), and 28+ (extremely severe). On the Stress subscale, the following are optimal cutoff scores for detecting the degree of stress: 15-18 (mild), 19-25 (moderate), 26-33 (severe), and 34+ (extremely severe).

Psychometric properties of the full version of the DASS scale suggest that it has excellent internal consistency and temporal stability and provides a better distinction between the features of depression and anxiety than other existing measures (Henry \& Crawford, 2005). In a sample of nonclinical volunteers and patients diagnosed with mood and anxiety disorders, Antony et al. (1998) assessed the internal consistency of the DASS-21 and reported high Cronbach's alphas 
for the Depression, Anxiety, and Stress subscales (.94, .87, .91, respectively). Similarly, Henry et al. (2005) reported high Cronbach's alphas for the Depression, Anxiety, and Stress subscales $(.88, .82, .90$, respectively) in a non-clinical population. The concurrent validity of the DASS-21 with other measures of depression and anxiety has also been investigated in a clinical sample of outpatients diagnosed with an anxiety disorder or major depressive disorder (Antony et al., 1998). The Stress scale was found to correlate moderately with other measures of depression and anxiety (.69-.70); the Depression scale correlated most highly with other measures of depression (.79) and moderately with the anxiety measures (.51-.71); and the anxiety scale correlated most highly with the anxiety scale (.85). Thus, the DASS-21 appears to be a reliable and valid measures of depression, anxiety, and stress, and offers several advantages to the original 42 -item version, including fewer items, a cleaner factor structure, and smaller interfactor correlations (Antony et al., 1998).

The Daytime Insomnia Symptom Response Scale (DISRS; Carney, Harris, Falco, \& Edinger, 2013). The DISRS is a 20-item sleep-specific self-report measure designed to assess daytime ruminative tendencies in insomnia populations. Individuals are queried on how frequently they engage in the behaviours listed when feeling tired, for example: "Think about how unmotivated you feel, Think about how your thoughts are cloudy". Responses are rated on a 4-point Likert scale ranging from 1 (Almost Never) to 4 (Almost Always). The items are added to compute a total score, which ranges from $20-80$. Higher scores indicate higher levels of rumination.

Among two distinct samples of individuals with varying levels of depressed mood and insomnia severity, internal consistency of the scale was found to be highly acceptable (Cronbach's $\alpha=.93$ and .94). Scores from the DISRS were significantly correlated to scales 
assessing related constructs, such as fatigue, mood disturbance, and general rumination, which support its validity (Carney et al., 2013). DISRS score was used to assess perseverative cognition in the present study.

The State-Trait Anger Expression Inventory $2^{\text {nd }}$ edition (STAXI-2, Spielberger, Sydeman, Owen, \& Marsh, 1999). The STAXI-2 is a 57-item self-report scale that assesses for the experience, expression, and control of anger. Responses are rated on a 4-point Likert scale ranging from "Not at all" to "Almost always". The 9 subscales include State Anger (S-Ang; measures the intensity of angry feelings), State Anger/Feelings (S-Ang/F), State Anger Expression (S-Ang/VP), Trait Anger (T-Ang), Trait Anger/Temperament (T-Ang/T), Trait Anger/Reaction (T-Ang/R), Anger Expression-Out (AX-O), Anger Expression-In (AX-I), and Anger Control (AC). Internal consistency measures of these subscales ranged from $\alpha=.73$ to .95.

For the purposes of this study, only the "trait" subscales were used in the analyses. The T-Ang subscale measures how often angry feelings are experienced over time, while the TAng/T measures the disposition to experience anger without any specific provocation. The TAng/R subscale measures the frequency that angry feelings are experienced in situations that involve frustration and/or negative evaluation. Test-retest reliability for T-Ang assessed at 14 days is 0.77 (Jacobs, Latham, \& Brown, 1988). Convergent and discriminant validity studies comparing the T-Ang and anger expression scales with other measures of physiological anger, self-reported anger, and personality support the use of these subscales (Deffenbacher et al., 1996; Mills, Schneider, \& Dimsdale, 1989). 
Semi-Quantitative Food Frequency Questionnaire (SFFQ, Laviolle et al., 2005).

The SFFQ is a 14-item self-administered questionnaire that takes approximately 5

minutes to complete. Though there are a plethora of dietary assessment questionnaires available, this questionnaire is unique in that it was designed specifically to assess the consumption of foods known to be associated with cardiovascular disease risk. The 14 questions were selected to provide information about three categories known to be most important for assessment of CVD risk: 1) fruit and vegetable intake, 2) saturated fatty acid intake (SFA), and 3) monounsaturated fatty acid intake (MUFA). These scores can also be combined to provide a global score. Validity of this measure was assessed using both a 7-day dietary history and against biomarkers. Spearman correlation coefficients revealed reasonable correlation with dietary history, ranging from 0.47 (fruits and vegetables) to 0.63 (saturated fatty acids/polyunsaturated fatty acids). All correlations were significant at $p<.05$, with a mean of 0.54 . Biomarker-based validity ranged from 0.21 (saturated fatty acids) to 0.53 (omega-3 polyunsaturated fatty acids). Reproducibility assessed by the intraclass correlation coefficient ranged from 0.71 (monounsaturated fatty acids) to 0.93 (global score), with a mean value of 0.81 .

As per the Laviolle (2005) article, the 14-item SFFQ attributes a negative score of 17 points to Saturated Fatty Acid (SFA) questions, relating to questions 1, 2, 4, 5, 7 and 12. For Mono-Unsaturated Fatty Acids (MUFA), 0-3 Poly-Unsaturated Fatty Acids (PUFA) and fruits and vegetables, a positive score of 19 can be attributed to the corresponding questions. The MUFA questions correspond to a maximum of 4 points, for questions 6,13 and 14. 0-3 PUFA is taken into account in questions 3 and 9, for a maximum possible score of 8 points. Finally, intake for fruits and vegetables relates to questions 8,10 and 11, for a maximum possible score of 7 points. The combination of the MUFA, PUFA and fruits and vegetables maximum score totals 
the 19 possible positive points to be allocated. The global score incorporating the three subscales was used for the analyses herein.

Medication Quantification Scale (MQS; Masters Steedman et al., 1992).

The MQS provides a quantitative index for the most common prescription and nonprescription medications based on the known effects of their long-term use. Scores for this scale are derived on the basis of weights assigned to each type of medication and the actual dosage levels used. For example, an as-needed nonsteroidal anti-inflammatory medication is assigned a predetermined detrimental weight which is multiplied by dosage weights and then summed across days monitored. This provides a total score that can be entered as a covariate. Previous studies have found the MQS to have adequate internal consistency and validity (Stormo, Kee, Steedham, \& Middaugh, 1998).

\subsubsection{At home monitoring}

Consensus Sleep Diary (CSD; Carney et al., 2012).

Completion of a sleep diary upon awakening is a standard assessment tool in insomnia research (Bastien et al., 2001) because insomnia is a subjective disorder. The Consensus Sleep Diary is the "gold-standard" for subjective, prospective sleep assessment (Carney et al., 2012). Participants were asked to complete a two-week expanded version of the Consensus Sleep Diary in order to determine eligibility for the ID group. This specific sleep diary has been developed by a panel of insomnia experts and was revised based on qualitative input from patients. This sleep diary includes information surrounding nighttime bed habits, such as the length of time it takes to fall asleep, number and length of nocturnal awakenings, time of final awaking, and rise time. A cutoff sleep efficiency score of $85 \%$ was used to determine sleeper status in addition to 
examination of the ISI (Carney et al., 2012). All information was recorded daily upon wakening, over the two-week assessment period of the study.

\subsubsection{Psychophysiological Measures}

\section{Cardiac Impedance}

Cardiac Impedance was assessed via the NICO100 cardiac amplifier by BioPac Systems, Inc. It is designed to emit a high frequency current source that injects a very small $(400 \mu \mathrm{A})$ current through the thoracic volume that is defined by the placement of surface electrodes. When directed through the thorax, the current seeks the shortest and most conducting pathway. This route is through the thoracic aorta and vena cava superior and inferior.

To direct the current, $1 \mathrm{~cm}$ diameter EL500 disposable surface electrodes were arranged in a modified Lead II Einthoven configuration (See Figure 1). A separate set of monitoring electrodes is used to monitor the voltage that develops across the thorax volume. Because the current generated by the Biopac amplifier is constant, the voltage that is recorded is proportional to the impedance characteristics of the thorax (referred to as dZ). Impedance magnitude $\left(Z_{0}\right)$, the primary measure of cardiac impedance, was measured at a frequency of $1000 \mathrm{kHz}$.

Cardiac impedance data was analyzed using the accompanying AcqKnowledge software (Biopac Systems, Inc.). Data was automatically filtered through a band-pass filter for artifacts. As data was acquired at a frequency of 1000 measurements per second, data was collapsed and averaged into smaller periods of time (20 seconds), which provided 147 data points for each of $\mathrm{CO}$ and PEP variables across the longitudinal paradigm. This interval was chosen as it represents the amount of time between each auditory signal (full paradigm described below). Previous researchers have recommended a 20 -second time interval to assess for these cardiac impedance values (e.g. Kelsey, Soderlund, \& Arthur, 2004), and BIOPAC recommends 20- 
second intervals to allow for ensemble averaging, which is helpful to eliminate artifacts in the beat-to-beat signal (Cardiovascular Reactivity Measurements, BIOPAC, 2011). Pre-ejection period (PEP; in milliseconds) and cardiac output (CO; liters/minute) were thus ensembleaveraged for each of the 20 -seconds between the auditory startle signals.

As specific phases during the paradigm were of interest, dummy coding was used in the HLM analyses to compare the CO and PEP values in specific phases (e.g. DP1 vs. DP2) between the NS and ID groups (while taking into account each participants' own within-person variation in CO and PEP). The details of the challenge paradigm are presented in detail below; in brief, the challenge consists of six main phases: an adaptation period followed by approximately two minutes in the dark or light (participants are randomized and the conditions are counterbalanced) repeated four times (for example, adaptation-dark-light-dark-light-recovery).

\section{Heart Rate Variability}

High frequency HRV (normalized unit) for each of the 4 phases was calculated from the raw BIOPAC data using external software package Kubios HRV (Kubios HRV v. 2.2; Biosignal Analysis and Medical Imaging Group, 2014). Kubios HRV is a program owned by MATLAB that allows for the analysis of ECG data into an HRV correlate. For the purposes of this analysis, the frequency-domain analytic method was chosen, which is the most often-used method in HRV analysis (Task Force of the European Society of Cardiology and The North American Society of Pacing and Electrophysiology, 1996). The software uses a "smoothn priors" method that allows for the detection and removal of artifacts as well as a detrending technique. The high frequency HRV mean value for each participant by phase was extracted and entered into the master database for analysis. These mean values are comparable to norm HF HRV values of individuals in a supine position (Nunan, Sandercock, \& Brodie, 2010). 
Figure 1. BIOPAC Lead II Einthoven Configuration

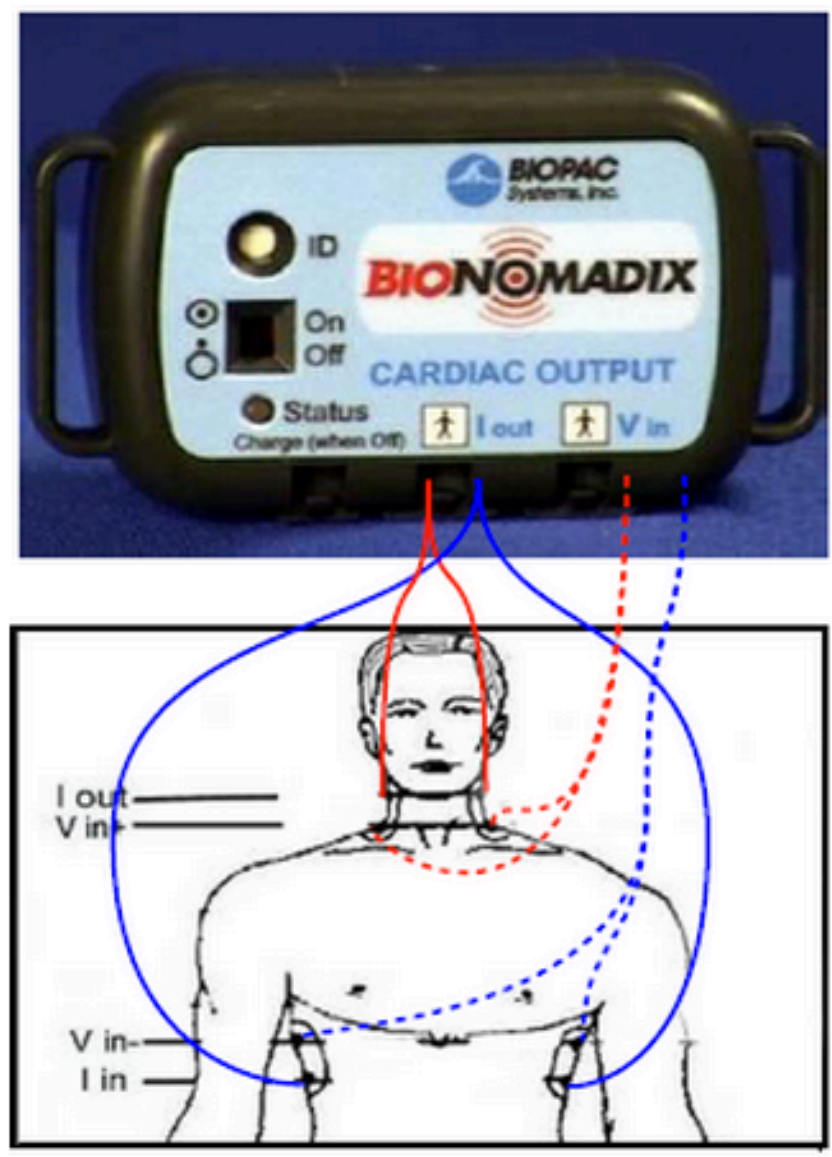




\subsection{Procedure}

All participants participated in a screening assessment to assess for study eligibility. This screening interview was approximately one-hour in duration and took place at 105 Bond Street, Ryerson University. During this one-hour session, participants were informed of the purpose of the study, description of procedures, and any risks and benefits associated with participation. Written consent was required in order to participate. After consent was obtained, trained graduate or undergraduate students administered the SCID and DSISD in order to determine whether the participant met eligibility requirements. If so, they were asked to complete 7 days of at-home sleep monitoring using the Consensus Sleep Diary. After the monitoring period, participants returned the Sleep Diary to the lab, from which a sleep efficiency (SE) score was calculated according to the guidelines in the Consensus Sleep Diary (Carney et al., 2012). If the participant's SE was $<85 \%$ and ISI score was $<14$, they were entered into the Insomnia Disorder (ID) group. Participants with a SE of $85 \%$ or above with no history of insomnia on the DSISD were entered into the "normal sleeper" (NS) group. Both advanced into stage two of the study, which included the experimental challenge paradigm.

Participants were invited back to the lab between the hours of 9:00am to 5:00pm to complete stage 2 of the study. Prior to arrival at the laboratory, participants were informed that the purpose of the study is to investigate physiological reactivity to unexpected noise while in dark and light conditions, though they were unaware of the study hypotheses. They were also informed that reactivity would be monitored via sensors placed on the surface of the skin around the neck and chest. Participants were asked to sign an informed consent agreement.

To begin, all participants completed a battery of self-report measures, including a demographics form that inquired about basic demographics and health information such as 
smoking and exercise frequency, alcohol intake (see Appendix A), and the ISI, DISRS, SFFQ, STAXI-2, and the DASS-21. To respect participant modesty, a hospital gown was offered to participants to wear throughout the challenge paradigm. Trained graduate or undergraduate students weighed $(\mathrm{kg})$ and assessed the height $(\mathrm{cm})$ of participants in order to calculate BMI, which was included as a covariate in the analyses. Investigators also applied the electrodes for assessment of cardiac impedance measures as per the configurations recommended by Sherwood and colleagues, who developed methodological guidelines for impedance cardiography in 1990 (Sherwood et al., 1990). Skin was cleaned using a hypoallergenic cleaning solution, and one-use sterile electrodes were attached using a conductant paste and surgical tape. The experiment was conducted in a sound-attenuated, temperature-controlled room, near-perfect levels of darkness (i.e., luminance verified via telephometer at $0.6 \mathrm{ft} \mathrm{L}$ ). The participant was instructed to lie down on the bed and to simply relax for the duration of the experiment without attempting to fall asleep. Basal transthoracic impedance signals were inspected via the AcqKnowledge software prior to the beginning of the paradigm, and minor adjustments were made as necessary to ensure the best quality signal. Participants were asked to keep their eyes open for the duration of the experiment. Infrared cameras allowed the experimenter to see the participant in both light and dark conditions on a screen in another room, and participants were instructed to simply wave their hand if they wanted the experimenter to re-enter the room or to terminate the paradigm. When the experiment was initiated, the audio file was played over the headphones, and lights were turned on and off remotely. Following the listening paradigm, the experimenter returned to the room to remove the equipment. Participants were debriefed and compensated $\$ 10$ for their time. This compensation is based on a rate of $\$ 10 /$ hour, with the total experimental time taking approximately 1 hour in duration. 


\subsubsection{Challenge Paradigm}

Use of a challenge paradigm in this study was essential, as a challenge or fear stimulus allows the heart to demonstrate its ability to adjust its cardiac output according to the environment, introducing variability that allows for a more accurate picture of cardiac function. Acoustic startle paradigms have a long history in psychophysiological research, particularly with respect to evaluation of sympathetic response (e.g. Bradley, Lang, \& Cuthbert, 1993; Ekman, Friesen, \& Simons, 1985; Jones \& Kennedy, 1951). The startle challenge paradigm herein is based on a fear of the dark paradigm used by Grillon and colleagues (Grillon, Morgan, Davis, \& Southwick, 1998; Grillon, Pellowski, Merikangas, \& Davis, 1997). In previous studies, this exact paradigm has demonstrated a significant physiological startle effect assessed via EMG; specifically, among individuals with insomnia who demonstrate a fear of the dark (Carney et al., 2013). Though this paradigm has not been used to assess for a similar startle response assessed via cardiac impedance measures, it was thought that this previously-validated startle paradigm would be appropriate for the purpose of assessing for cardiac changes. Similar acoustic startle paradigms have been used in studies evaluating cardiac reactivity; for example, Elsesser and colleagues used a white noise acoustic startle paradigm to evaluate changes in heart rate among a sample of individuals exposed to trauma (Elsesser, Freyth, Lohrmann, \& Sartory, 2008). His startle paradigm involved random bursts of white noise for the same duration of the present study, but would not allow comparison of time periods of interest between groups in the current study design. A thorough review of the startle and cardiac reactivity literature reveals a paucity of research using more sophisticated evaluation of cardiac reactivity. One group evaluated respiratory sinus arrhythmia, a cardiac correlate of parasympathetic activity, using an 
anticipatory electric shock paradigm (Gorka et al., 2013); however, the Grillion paradigm was chosen due to ease of use and previous validation with this population.

During the paradigm, participants listened to sudden bursts of white noise stimuli biaurally via stereo headphones in accordance with counterbalanced light and dark conditions. Background white noise was presented continuously during this experiment. The acoustic startle stimulus was a 40 millisecond (ms) burst of noise with a nearly instantaneous rise time. The background white noise and startle stimulus were 60 decibels (dBA) and $102 \mathrm{dBA}$ in intensity, respectively. The startle stimulus was presented either alone (S), or $120 \mathrm{~ms}$ after a $30 \mathrm{~ms}-1 \mathrm{ong}$, 65 dBA white noise pre-pulse (PP; pre-pulses were administered ).

Participants were randomly assigned to either "adaptation light" (Group A) or "adaptation dark" (Group B) conditions. The full baseline adaptation period was five minutes in length for both conditions. Previous research has demonstrated that this time period is an acceptable duration for assessment of baseline cardiac reactivity (Kelsey et al., 1999, 2000). The listening paradigm began with an adaptation period in the light, consisting of an initial 3-minute presentation of white background noise, followed by 6 startle stimuli presented 30 seconds apart. This adaptation period was followed by the presentation of four alternating light and dark phases, with the offset of one phase immediately followed by the onset of the other. The experiment was divided into two blocks, with each block containing two phases, one light and one dark. Each phase contained two sound (S) and two prepulse plus sound (PP-S) startle stimuli. Thus, a total of 16 acoustic stimuli were presented (twenty-two including the adaptation period). The stimuli in the listening paradigm was presented as follows for all participants, regardless of which group they were randomized to: Phase 1) S/PP-S/S/PP-S; Phase 2) PP-S/S/PP-S/S; Phase 3) S/PP-S/PPS/S; Phase 4) PP-S/S/S/PP-S (see Figure 2 for a visual depiction). The first startle stimuli in 
each phase was delivered 20 seconds following phase onset. The light was turned on for the duration of the adaptation phase in Group A and off for the adaptation phase in Group B. Illumination of the room was controlled by a trained research assistant using an external light switch, consistent with the timing of the listening paradigm audio file. The audio information was connected directly to the BIOPAC equipment, so that the audio signal could be seen on the signal screen along with the cardiac impedance signals. 
Figure 2. The Startle Paradigm, Randomized by Group.

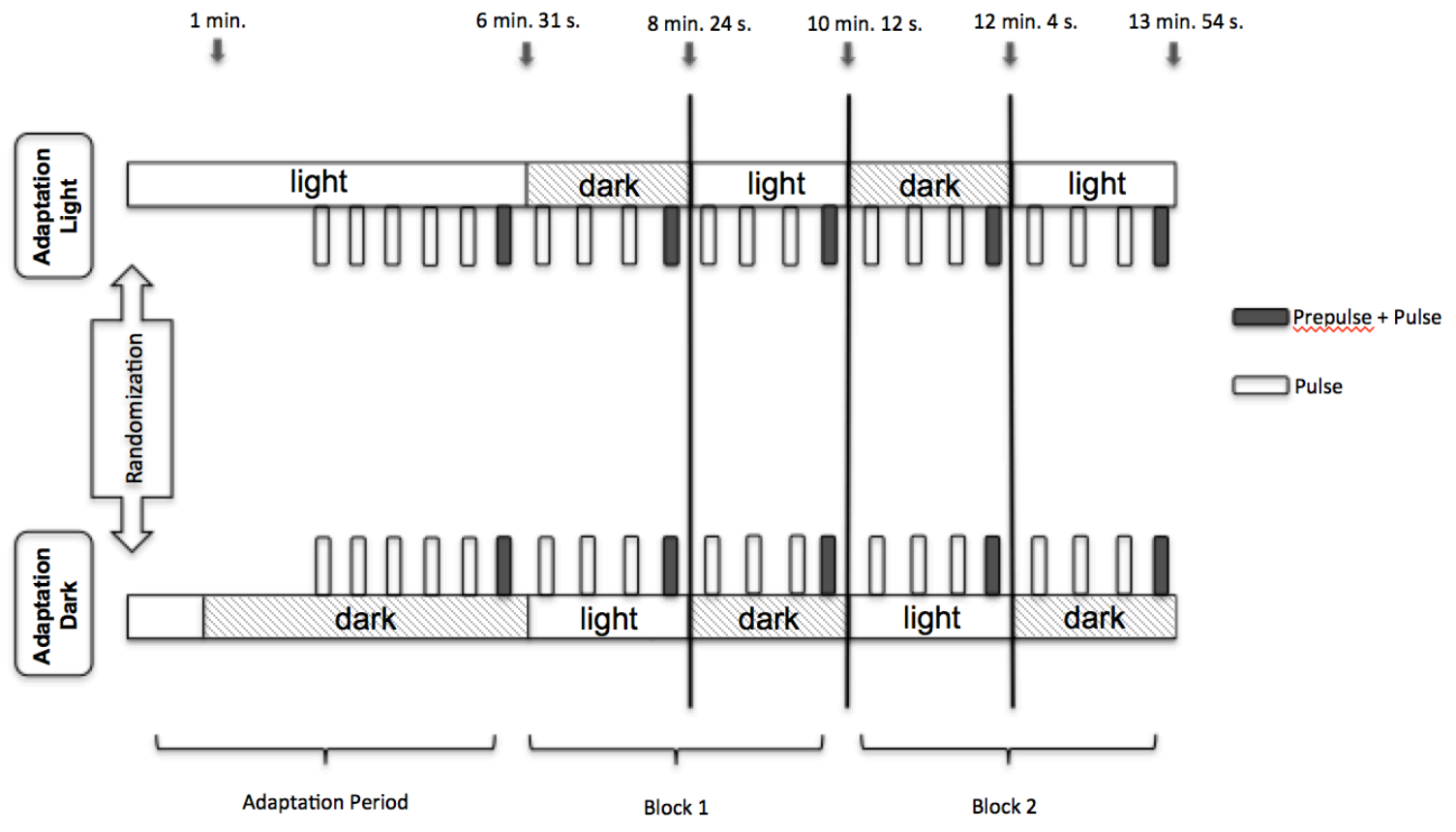




\section{CHAPTER FIVE}

\section{RESULTS}

\subsection{Preliminary Analyses}

All statistical analyses were conducted using IBM SPSS software (Versions 19.0 and 21.0; SPSS Inc., Chicago, IL, USA). Prior to conducting primary analyses, the data were visually inspected for violations of the assumption of normality. Means for each primary variable were calculated to ensure skewness and kurtosis values fell between normal ranges of $|2|$ and $|7|$, respectively (West, Finch, \& Curran, 1995). The MQS variable did not fall within these parameters; therefore, it was transformed using a log transformation and re-evaluated to ensure that its distribution approximated normality.

\subsection{Demographic Characteristics of the Sample}

The study population consisted of 69 participants. However, due to various technical issues (e.g. faulty signal, amplifier power failure) and various other unforeseeable problems during the experiment (e.g. the participant moved around and disconnected the electrodes, the participant indicated in the questionnaire that they are taking antihypertensive medications) the final sample included 49 participants, including $(n=26)$ meeting criteria for insomnia disorder (ID) and $(\mathrm{n}=23)$ normal sleeper (NS) comparisons. Table 1 depicts the demographic and clinical characteristics of the sample. A Chi-Square analysis was conducted to evaluate group differences on categorical demographic variables. The ID and NS groups did not differ significantly with respect to sex: $\chi^{2}(1)=.001, p=.98$, ethnicity: $\chi^{2}(6)=6.66, p=.35$, employment status: $\chi^{2}(2)=.029, p=.99$, marital status: $\chi^{2}(4)=6.10, p=.19$, use of alcohol frequently or in large quantities: $\chi^{2}(2)=1.64, p=.44$, current or past smoker: $\chi^{2}(1)=.016, p=$ 
.65 , or exercise: $\chi^{2}(3)=.86, p=.84$. Consistent with the insomnia literature, groups did differ with respect to possible comorbid diagnosis: $\chi^{2}(2)=12.31, p=.002$. The means of self-report dependent variables are reported in Table 2. A Bonferroni adjustment was used to accommodate the 14 different $t$ tests. As expected, groups differed on sleep variables TST, SE, TWT, and ISI, as well as all DASS subscales, the DISRS, and age. Groups did not differ significantly on BMI, total trait anger and anger subscales, MQS, or SFFQ. 


\section{Table 1}

\section{Participant Demographics}

\begin{tabular}{|c|c|}
\hline Variable & $n(\%)$ \\
\hline \multicolumn{2}{|l|}{ Sex } \\
\hline Female & 34 (69) \\
\hline Male & $15(31)$ \\
\hline \multicolumn{2}{|l|}{ Ethnic Background } \\
\hline Aboriginal Canadian & $1(2)$ \\
\hline African Canadian & $1(2)$ \\
\hline Caribbean Canadian & $1(2)$ \\
\hline European Canadian & $33(67)$ \\
\hline South Asian Canadian & $3(6)$ \\
\hline Pacific Islander Canadian & $1(2)$ \\
\hline Other & $9(18)$ \\
\hline \multicolumn{2}{|l|}{ Living Arrangement } \\
\hline Living alone & $9(18)$ \\
\hline With spouse/partner & $14(29)$ \\
\hline With spouse/partner and children & $6(12)$ \\
\hline With friend(s)/roommate(s) & $6(12)$ \\
\hline With family member(s) & $12(25)$ \\
\hline Other & $1(2)$ \\
\hline \multicolumn{2}{|l|}{ Relationship Status } \\
\hline Single & $27(55)$ \\
\hline Married/common-law & $16(33)$ \\
\hline Live-in partner (less than 2 years) & $3(6)$ \\
\hline Divorced & $2(4)$ \\
\hline Widowed & $1(2)$ \\
\hline \multicolumn{2}{|l|}{ Employment Status } \\
\hline Full time & $26(53)$ \\
\hline Part-time & $6(12)$ \\
\hline Not working & $17(35)$ \\
\hline
\end{tabular}


Table 2

Group Comparison of Sleep Variables and Self-Report Dependent Variables

\begin{tabular}{cccccccc}
\hline & & \multicolumn{2}{c}{$\begin{array}{c}\text { Insomnia Disorder } \\
(n=26)\end{array}$} & \multicolumn{2}{c}{$\begin{array}{c}\text { Normal Sleeper } \\
(n=23)\end{array}$} & \multicolumn{2}{c}{ Statistics } \\
\cline { 3 - 7 } & & Mean & SD & Mean & SD & $t$-statistic & $p$-value \\
\hline Sleep & & & & & & & \\
Variables & ISI & 17.77 & 3.70 & 1.96 & 2.53 & 17.65 & $<.001^{* *}$ \\
& CSD TST & & & & & & \\
& (hours) & 5.66 & 1.41 & 7.52 & .59 & -6.2 & $<.001^{* *}$ \\
& CSD TWT (hours) & 2.61 & 1.03 & .58 & .37 & 9.38 & $<.001^{* *}$ \\
Self- & CSD SE (\%) & 68 & .13 & 93 & .05 & & \\
Report & & & & & & & \\
Variables & Age & 45.19 & 15.79 & 30.61 & 11.70 & 3.7 & $.001^{* *}$ \\
& & & & & & & \\
& Trait Anger Total & 24.27 & 3.2 & 24.96 & 3.0 & -.77 & .45 \\
& Trait Anger-T & 9.54 & 1.7 & 10.57 & 1.6 & -2.1 & .04 \\
& Trait Anger-R & 10.08 & 1.74 & 10.52 & 1.65 & -.92 & .37 \\
& DISRS & 45.19 & 12.61 & 33.91 & 11.75 & 3.23 & $<.001^{* *}$ \\
& DASS-A & 3.12 & 2.6 & .70 & 1.4 & 4.04 & $<.001^{* *}$ \\
& DASS-D & 4.92 & 5.4 & 1.09 & 1.6 & 3.43 & $.002^{*}$ \\
& DASS-S & 7.04 & 4.5 & 2.26 & 2.8 & 4.44 & $<.001^{* *}$ \\
& SFFQ & 7.35 & 4.7 & 3.4 & 3.6 & 2.59 & .013 \\
& BMI & 25.20 & 5.11 & 23.71 & 4.1 & 1.12 & .27 \\
& MQS & 3.37 & 5.08 & .28 & .97 & 3.03 & .005 \\
\hline
\end{tabular}

Note. ISI = Insomnia Severity Index, CSD = Consensus Sleep Diary (mean calculations across two-week period), TST = Total Sleep Time, TWT = Total Wake Time, SE = Sleep Efficiency, Trait Anger - T = Angry Temperament subscale of the State-Trait Anger Expression Inventory, Trait Anger $-R=$ Angry Reaction subscale of the State-Trait Anger Expression Inventory, DISRS = Daytime Insomnia Symptom Response Scale, DASS-A = Anxiety subscale of the Depression Anxiety Stress Scales, DASS-D = Depression subscale of the Depression Anxiety Stress Scales, DASS-S = Stress subscale of the Depression Anxiety Stress Scales, SFFQ = Semi Quantitative Food Frequency Questionnaire, BMI = Body Mass Index, MQS = Medication Quantification Subscale; * indicates significance at $p<.004$ (Bonferroni adjustment), ** indicates significance at $p<.001$. 


\subsection{Hierarchical Linear Modeling Analysis}

One of the strengths of this study is the use of continuous psychophysiological data to assess for cardiac impedance variables. Due to the hundreds of longitudinal data points for each participant, a sophisticated statistical analysis was required that would allow for examination of both within-subject (i.e., person-specific changes over time) and between-subject changes. The within-subjects level of this analysis violates the assumption of independence that is necessary for many statistical tests, as observations taken from the same individual on several occasions over time cannot be considered to be independent. In order to accommodate this violation of independence, a multilevel modeling technique was used; specifically, hierarchical linear modeling (HLM). This data analysis technique takes into account the "nested" structure of psychophysiological data, i.e., data that is theoretically predicted to cluster together nonindependently (for example, from the same participant). Mixed effects models like HLM allow

for analysis of within-subject changes over time as well as the role of chosen group-level data as predictors of the subject-level outcome variables (in this case, CO and PEP; Cheng, Edwards, Maldonado-Molina, Komro, \& Muller, 2010).

HLM considers data on two "levels", that is, both within-person (Level 1) and betweenperson (Level 2; McCrae et al., 2008; Willett, Singer, \& Martin, 1998; Zautra, Johnson, \& Davis, 2005). At Level 1, the model is considered without any additional predictors of the differences between individuals at that level. Only the mean score of the outcome variable (the intercept of the model) for each person, the variance of all the intercepts, and within-person variability are modeled. Variance at Level 1 is then explained by one or more predictors in Level 2, the conditional model. More simply, the Level 1 model describes the repeated measures (i.e. psychophysiological) data for the participants, and Level 2 includes variables that measure 
systematic differences among participants that might help to explain the pattern of change among the psychophysiological data. Analysis at Level 1 for the data herein indicated that a model with predictors should be pursued, in case additional variables may explain the variance in the model.

In HLM analysis, there is no universally accepted standard for power computation (Costelloe \& O'Brien, 2000). As power analysis depends on covariance structure, which is not available until data collection is complete, it is difficult to estimate adequate sample size prior to collecting the data. Therefore, a power analysis was not conducted prior to initiation of this study.

\subsubsection{HLM Data Preparation}

Prior to testing the study hypotheses, dependent variables CO and PEP were person mean-centered. That is, a mean variable of PEP and CO for each participant was calculated, and this mean was subtracted from each CO and PEP longitudinal variable throughout the paradigm. Thus, in the model, each person's mean CO and PEP represented their personal mean CO and PEP, while each person mean-centered CO and PEP variables represented their own fluctuations around their own mean $\mathrm{CO}$ and PEP throughout the paradigm. This person-mean centering technique is superior to group mean centering, as it allows the model to contain more information for each nested variable.

As a data screening technique, psychophysiological data points representing CO and PEP for each participant were visually inspected via scatterplots. Unusually visually steep positive or negative slopes from point to point were further inspected, and code was written for both variables that data would be automatically deleted if adjacent data points differed by more than $50 \%$ (i.e. a physiologically impossible change). This approach is more conservative than the one described in (Newlin \& Levenson, 1979). This step was necessary in order to remove erroneous 
data points that likely emerged due to signal errors (e.g. the participant moved at that moment and disrupted the signal). Overall, less than $2 \%$ of the total data sample was deleted.

Fortunately, unlike traditional regressions, HLM is able to handle missing data, and computation could proceed as normal.

In order to evaluate changes of psychophysiological variables across the time periods of interest in the paradigm (e.g., from Dark Phase 1 to Dark Phase 2), dummy coding was used. With this coding structure, the comparisons of interest could be assessed, as well as cross-level interactions (e.g., Dark Phase 1 was coded as 000 1, and Dark Phase 2 was coded as 0010 to allow for the HLM analysis to include phase as a Level 2 predictor).

\subsubsection{HLM Data Analysis}

In order to conduct these HLM analyses, syntax code from Peugh and Enders (2005) was adapted for this data set. As discussed above, the first step of HLM is to construct the null model (i.e. a model containing no predictors). The unconditional repeated-measures model revealed that there is significant variability in both $\mathrm{CO}$ and PEP variables, suggesting that it is worthwhile to construct a conditional model that could potentially explain some of this variability. There was statistically significant variability both between participants (Wald $\mathrm{Z}=$ $4.87, p<.001$ ) and within participants (Wald $\mathrm{Z}=8.57, p<.001$ ) for PEP and CO (betweenperson Wald $\mathrm{Z}=4.87, p<.001$; within-person Wald $\mathrm{Z}=8.57, p<.001$ ). Table 3 depicts the estimates of the variance components that are associated with the fixed and random effects for these models. 
Table 3

Unconditional Model for CO and PEP

\begin{tabular}{|c|c|c|c|c|}
\hline & & \multicolumn{3}{|c|}{$95 \%$ Confidence Interval } \\
\hline Fixed Effects & Estimate & $S E$ & Lower Bound & Upper Bound \\
\hline \multicolumn{5}{|l|}{ Intercept } \\
\hline $\mathrm{CO} * * *$ & 7.82 & .34 & 7.13 & 8.50 \\
\hline $\mathrm{PEP} * * *$ & .1228 & .003 & .1161 & .1296 \\
\hline \multicolumn{5}{|c|}{ Random Effects } \\
\hline \multicolumn{5}{|c|}{ Between-person variance } \\
\hline $\mathrm{CO} * * *$ & 5.68 & 1.17 & 3.80 & 8.49 \\
\hline $\mathrm{PEP} * * *$ & .000539 & .00011 & .00036 & .0008 \\
\hline \multicolumn{5}{|c|}{ Within-person variance } \\
\hline $\mathrm{CO} * * *$ & .36 & .04 & .29 & .45 \\
\hline $\mathrm{PEP} * * *$ & .000033 & .00039 & .00003 & .00004 \\
\hline
\end{tabular}


The Intraclass Correlation Coefficient (ICC) matrix was computed from the unconditional model to evaluate within-person vs. between-person variability to be explained. In the literature for HLM analyses, there is no consensus on an ICC cutoff value; however, Woltman et al (2012) argue that if the ICC (range 0 - 1) is very low, HLM analyses may not add any additional computational strength to a traditional analysis. In this analysis, the ICC for PEP $=.95$ and the $\mathrm{ICC}$ for $\mathrm{CO}=.94$, indicating that variance of each of the dependent variables are almost entirely explained on Level 1 of the model (i.e. within subjects); therefore, it was crucial to run this mixed longitudinal analysis.

In order to determine the next model, the backward elimination approach recommended by Cheng et al., 2010 was employed. That is, the full model for both CO and PEP (i.e. all specified theoretically-driven predictors plus sleep variables TST, TWT and ISI) was entered first, and predictors that did not contribute significantly to the model were deleted. In addition, the -2 Restricted Log Likelihood estimate (a commonly-used measure for model goodness-of-fit) was inspected, and the model associated with the lowest number (indicating the best fit of predictors) was selected as final. As Table 4 indicates, Age, BMI, SFFQ, MQS, Total Anger, and Total Anger - R were found to be statistically significant predictors of $\mathrm{CO}$, even after the statistically significant remaining within-person and between-person variances were taken into account. Total Anger - $\mathrm{R}$ was included in this model because though it did not emerge as a significant predictor, in combination, this and the other predictors produced the model that best fit the mean CO data (-2 Restricted Log Likelihood $=560.6)$. Table 5 depicts the parameter estimates for both fixed (population characteristics) and random (participant-specific characteristics) effects for $\mathrm{CO}$. 
Table 4

Conditional Model For CO Including Theoretical Predictors

\begin{tabular}{cccccc}
\hline Fixed Effect & B & SE & df & $\boldsymbol{F}$ & $\boldsymbol{p}$ \\
\hline Intercept & 11.33 & 3.12 & 41 & 12.67 & $.001^{* *}$ \\
Age & -.04 & .03 & 41 & 2.68 & $.05^{*}$ \\
BMI & -.19 & .08 & 41 & 5.41 & $.01^{*}$ \\
SFFQ & .29 & .09 & 41 & 9.95 & $<.001^{* *}$ \\
MQS & .62 & .33 & 41 & 3.52 & $.04^{*}$ \\
T_Ang & -.46 & .26 & 41 & 3.17 & $.04^{*}$ \\
T_Ang_T & .70 & .33 & 41 & 4.42 & $.02^{*}$ \\
T_Ang_R & .46 & .36 & 41 & 1.60 & .11 \\
\hline Random Effect & & Estimate & SE & .04 & p \\
\hline Random Intercept Variance & .36 & 1.08 & 8.57 & $<.001^{* *}$ \\
Level-1 Residual Variance & 4.80 & $.001^{* *}$ \\
\hline
\end{tabular}

Note. $\mathrm{CO}=$ Cardiac Output, Trait Anger $-T=$ Angry Temperament subscale of the State-Trait Anger Expression Inventory, Trait Anger $-R=$ Angry Reaction subscale of the State-Trait Anger Expression Inventory, SFFQ = Semi Quantitative Food Frequency Questionnaire, BMI = Body Mass Index, $M Q S=$ Medication Quantification Subscale; * indicates significance at $p<.05$, ** indicates significance at $p<.01$.

Table 5

Conditional Model for PEP Including Theoretical Predictors

\begin{tabular}{|c|c|c|c|c|c|}
\hline Fixed Effect & B & SE & df & $F$ & $p$ \\
\hline Intercept & .16 & .03 & 41 & 23.13 & $<.001 * *$ \\
\hline Age & -.0005 & .0002 & 41 & 3.39 & $.04 *$ \\
\hline BMI & -.002 & .0009 & 41 & 3.67 & $.03 *$ \\
\hline SFFQ & .002 & .001 & 41 & 3.63 & $.03 *$ \\
\hline MQS & .004 & .003 & 41 & 1.07 & .15 \\
\hline T_Ang & -.002 & .003 & 41 & .47 & .25 \\
\hline T_Āng_T & .002 & .004 & 41 & .49 & .24 \\
\hline $\mathrm{T}$ Ang_R & .003 & .004 & 41 & .50 & .24 \\
\hline Random Effect & & Estimate & SE & $z$ & $p$ \\
\hline \multicolumn{2}{|c|}{ Random Intercept Variance } & .00033 & .00 & 4.46 & $<.001 * *$ \\
\hline \multicolumn{2}{|c|}{ Level-1 Residual Variance } & .0005 & .0001 & 8.57 & $<.001 * *$ \\
\hline
\end{tabular}

Note. PEP = Pre-Ejection Period, Trait Anger $-T=$ Angry Temperament subscale of the StateTrait Anger Expression Inventory, Trait Anger $-R=$ Angry Reaction subscale of the State-Trait Anger Expression Inventory, SFFQ = Semi Quantitative Food Frequency Questionnaire, BMI = Body Mass Index, MQS = Medication Quantification Subscale; * indicates significance at $p<$ $.05, * *$ indicates significance at $p<.01$. 
The same model was used for PEP; however, fewer predictors were found to be statistically significant. Medication (MQS) and anger variables (T_Ang, T_Ang_T, and T_Ang_R) were not found to be significant predictors of between-person variance in PEP. The residual estimate was still found to be statistically significant for both models (CO Wald $Z=$ 8.57; PEP Wald $Z=8.57, p<.001$ ); thus, there appears to be residual variance that contributes to differences between participants on the variables of interest, but this variance was not explained by the combination of predictors chosen.

The next model was built based on the previous conditional model to assess for percent of variance explained by phase. When DP1, DP2, and Recovery phases were entered into the model as predictors for CO, though the -2 Restricted Log Likelihood value dropped to 539.0 (indicating a better overall model fit to the data), these phases were not found to be statistically significant predictors in the model (See Table 6). Likewise with PEP, there was also an improvement in the -2 Restricted Log Likelihood Ratio, but the three phases variables were not significant predictors of PEP (See Table 7). This result implies that there does not appear to be any systematic differences between participants on phase; i.e., they are not systematically different. 
Table 6

Conditional Model for CO Including Percent of Variance Explained by Phase

\begin{tabular}{|c|c|c|c|c|c|}
\hline Fixed Effect & B & SE & df & $F$ & $p$ \\
\hline Intercept & 11.37 & 2.91 & 49 & 15.24 & $<.001 * *$ \\
\hline Age & -.04 & .02 & 49 & 3.20 & $.04 *$ \\
\hline BMI & -.19 & .08 & 49 & 6.46 & $.007 * *$ \\
\hline SFFQ & .29 & .09 & 49 & 11.89 & $<.001 * *$ \\
\hline MQS & .62 & .23 & 49 & 4.20 & $.02 *$ \\
\hline T_Ang & -.46 & .23 & 49 & 3.80 & $.03 *$ \\
\hline T_Āng_T & .70 & .30 & 49 & 5.28 & $.01 * *$ \\
\hline T_Ang_R & .48 & .33 & 49 & 1.91 & .09 \\
\hline DP1 & -.12 & .12 & 147 & 1.0 & .16 \\
\hline DP2 & .08 & .12 & 147 & .41 & .27 \\
\hline Recovery & .12 & .12 & 147 & 1.1 & .12 \\
\hline Random Effect & & Estimate & SE & $z$ & $p$ \\
\hline \multicolumn{2}{|c|}{ Random Intercept Variance } & 4.0 & .83 & 4.84 & $<.001 * *$ \\
\hline \multicolumn{2}{|c|}{ Level-1 Residual Variance } & .35 & .04 & 8.57 & $<.001 * *$ \\
\hline
\end{tabular}

Note. $\mathrm{CO}=$ Cardiac Output, Trait Anger $-T=$ Angry Temperament subscale of the State-Trait Anger Expression Inventory, Trait Anger $-R=$ Angry Reaction subscale of the State-Trait Anger Expression Inventory, SFFQ = Semi Quantitative Food Frequency Questionnaire, BMI = Body Mass Index, $M Q S=$ Medication Quantification Subscale, DP1 = Dark Phase 1, DP2 = Dark Phase 2; * indicates significance at $p<.05, * *$ indicates significance at $p<.01$.

Table 7

Conditional Model for PEP Including Percent of Variance Explained by Phase

\begin{tabular}{|c|c|c|c|c|c|}
\hline Fixed Effect & B & SE & df & $F$ & $p$ \\
\hline Intercept & .16 & .03 & 49 & 27.80 & $<.001 * *$ \\
\hline Age & -.0005 & .0002 & 49 & 4.05 & $.03 *$ \\
\hline BMI & -.002 & .0008 & 49 & 4.39 & $.02 *$ \\
\hline SFFQ & .002 & .0009 & 49 & 4.32 & $.02 *$ \\
\hline MQS & .004 & .003 & 49 & 1.28 & .13 \\
\hline T_Ang & -.002 & .002 & 49 & .57 & .23 \\
\hline T_Āng_T & .002 & .003 & 49 & .59 & .22 \\
\hline T_Ang_R & .003 & .004 & 49 & .60 & .22 \\
\hline DP1 & .0002 & .001 & 147 & .03 & .43 \\
\hline DP2 & -.0008 & .001 & 147 & .44 & .25 \\
\hline Recovery & -.001 & .001 & 147 & 1.43 & .12 \\
\hline Random Effect & & Estimate & SE & $z$ & $p$ \\
\hline \multicolumn{2}{|c|}{ Random Intercept Variance } & .0004 & .00009 & 4.86 & $<.001 * *$ \\
\hline \multicolumn{2}{|c|}{ Level-1 Residual Variance } & .00003 & .00000 & 9.22 & $<.001 * *$ \\
\hline
\end{tabular}

Note. PEP = Pre-Ejection Period, Trait Anger $-T=$ Angry Temperament subscale of the StateTrait Anger Expression Inventory, Trait Anger $-R=$ Angry Reaction subscale of the State-Trait Anger Expression Inventory, SFFQ = Semi Quantitative Food Frequency Questionnaire, BMI = Body Mass Index, MQS = Medication Quantification Subscale, DP1 = Dark Phase 1, DP2 = Dark Phase 2; * indicates significance at $p<.05$, ** indicates significance at $p<.01$. 
The final full conditional model was built next to assess for the addition of the interaction between adaptation period, sleeper status, and phase (i.e., does the CO or PEP value depend on one's sleeper status, randomized adaptation period, and phase?). In order to assess for the change in cardiac impedance variables across time points of interest during the paradigm, dummy coding was created and then analyzed so that the non-longitudinal mean timepoints could be compared (e.g. Adaptation period vs. Dark Phase 2). Cross-level interactions were also assessed. This model cannot be interpreted, as the output indicated that the Hessian matrix is not positive definite. That is, it is likely that the values of PEP and CO in the chosen phases were not any more similar between people than a random selection would indicate. Therefore, the chosen phases cannot be compared, as the variance for phase is zero (i.e., the model was unable to uniquely estimate any variation from phase to phase above and beyond residual variation from person to person). An inspection of the distribution of each person's scores on PEP and CO in Figures 3 and 4 do not reveal any particular pattern that might be expected over the course of the experiment; thus, this hypothesis of limited systematic variance is probable. In addition, a comparison of the means for CO and PEP across phases reveals that they are similar (See Table 8). 
Figure 3

CO for Each Participant Across Paradigm Phases

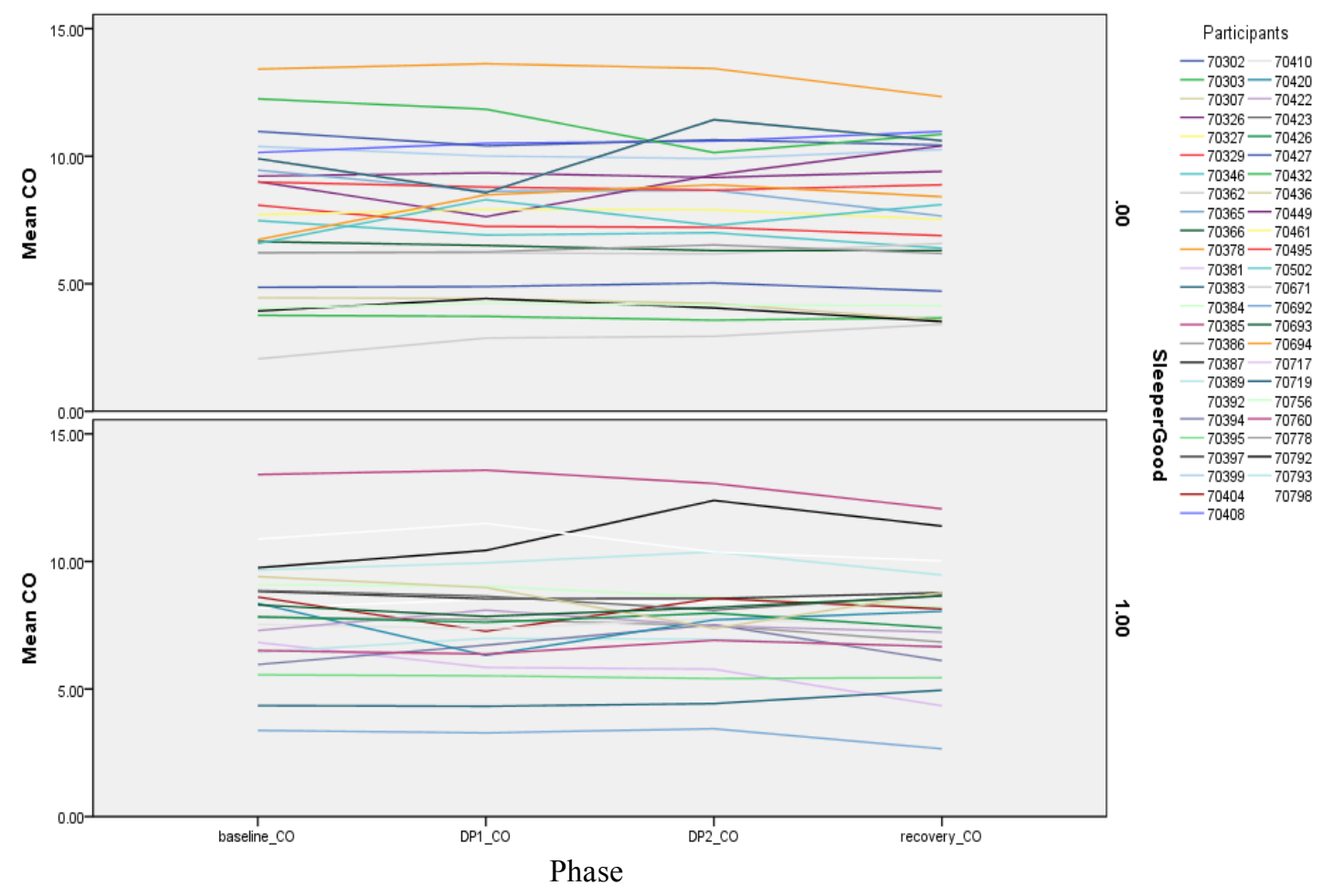

Note. SleeperGood $0.00=$ Insomnia Disorder group, SleeperGood $1.00=$ Normal Sleepers. 
Figure 4

\section{PEP for Each Participant Across Paradigm Phases}

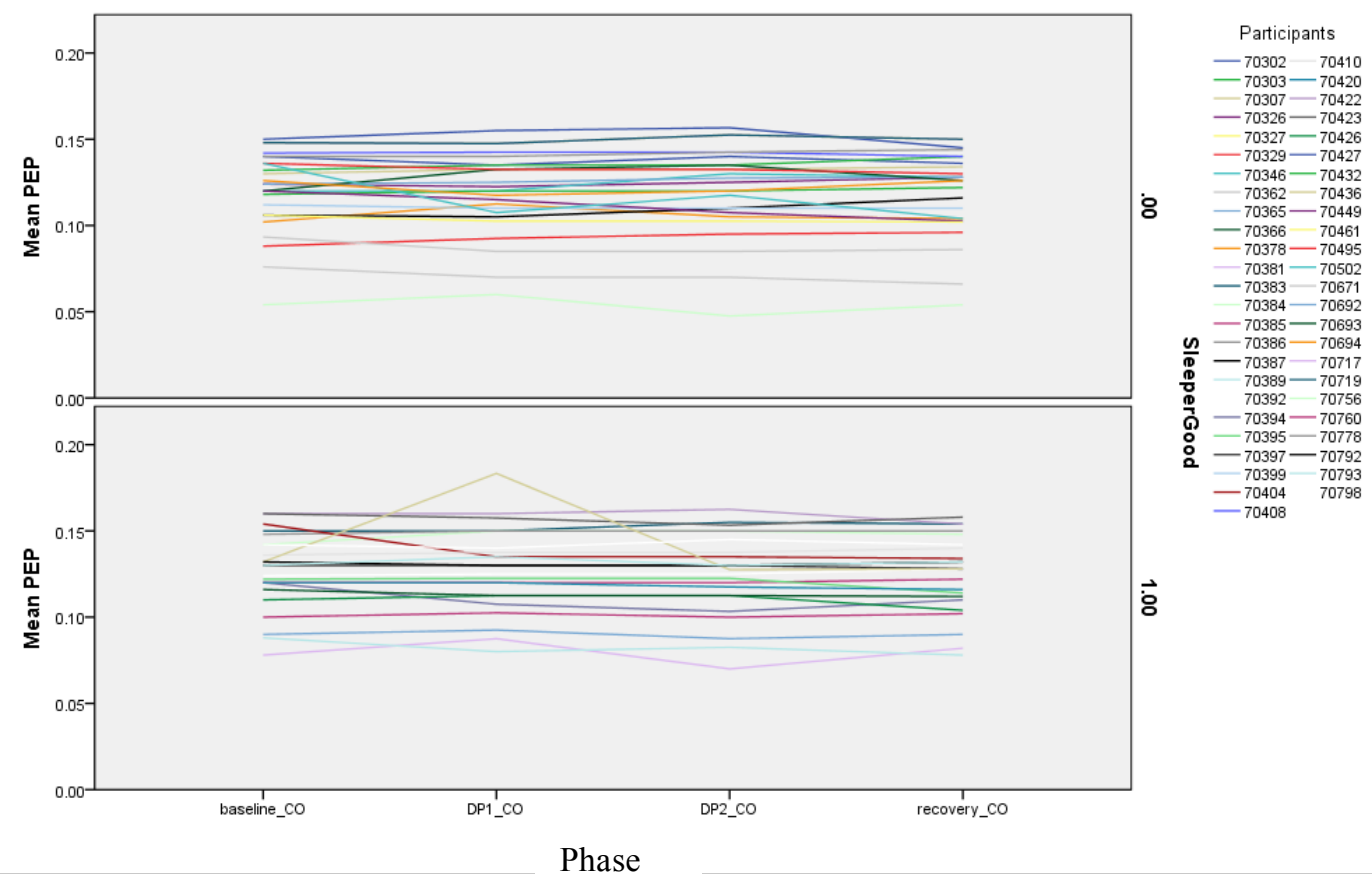

Note. SleeperGood $0.00=$ Insomnia Disorder group, SleeperGood $1.00=$ Normal Sleepers . 
Table 8

Mean CO and PEP values by Phase

\begin{tabular}{ccccc}
\hline & \multicolumn{2}{c}{$\begin{array}{c}\text { Insomnia Disorder } \\
(n=26)\end{array}$} & \multicolumn{2}{c}{$\begin{array}{c}\text { Normal Sleeper } \\
(n=23)\end{array}$} \\
\cline { 2 - 5 } & Mean & SD & Mean & SD \\
\hline CO (mL/min) & & & & \\
Adaptation & 7.79 & 2.67 & 7.56 & 2.39 \\
Dark Phase 1 & 7.78 & 2.64 & 7.56 & 2.40 \\
Dark Phase 2 & 7.76 & 2.55 & 7.56 & 2.35 \\
Recovery & 7.75 & 2.49 & 7.20 & 2.40 \\
PEP (seconds) & & & & \\
Adaptation & .120 & .02 & .126 & .023 \\
Dark Phase 1 & .119 & .02 & .127 & .025 \\
Dark Phase 2 & .119 & .03 & .121 & .024 \\
Recovery & .117 & .03 & .121 & .023 \\
\hline
\end{tabular}

Note. $C O=$ Cardiac Output, PEP = Pre-Ejection Period. 


\subsection{Post-hoc Analyses}

Although not a stated objective for this study, a post-hoc exploratory analysis using high frequency HRV was conducted in an effort to place the results of this study within the current literature. As discussed in earlier sections, previous research conducted in this area of study has primarily employed HRV as a correlate of cardiovascular health (see section 1.3 for a discussion of the limitations of this approach). The indices CO and PEP were chosen as the primary variables of interest in the current study due to the accumulating scientific evidence that they are superior indices of cardiac sympathetic activity. Unfortunately, however, since most previous work has not used these indices, the results of this study are difficult to compare to the existing literature. Therefore, a post-hoc analysis was conducted using a multiple regression wherein HF HRV (a well-validated index of parasympathetic cardiac activation, see section 1.3) was predicted by a combination of predictor variables found to be important in the HLM analysis, including the sleep variables of interest. High frequency HRV was chosen rather than low frequency HRV because it has more research support as an accurate correlate of cardiovagal activity; however, results should still be interpreted with caution, as HF and LF HRV do not work in a perfect inverse relationship, and inferring sympathetic activity from a parasympathetic index is hardly robust (Billman, 2013; Eckberg, 1997; Goldstein et al., 2011). However, it was necessarily to include this post hoc analysis in order to place the current results within the existing literature.

Data for five participants was excluded from this analysis, as their HF values were over 3 standard deviations away from the mean value for all phase periods, indicating that the signal was likely erroneous. Descriptive statistics for the HF HRV variables can be found in Table 9. All participants were included in the analysis, such that they were not separated by diagnostic 
category. For all variables in each model, Tolerance and Variance Inflation Factor variables were $>0.10$ and $<10.0$, respectively, which excluded multicollinearity (Myers, 1990). 
Table 9

Mean HF HRV (normalized unit) values by Phase

\begin{tabular}{ccc}
\hline & \multicolumn{2}{c}{ Participants } \\
& $(n=44)$ \\
\cline { 2 - 3 } & Mean & SD \\
\hline Adaptation & 43.40 & 19.41 \\
Dark Phase 1 & 45.34 & 19.77 \\
Dark Phase 2 & 42.56 & 17.63 \\
Recovery & 43.52 & 17.19 \\
\hline
\end{tabular}


As the primary interest of these post hoc tests was to evaluate cardiac responsivity to dark phase 2 DP2) and in the recovery period, two hierarchical regressions were run predicting high frequency HRV in both DP2 and the Recovery periods. At first, an exploratory enter-method regression was used using all significant variables from the HLM analysis (i.e. Age, BMI, SFFQ, MQS, T_Ang_T) as well as sleep variables TST and ISI to evaluate their relative importance (TWT was excluded as it was demonstrated to be the least influential sleep variable in the HLM analysis). In order to preserve power with a small sample size, the analysis was re-run as a hierarchical multiple regression minus the variables shown to exhibit the least influence on variance. In the hierarchical regression, Age was entered in the first step, followed by SFFQ, T_Ang_T, TST, and ISI.

In the first regression model predicting DP2 HF HRV, step 1 (Age) was significant (F change $=7.82, p=<.001)$; thus, age significantly predicts HF HRV ( $(=-.40, p=.03)$. In step 2 , the SFFQ was not found to significantly predict HF HFV (F change $=.36, p=.55)$. T_Ang_T was added at the third step, which was also not found to contribute to the prediction of HF HRV (F change $=0.58, p=.45$ ). Total Sleep Time (TST) was added on the fourth step; this was not found to improve the prediction model ( $\mathrm{F}$ change $=.00, p=1.00$ ). Finally, ISI was entered in the last step and was found to significantly predict HF HRV (F change $=8.08, p<.001$; see Table $10)$. 


\section{Table 11}

Hierarchical Multiple Regression Analysis Predicting HF HRV in Dark Phase 2

\begin{tabular}{|c|c|c|c|c|c|}
\hline Predictor & $B$ & $p$ & Adjusted $\mathrm{R}^{2}$ & F Change & $p$ \\
\hline Step 1 & & & .14 & 7.82 & $.008 * *$ \\
\hline Age & -.40 & $.008 * *$ & & & \\
\hline Step 2 & & & .12 & .36 & .55 \\
\hline Age & -.43 & $.007 * *$ & & & \\
\hline SFFQ & .09 & .55 & & & \\
\hline Step 3 & & & .11 & .58 & .45 \\
\hline Age & -.38 & $.02 *$ & & & \\
\hline SFFQ & .09 & .57 & & & \\
\hline T_Ang_T & .12 & .45 & & & \\
\hline Step 4 & & & .09 & .00 & 1.0 \\
\hline Age & -.38 & $.03 *$ & & & \\
\hline SFFQ & .09 & .21 & & & \\
\hline T_Ang_T & .12 & .56 & & & \\
\hline TST & .00 & 1.0 & & & \\
\hline Step 5 & & & .23 & 8.08 & $.007 * *$ \\
\hline Age & -.28 & .08 & & & \\
\hline SFFQ & .19 & .21 & & & \\
\hline T_Ang_T & .13 & .41 & & & \\
\hline TST & -.34 & .08 & & & \\
\hline ISI & -.55 & $.007 * *$ & & & \\
\hline
\end{tabular}

Note. $H F H R V=$ High Frequency Heart Rate Variability, SFFQ = Semi-Quantitative Food Frequency Questionnaire, T_Ang_T = Temperament subscale of the State/Trait Anger Inventory, $T S T=$ Total Sleep Time, ISI = Insomnia Severity Index; * indicates significance at $p<.05$, ** indicates significance at $p<.01$. 
In the second regression model, the same stepwise multiple regression was conducted, with HF HRV in the Recovery phase as the dependent variable. In this regression model, age was found to be a significant predictor of HF HRV (Recovery) in the first step (F change $=7.82$, $p=<.001)$; thus, age significantly predicts HF HRV $(\beta=-.41, p=.006)$. No other predictor variables were found to significantly predict the outcome variable (See Table 11). 
Table 12

Hierarchical Multiple Regression Analysis Predicting HF HRV in Recovery Phase

\begin{tabular}{|c|c|c|c|c|c|}
\hline Predictor & $\beta$ & $p$ & Adjusted $\mathrm{R}^{2}$ & F Change & $p$ \\
\hline Step 1 & & & .15 & 8.5 & $.006^{* *}$ \\
\hline Age & -.41 & $.006 * *$ & & & \\
\hline Step 2 & & & .16 & 1.5 & .22 \\
\hline Age & -.47 & $.003 * *$ & & & \\
\hline SFFQ & .18 & .22 & & & \\
\hline Step 3 & & & .15 & .41 & .53 \\
\hline Age & -.43 & $.01 *$ & & & \\
\hline SFFQ & .18 & .23 & & & \\
\hline T_Ang_T & .10 & .53 & & & \\
\hline Step 4 & & & .18 & 2.5 & .12 \\
\hline Age & -.40 & $.02 *$ & & & \\
\hline SFFQ & .19 & .20 & & & \\
\hline $\mathrm{T}$ Ang $\mathrm{T}$ & .03 & .87 & & & \\
\hline TST & .24 & .12 & & & \\
\hline Step 5 & & & .22 & 2.9 & .10 \\
\hline Age & -.34 & $.04 *$ & & & \\
\hline SFFQ & .25 & .09 & & & \\
\hline T_Ang_T & .20 & .84 & & & \\
\hline TST & .19 & .85 & & & \\
\hline ISI & -.34 & .10 & & & \\
\hline
\end{tabular}

Note. HF HRV = High Frequency Heart Rate Variability, SFFQ = Semi-Quantitative Food Frequency Questionnaire, T_Ang_T = Temperament subscale of the State/Trait Anger Inventory, $T S T=$ Total Sleep Time, ISI = Insomnia Severity Index; * indicates significance at $p<.05$, ** indicates significance at $p<.01$. 


\section{CHAPTER 6}

\section{DISCUSSION}

\subsection{Synthesis of the Literature and Findings from the Current Study}

Previous research has suggested that insomnia may be an independent predictor of cardiovascular health. The current study was designed to address some of the weaknesses of prior CVD and insomnia research. Both advanced statistical models (multi-level modeling) and more traditional techniques (multiple regression) were used to evaluate the relationship between sleep and specific cardiac indices. Interestingly, these different statistical techniques revealed conflicting results: multi-level modeling showed that sleep variables indicative of both insomnia and total sleep time do not appear to be associated with well-validated indices of cardiovascular functioning, while hierarchical regression showed that subjective insomnia predicts a different index of cardiovascular functioning even among other well-established predictor variables. The following paragraphs will explore possible explanations for these contradictory results.

First, a more contemporary statistical technique (i.e., multi-level modeling) specifically was used in this study due to its ability to assess both within-person and between-person variability with respect to the outcome variable. Previous work assessing the same relationship between risk for CVD and insomnia has not taken into account within-person variability. Findings from this analysis indicated that over $90 \%$ of the variability in both PEP and CO was accounted for on an individual level: that is, less than $10 \%$ of the variability in these outcome measures was accounted for by group-based predictor variables, including sleep indices. Among these other group-based predictor variables, all of which have been well established in previous research to influence risk for CVD, sleep was not found to be significantly important among that remaining $10 \%$ of variability in the outcome measures. In the scientific interest of parsimony, 
the simplest explanation must be considered: insomnia is not directly related to cardiovascular health. Given that several well-established predictors of CV health (such as age and BMI) were included in these group variables, perhaps it is not surprising that among the remaining $10 \%$ of variability, sleep was found to be nonsignificant. Nonetheless, this result is in contrast to some other studies that have found sleep to be important to CV risk (e.g. Schwartz et al., 1999; Sofi et al., 2014), and these discrepant findings warrant contemplation.

One glaring difference between the present study's multi-level modeling results and previous research that evaluated insomnia and risk for CVD is the $\mathrm{CV}$ index correlate used. Most previous research used some form of HRV (e.g. HF/LF HRV ratio), which, as discussed in previous sections, is fraught with controversy and has been largely debunked (e.g. Heathers, 2014). The concept for the present study was actually borne from the author's previous Master's thesis work wherein HRV was used as an estimate of sympathetic activation in both normal sleepers and those with ID. Unfortunately, it was discovered that possible inherent measurement error from HRV may have led to confusing and possibly misleading results (see section 1.3.2; Lachowski, 2012). Pre-ejection period, one of the primary CV indices in this study, is the most well-validated index of cardiac sympathetic activity (Newlin \& Levenson, 1979), which has been proposed to be the mechanistic link through which $\mathrm{CV}$ risk might increase among individuals with insomnia (Brosschot et al., 2007). It was hypothesized that poorer sleep would be associated with decreased PEP, representing sympathetic hyperactivation. The multi-level modeling analysis was not consistent with this hypothesis. A possible explanation for discrepant results between the present study and previous work may be the difference between chosen CVD risk indices: one actually measures sympathetic activity (PEP), while the other does not (HRV). 
Essentially, previous research may have been misleading with respect to their conclusions about sympathetic hyperactivity as assessed by HRV, as HRV is not an accurate correlate of the SNS.

In an effort to place the findings of the present study within the current literature that used HRV as a correlate of CVD risk, a post-hoc analysis was conducted wherein HF HRV, a validated correlate of parasympathetic activity (e.g. Heathers, 2014) was used as an outcome variable in a linear regression model. High frequency HRV was chosen due to questions of validity with other HRV measures; the HF band spectrum of HRV has been validated for estimating parasympathetic activity (Task Force, 1996), while the LF band spectrum has been largely debunked. The post hoc linear regression analysis revealed that among the important variables that were identified as significant predictors in the primary MLM analyses, subjective insomnia (as assessed by the ISI) was found to significantly predict HF HRV. Thus, even within the present study, results are discrepant when the CVD index correlate is changed. In sum, insomnia was found to be unimportant to correlates of CVD risk in an analysis that considers within subject factors (i.e., MLM), but subjective impression of insomnia symptoms correlated with somewhat dubious HRV indices in analyses that do not account for within subject variability (i.e., linear regression).

The CV indices in the MLM analyses are reflective of sympathetic activity, and HF HRV in the post hoc analyses is a correlate of parasympathetic CV activity. It is important to assert that the two analyses are not necessarily comparable, as their index correlates are estimations of two opposing (but not necessarily complementary) sides of the central nervous system. Unfortunately, HRV cannot be assessed in a way that would allow for MLM analysis: its measurement does not allow for instantaneous time point extraction in the same way as cardiovascular reactivity variables (HRV requires evaluation of changes in the rate of heart beat 
over time). If PEP and HF HRV do not measure the same thing, which index is most representative of the mechanism of CVD risk in which we are interested?

As previous researchers have hypothesized sympathetic hyperactivity to be the mechanism through which insomnia may increase risk for CVD (Brosschot et al., 2006), the results of the analysis herein should be contemplated with consideration for sympathetic activity. Though HF HRV is representative of parasympathetic activity, in the post hoc analysis, the beta values for age and ISI are negative. These negative beta values indicate that as age and insomnia severity increase, parasympathetic influence to the heart decreases. It is tempting to assume that, due to the popular opinion that the SNS and PNS branches of the central nervous system are complementary, the results of this study indicate that sympathetic activity increased with insomnia score. Consequently, insomnia may be associated with sympathetic dominance, which is hypothesized to increase risk for CVD. However, sophisticated research on the complicated physiological influences to the CNS has shown that the SNS and PNS do not work in a perfect inverse relationship (Eckberg, 1997). Thus, it cannot necessarily be assumed that this post hoc finding of insomnia as significantly influential to LH HRV implicates sympathetic hyperarousal among those with insomnia. Simply put, inferences from HRV are messy, while inferences from PEP and CO are straightforward due to their construct validity. Consequently, it is more parsimonious to accept the results of the MLM analysis: sleep does not appear to be important to correlates of CVD risk.

\subsection{Consideration of Characteristics of the Sample}

Even after accepting the validity of the results of the MLM analysis herein, there may be other considerations for why the MLM analysis did not reflect sympathetic dominance of the heart by way of significant CO and PEP predictors. One of the strengths of the present study 
was careful classification of the sample using a comprehensive battery of questionnaires to assess demographic characteristics, sleep profile, and psychological characteristics in addition to eating habits and modifiable health behaviours. This degree of classification allowed for close examination of the studied sample, particularly with respect to modifiable health behaviours. Interestingly, it appears that the sample herein may be healthier than traditional norms. For example, less than $1 \%(3 / 49)$ of the present sample smoked cigarettes. This number is well below Canadian norms, which indicate that approximately $20 \%$ of the population smokes cigarettes (Statistics Canada, 2015). Alcohol consumption reported in the present sample is closer to the national average, with approximately $20 \%$ consuming alcohol (at least 5 or more drinks on one occasion) once a month or more either currently or in the past (Government of Canada, 2014b). With respect to exercise, $88 \%$ of the present sample reported exercising enough to break a sweat at least 1-2 times per week, which is more than the $52 \%$ of individuals over 12 who described being at least moderately active in their leisure time according to a Statistics Canada 2005 survey (Government of Canada, 2005). As nutrition was evaluated with a fatcentric questionnaire that has not been evaluated in Canada, it is not possible to make the same population comparisons. However, comparison of these modifiable health behaviours within the present study to Canadian population statistics highlights the relative health of the present sample, particularly with respect to these modifiable health behaviours. It is possible that this is an important consideration, as it is well known that smoking, alcohol, exercise, and nutrition all significantly impact cardiovascular health (see Introduction).

The present sample may also have been unique with respect to sleep differences between groups. Age was found to be significantly different between groups, with the average age of normal sleepers (30.61) being significantly lower than the average age of those with insomnia 
(45.19). In all analyses, age was found to be significantly predictive of CV correlate variables. Thus, it is possible that the insomnia group was, at a baseline, more likely to have impaired CV index correlates. Perhaps this age difference between groups can be explained by the difference between presenting for treatment and participating for compensation; those with insomnia selfpresented for treatment, while normal sleepers were recruited and paid a modest compensatory

sum. Future studies should take this inherent bias into account with careful recruitment methods, particularly to ensure an appropriate age range for the comparison group. Fortunately, age was always considered as a predictor in the analyses and thus the effects of this difference were taken into account.

\subsection{The Challenge Paradigm: Was it Enough?}

The present study was conducted as part of a larger study, one element of which involved exploring the construct of fear of the dark among those with insomnia. Fear of the dark was assessed using the same challenge paradigm contained herein that was used to provide the heart with an external stimulus to which it could exert its autonomic response. This particular paradigm, designed by Grillon and colleagues (1998), has been successful in prior research in eliciting EMG response (e.g. Carney, Moss, Atwood, Crowe, \& Andrews, 2014). As discussed in section 4.3.1, acoustic startle paradigms have a long history in cardiovascular reactivity research, and it was thought that this Grillon et al. paradigm would be appropriate to elicit cardiac reactivity and allow for within- and between-person evaluation of cardiac sympathetic response. However, an examination of the mean CVD index values indicates that there is little difference phase to phase (see Tables 9 and 10), and visual inspection of each participant's PEP and $\mathrm{CO}$ data over the course of the paradigm reveals little change (see Figures 2 and 3). Perhaps the acoustic and dark/light challenge paradigm simply was not "challenging" enough to foster 
the variable autonomic modulation required for analysis. Other studies investigating cardiovascular reactivity have used more challenging paradigms, such as Gorka and colleagues' 2013 investigation of cardiac reactivity using a challenge consisting of anticipation of electric shock. The hypothesis of a blasé paradigm is challenged, however, by the post hoc analysis: this linear regression indicated that insomnia predicted mean HF HRV in a particular phase only (Dark Phase 2). Therefore, there was some difference in autonomic activity between the phases; if this difference were negligible, results would have been consistent across all phases. Thus, it is unlikely that the paradigm failed to elicit cardiac reactivity response. It may be that when individual cardiac variation is taken into account, as in the MLM analyses, there simply aren't real between-group differences and the problem does not inherently lie with the challenge paradigm. As very few paradigms have been used for a similar purpose and the one contained within has been validated in a previous sample, there were sound reasons for why the paradigm herein was chosen. Nonetheless, future studies designed with the goal of assessing cardiac reactivity may benefit from a paradigm considered more "stressful" than the one contained herein. 


\subsection{Limitations and Future Directions}

A few important potential limitations of this study warrant further exploration. With respect to the study sample, participants were over $2 / 3(69 \%)$ female. It should be noted that insomnia has been shown to afflict more females than males at a risk ratio of 1.41 (Zhang \& Wing, 2006). Thus, our sample's unequal sex distribution is only slightly more skewed in favour of females than population-based sex distributions for insomnia. Nonetheless, this uneven distribution of sex may limit generalizability of the findings for men. In addition, age was found to differ significantly between groups; the average age of normal sleepers is significantly younger than the average age for the PI group. The potential impact of this group-level age difference has been explored above (see section 6.2), but it should be noted that future studies should employ careful recruitment strategies in order to minimize the potential confounding effects of age difference between groups, and should age- and gender-match insomnia and noninsomnia participants.

One of the strengths of this study is the consideration of modifiable health behaviours as covariates in the analyses. Alcohol intake, activity level, nutrition, and cigarette smoking were all evaluated in each participant because of their purported links to either sleep or CVD risk. Though there is an obvious benefit to adding these measures, one must take into account participant burden. In an attempt to strike a balance between acquisition of relevant information and minimal additional participant burden, more brief measures were chosen to capture these constructs. Consequently, some information may have been lost with respect to detail. For example, weekly physical activity was assessed via a 5-point Likert scale. Other researchers have gathered information regarding physical activity via a worn device (e.g. Actiwatch), which allows for continuous, sensitive collection of activity data over a predefined time period. 
Unfortunately, due to both limited funding and participant burden constraints, this data collection avenue was not possible. It is possible that access to richer information on physical activity may influence this study's findings, as physical activity is a variable that is well known to be associated with both risk for CVD and sleep. Similarly, individuals were asked brief questions about alcohol and smoking (see Appendix A for exact measures). More sensitive measures may have elicited more precise and nuanced data; however, these measures would have also taken more time for participants to complete. In the design of all studies, there are trade-offs with respect to burden and depth/breadth of acquired data. The choice to prioritize participant burden did result in loss of some more detailed data involving the modifiable health behaviour constructs, which theoretically may be important to the study findings. Future studies may consider prioritizing these potentially confounding variables by including more detailed assessment measures.

Nutrition, another modifiable health behaviour, was assessed via a semi-quantitative food questionnaire that focused primarily on fats. This measure was chosen specifically for this study due to accumulating research that different kinds of fats are linked to both increased and decreased risk for CVD (de Lorgeril et al., 1994; GISSI-Prevenzione Investigators, 2000). The major benefit to this particular questionnaire is due to its separation of "good fats" and "bad fats" based on participant responses. Unfortunately, as with all self-report nutrition questionnaires, people are not necessarily accurate when it comes to reporting food intake; therefore, there is likely to be some error in these results. Nonetheless, as the errors are not likely to be systematic, it is also not likely that a group effect will influence the results. Future studies may consider the use of technology as a way to capture nutrition information in real time as a way to overcome memory biases. The most accurate studies evaluating nutrition usually involve pre-selected 
meals, continuous blood draws to evaluate changes in the blood, or lab-based studies. All of these methods are intrusive, burdensome, and costly; once again, researchers must accept some imperfections in data acquisition in order to minimize other important costs.

In the sleep and CVD literature, some other insomnia researchers have investigated the relationship between sleep and risk for CVD by categorizing "short" and "long" sleepers (often defined as $<5$ hours and $>9$ hours, respectively) for comparison to "normal" sleepers (for a review, see Vgontzas et al., 2013). Some of these studies have found that high or low total sleep time are related to CVD risk (e.g. Bathgate et al., 2016; Meng et al., 2013). This dichotomization approach was not used in this investigation, which may be viewed as a limitation. At first glance, results from these studies are compelling and seemingly point to the utility of a data dichotomization technique, which may identify underlying insomnia phenotypes that incur risk for CVD (i.e. exceptionally short and long sleepers). Dichotomization as a data manipulation technique is chosen for a number of reasons; for example, potential higher correlations between variables of interest, appeal to both researcher and audience for ease and understanding (the ANOVA is fairly ubiquitous), and the perception that dichotomization is actually a more conservative statistical technique, making the results appear more convincingly "significant" (MacCallum, Zhang, Preacher, \& Rucker, 2002). However, many researchers (e.g. Cohen, 1983; Irwin \& McClelland, 2003; MacCallum, Zhang, Preacher, \& Rucker, 2002; Young, 2016) have statistically investigated both the costs and benefits of dichotomizing a continuous variable (or variables) in research. For all of the "pros" listed above, these researchers argue that the actual loss of information with respect to individual differences, potential spurious main and interaction effects, and havoc wreaked on effect sizes does not justify the use of dichotomization. In fact, they argue that only very rarely is dichotomization 
statistically or conceptually justified. These rare circumstances are 1) when a taxonomic analysis provides clear evidence for the existence of discrete taxons or groups within the observed sample data, or 2) when the sampling distribution of a variable is extremely skewed, with a large number of observations at the most extreme scores on the distribution (e.g. smokers vs. nonsmokers).

Though it is tempting to following the footsteps of Vgontzas and colleagues and investigate the potential specific phenotypes of short and long sleep duration versus normal sleep duration, it must be considered whether or not reducing continuous sleep data to categories is statistically justifiable. According to the arguments proposed by the researchers mentioned above, then this dichotomization approach is not justified: there is no clear support for the existence of specific groups or taxons at a measurable data point (e.g. why select total sleep times above 9 hours and not 8.5?), and the sample distribution of sleep data is not skewed enough at the tails to conceptually warrant this decision. Thus, after consideration for the statistical and conceptual pitfalls of using a dichotomization technique, it does not seem justifiable to pursue these additional dichotomization analyses in this sample, and results from previous work that have used this technique should be interpreted with caution.

\subsection{Clinical and Research Implications}

Health information is one of the most commonly-searched topics on the internet; in fact, $85 \%$ of physicians in a 2003 Canadian study reported experiencing patients who brought healthrelated material gathered from the internet to appointments (McMullan, 2006; Murray et al., 2003). An internet search using common general health websites for information about health consequences of insomnia found reports that having insomnia will have dangerous cardiac consequences and will increase one's risk for cardiovascular disease (e.g. "Heart Failure Tied to Insomnia Symptoms", PsychCentral, 2014). This alleged link has implications for the way 
insomnia is treated among the $30 \%$ of adults who have it (Buysse et al., 2006; Ohayon, 2002): if insomnia or poor sleep increases the risk for CVD, the impetus is compelling for swifter and more effective insomnia treatments.

In contrast to widespread information purporting a link between insomnia and CVD, findings from this study highlight the relative unimportance of insomnia to risk for CVD among a comprehensive group of pre-established risk factors. Clinically, then, this result is significant: labeling insomnia as dangerous to the heart may contribute to unnecessary anxiety about the health consequences of insomnia. As anxiety about sleep is a perpetuating factor for the maintenance of insomnia (Spielman, Saskin, \& Thorpy, 1987), disseminating this misleading information about insomnia and risk for CVD may inadvertently serve to exacerbate and maintain insomnia symptoms. Many insomnia sufferers are anxious about the health implications of their insomnia (Carney \& Edinger, 2006; Morin, Vallières, \& Ivers, 2007) and this anxiety worsens and perpetuates the insomnia. If the cardiovascular risk research does not apply to those with insomnia then clinicians should concentrate on disseminating evidence-based information that insomnia conveys risk for problems other than increased cardiovascular risk. That is, insomnia may be more a risk for comorbid mental health conditions than cardiovascular conditions. Instead, perhaps it is more clinically useful to focus on resolving insomnia for quality of life improvement and for the sake of its positive effect on psychological comorbidities such as depression and anxiety (e.g. Manber et al., 2008). Extensive research has shown that insomnia is comorbid with depression in approximately $67 \%$ of cases (Franzen \& Buysse, 2008) and with clinically significant anxiety in $60-70 \%$ of cases (Ramsawh, Stein, Belik, Jacobi, \& Sareen, 2009), as well as with other common psychological disorders (Sarsour, Morin, Foley, Kalsekar, \& Walsh, 2010). Instead of frightening insomnia sufferers with misinformation about 
increased CVD risk, clinicians could focus on directing clients to appropriate evidence-based treatment for their insomnia and likely comorbid psychiatric condition(s).

Findings from the present study also point to important implications for future work in the area of psychophysiological research. In particular, the findings highlight potentially significant difference in findings with the use of varying statistical techniques with longitudinal data. Multi-level modeling was designed to account for within-person variability; this technique is essential for longitudinal psychophysiological data, where each continuous data point is influenced by the one just before and is consequently not independent. Traditional linear regression analysis was not designed to account for this within-person variability. Though MLM is more technically difficult and time-consuming, the differing results contained within the present study point to the importance of choosing appropriate statistical techniques with which to analyze data. Otherwise, scientists are presenting results that would potentially be significantly different when analyzed with the appropriate statistical test.

Findings from the present study also point to another research-related implication: the importance of choosing psychophysiological variables with high construct validity (that is, they measure what they purport to be measuring). As explained in detail, most previous research on insomnia and CVD risk has used HRV as the CVD risk correlate. This method has been largely debunked, but unfortunately, researchers continue to use this variable as a correlate of sympathetic nervous system activity. The appeal is in the relative utility and low cost of this method (all that is needed is continuous pulse rate and a simple HRV analysis program); however, as results from this study corroborate, HRV is not an accurate portrayal of SNS activity. It is time for scientists to leave HRV behind as more advanced psychophysiological 
technology has allowed for more accurate assessment of SNS activity (e.g., with the use of preejection period).

\subsection{Conclusion}

Prior to the present study, the body of literature surrounding insomnia and CVD risk was murky at best. Some researchers claimed that the presence of insomnia increases the risk of developing CVD (e.g. Schwartz et al., 1999; Sofi et al., 2014), while others failed to replicate this result (e.g. Kripke et al., 2002; Phillips \& Mannino, 2005). Much of the research in this area has been conducted at a population level using an epidemiological design; these studies resulted in poor characterization of the sample using nonspecific assessment measures. Other studies, though experimental, lacked a normal sleeper comparison group or neglected important confounding factors (e.g., modifiable health behaviours). This study was the first of its kind to combine the following features: 1) utilize an experimental design, 2) carefully characterize both groups, 3) collect continuous psychophysiological data with high construct validity, 4) utilize a challenge paradigm wherein the heart could demonstrate its influence from the CNS, and 5) measure and consider important confounding variables in the analyses. In addition, this study advanced our current understanding of the relationship between insomnia and CVD risk in the literature by employing a contemporary statistical technique that is essential for continuous psychophysiological data; this technique has not regularly been used to explore this relationship.

It should be noted that nonsignificant findings are often not considered important or noteworthy when compared to significant findings in psychological research. In this study, according to the MLM analyses, results for a relationship between sleep variables and CVD variables were nonsignificant. This finding is interesting when we consider the larger cultural context. Currently in North America, we live in a society with near universal, instant access to 
information via the internet. Health information is one of the top internet searches worldwide, and invested parties often use fear-based health headlines to attract visitors to their site (e.g., as "click bait" to get more people to visit their website in order to make more money from advertisers). The perceived relationship between insomnia and cardiovascular risk has been used as clink-bait in a similar way (e.g. "The Link Between Insomnia \& Heart Failure," n.d.). We have a responsibility as health researchers to disseminate current, up-to-date information to the public so that they may make informed choices about their health care.

The primary clinical implication from this study is that individuals with insomnia need not be worried about increased CVD risk. Clinicians should focus on directing insomnia sufferers to appropriate evidence-based treatment, but it is our responsibility also to disseminate that insomnia does not have the deleterious health consequences to the heart propagated by mainstream health media outlets. Hopefully, the individuals who receive this information will experience a decrease in anxiety due to less immediate pressure to "fix" the insomnia - which, incidentally, may alleviate their poor sleep. 


\section{REFERENCES}

American Academy of Sleep Medicine. (2005). The International Classification of Sleep Disorders - Revised. Chicago, IL.

American Psychiatric Association. (2013). Diagnostic and Statistical Manual of Mental Disorders (DSM-5) (Paperback). Retrieved from http://www.bookdepository.com/Diagnostic-Statistical-Manual-Mental-Disorders-DSM5-American-Psychiatric-Association/9780890425558

Anda, R., Williamson, D., Jones, D., Macera, C., Eaker, E., Glassman, A., \& Marks, J. (1993). Depressed affect, hopelessness, and the risk of ischemic heart disease in a cohort of U.S. adults. Epidemiology (Cambridge, Mass.), 4(4), 285-294.

Antony, M. M., Bieling, P. J., Cox, B. J., Enns, M. W., \& Swinson, R. P. (1998). Psychometric properties of the 42-item and 21-item versions of the Depression Anxiety Stress Scales in clinical groups and a community sample. Psychological Assessment, 10(2), 176-181. https://doi.org/10.1037/1040-3590.10.2.176

Appelhans, B. M., \& Luecken, L. J. (2006). Heart rate variability as an index of regulated emotional responding. Review of General Psychology, 10(3), 229-240. https://doi.org/10.1037/1089-2680.10.3.229

Aromaa, A., Raitasalo, R., Reunanen, A., Impivaara, O., Heliövaara, M., Knekt, P., ... Maatela, J. (1994). Depression and cardiovascular diseases. Acta Psychiatrica Scandinavica. Supplementum, 377, 77-82.

Bastien, C. H., Vallières, A., \& Morin, C. M. (2001). Validation of the Insomnia Severity Index as an outcome measure for insomnia research. Sleep Medicine, 2(4), 297-307. 
Bathgate, C. J., Edinger, J. D., Wyatt, J. K., \& Krystal, A. D. (2016). Objective but Not Subjective Short Sleep Duration Associated with Increased Risk for Hypertension in Individuals with Insomnia. SLEEP, 39(05), 1037-1045. https://doi.org/10.5665/sleep.5748

Bazzano, L. A., He, J., Ogden, L. G., Loria, C. M., Vupputuri, S., Myers, L., \& Whelton, P. K. (2002). Fruit and vegetable intake and risk of cardiovascular disease in US adults: the first National Health and Nutrition Examination Survey Epidemiologic Follow-up Study. The American Journal of Clinical Nutrition, 76(1), 93-99.

Berntson, G. G., Cacioppo, J. T., \& Quigley, K. S. (1991). Autonomic determinism: the modes of autonomic control, the doctrine of autonomic space, and the laws of autonomic constraint. Psychological Review, 98(4), 459-487.

Bigger, J. T., Fleiss, J. L., Steinman, R. C., Rolnitzky, L. M., Kleiger, R. E., \& Rottman, J. N. (1992). Frequency domain measures of heart period variability and mortality after myocardial infarction. Circulation, 85(1), 164-171. https://doi.org/ $<\mathrm{p}></ \mathrm{p}>$

Billman, G. E. (2013). The LF/HF ratio does not accurately measure cardiac sympatho-vagal balance. Frontiers in Physiology, 4. https://doi.org/10.3389/fphys.2013.00026

Billman, G. E., Kang, J. X., \& Leaf, A. (1997). Prevention of ischemia-induced cardiac Sudden death by $\mathrm{n}-3$ polyunsaturated fatty acids in dogs. Lipids, 32(11), 1161-1168. https://doi.org/10.1007/s11745-997-0149-2

Bonnet, M., \& Arand, D. (1998). Heart rate variability in insomniacs and matched normal sleepers. Psychosomatic Medicine, 60(5), 610-615.

Bonnet, M. H., \& Arand, D. L. (1992). Caffeine use as a model of acute and chronic insomnia. Sleep, 15(6), 526-536. 
Bonnet, M. H., \& Arand, D. L. (1995). 24-Hour metabolic rate in insomniacs and matched normal sleepers. Sleep, 18(7), 581-588.

Bonnet, M. H., \& Arand, D. L. (1996). The consequences of a week of insomnia. Sleep, 19(6), $453-461$.

Bosy-Westphal, A., Hinrichs, S., Jauch-Chara, K., Hitze, B., Later, W., Wilms, B., ... Muller, M. J. (2008). Influence of partial sleep deprivation on energy balance and insulin sensitivity in healthy women. Obesity Facts, 1(5), 266-273. https://doi.org/10.1159/000158874

Bradley, M. M., Lang, P. J., \& Cuthbert, B. N. (1993). Emotion, novelty, and the startle reflex: Habituation in humans. Behavioral Neuroscience, 107(6), 970-980. https://doi.org/http://dx.doi.org.ezproxy.lib.ryerson.ca/10.1037/0735-7044.107.6.970

Brien, S. E., Ronksley, P. E., Turner, B. J., Mukamal, K. J., \& Ghali, W. A. (2011). Effect of alcohol consumption on biological markers associated with risk of coronary heart disease: systematic review and meta-analysis of interventional studies. BMJ : British Medical Journal, 342. https://doi.org/10.1136/bmj.d636

Brondel, L., Romer, M. A., Nougues, P. M., Touyarou, P., \& Davenne, D. (2010). Acute partial sleep deprivation increases food intake in healthy men. The American Journal of Clinical Nutrition, 91(6), 1550-1559. https://doi.org/10.3945/ajcn.2009.28523

Brosschot, J. F., Gerin, W., \& Thayer, J. F. (2006). The perseverative cognition hypothesis: A review of worry, prolonged stress-related physiological activation, and health. Journal of Psychosomatic Research, 60(2), 113-124. https://doi.org/10.1016/j.jpsychores.2005.06.074

Brosschot, J. F., Van Dijk, E., \& Thayer, J. F. (2007). Daily worry is related to low heart rate variability during waking and the subsequent nocturnal sleep period. International 
Journal of Psychophysiology, 63(1), 39-47.

https://doi.org/10.1016/j.ijpsycho.2006.07.016

Bucher, H. C., Hengstler, P., Schindler, C., \& Meier, G. (2002). N-3 polyunsaturated fatty acids in coronary heart disease: a meta-analysis of randomized controlled trials. The American Journal of Medicine, 112(4), 298-304. https://doi.org/10.1016/S0002-9343(01)01114-7

Burgess, H. J., Penev, P. D., Schneider, R., \& Van Cauter, E. (2004). Estimating cardiac autonomic activity during sleep: impedance cardiography, spectral analysis, and Poincaré plots. Clinical Neurophysiology: Official Journal of the International Federation of Clinical Neurophysiology, 115(1), 19-28.

Burton, A. R., Rahman, K., Kadota, Y., Lloyd, A., \& Vollmer-Conna, U. (2010). Reduced heart rate variability predicts poor sleep quality in a case-control study of chronic fatigue syndrome. Experimental Brain Research, 204(1), 71-78. https://doi.org/10.1007/s00221010-2296-1

Busek, P., Vanková, J., Opavský, J., Salinger, J., \& Nevsímalová, S. (2005). Spectral analysis of the heart rate variability in sleep. Physiological Research / Academia Scientiarum Bohemoslovaca, 54(4), 369-376.

Buysse, D. J., Ancoli-lsrael, S., Edinger, J. D., Lichstein, K. L., \& Morin, C. M. (2006). Recommendations for a standard research assessment of insomnia. Sleep: Journal of Sleep and Sleep Disorders Research. Vol 29(9), 29, 1155-1173.

Buysse, D. J., Angst, J., Gamma, A., Ajdacic, V., Eich, D., \& Rössler, W. (2008). Prevalence, course, and comorbidity of insomnia and depression in young adults. Sleep: Journal of Sleep and Sleep Disorders Research, 31(4), 473-480. 
Cacioppo, J. T., Berntson, G. G., Binkley, P. F., Quigley, K. S., Uchino, B. N., \& Fieldstone, A. (1994). Autonomic cardiac control. II. Noninvasive indices and basal response as revealed by autonomic blockades. Psychophysiology, 31(6), 586-598. https://doi.org/10.1111/j.1469-8986.1994.tb02351.x

Carney, C. E., Buysse, D. J., Ancoli-Israel, S., Edinger, J. D., Krystal, A. D., Lichstein, K. L., \& Morin, C. M. (2012). The consensus sleep diary: standardizing prospective sleep selfmonitoring. Sleep, 35(2), 287-302. https://doi.org/10.5665/sleep.1642

Carney, C. E., Edinger, J. D., Meyer, B., Lindman, L., \& Istre, T. (2006). Symptom-focused rumination and sleep disturbance. Behavioral Sleep Medicine, 4(4), 228-241. https://doi.org/10.1207/s15402010bsm0404_3

Carney, C. E., Harris, A. L., Falco, A., \& Edinger, J. D. (2013). The Relation between Insomnia Symptoms, Mood, and Rumination about Insomnia Symptoms. Journal of Clinical Sleep Medicine. https://doi.org/10.5664/jcsm.2752

Carney, C. E., Harris, A. L., Moss, T. G., \& Edinger, J. D. (2010). Distinguishing rumination from worry in clinical insomnia. Behaviour Research and Therapy, 48(6), 540-546. https://doi.org/10.1016/j.brat.2010.03.004

Carney, C. E., Moss, T. G., Atwood, M. E., Crowe, B. M., \& Andrews, A. J. (2014). Are poor sleepers afraid of the dark? A preliminary investigation. Journal of Experimental Psychopathology, 5(1), 2-13. https://doi.org/http://dx.doi.org.ezproxy.lib.ryerson.ca/10.5127/jep.032312

Carney, C. E., Moss, T. G., Harris, A. L., Edinger, J. D., \& Krystal, A. D. (2011). Should we be anxious when assessing anxiety using the Beck Anxiety Inventory in clinical insomnia 
patients? Journal of Psychiatric Research, 45(9), 1243-1249.

https://doi.org/10.1016/j.jpsychires.2011.03.011

Carney, C. E., Moss, T. G., Harris, A. L., Edinger, J. D., \& Krystal, A. D. (n.d.). Should we be anxious when assessing anxiety using the Beck Anxiety Inventory in clinical insomnia patients? Journal of Psychiatric Research, In Press, Corrected Proof. https://doi.org/10.1016/j.jpsychires.2011.03.011

Carney, C. E., Ulmer, C., Edinger, J. D., Krystal, A. D., \& Knauss, F. (2009). Assessing depression symptoms in those with insomnia: An examination of the beck depression inventory second edition (BDI-II). Journal of Psychiatric Research, 43(5), 576-582. https://doi.org/10.1016/j.jpsychires.2008.09.002

Carney, R. M., Saunders, R. D., Freedland, K. E., Stein, P., Rich, M. W., \& Jaffe, A. S. (1995). Association of depression with reduced heart rate variability in coronary artery disease. The American Journal of Cardiology, 76(8), 562-564.

Cheng, J., Edwards, L. J., Maldonado-Molina, M. M., Komro, K. A., \& Muller, K. E. (2010). Real Longitudinal Data Analysis for Real People: Building a Good Enough Mixed Model. Statistics in Medicine, 29(4), 504-520. https://doi.org/10.1002/sim.3775

Cohen, J. (1983). The cost of dichotomization. Applied Psychological Measurement, 7(3), 249253. https://doi.org/10.1177/014662168300700301

Cohen, S., \& Rodriguez, M. S. (1995). Pathways linking affective disturbances and physical disorders. Health Psychology, 14(5), 374-380. https://doi.org/10.1037/02786133.14 .5 .374

Connor, W. E. (2000). Importance of n-3 fatty acids in health and disease. The American Journal of Clinical Nutrition, 71(1), 171S-175S. 
Costelloe, J. M., \& O’Brien, R. G. (2000). Power and sample size determination for linear models. In SUGI Proceedings. Cary, NC: SAS Institute.

Daley, M., Morin, C. M., LeBlanc, M., Grégoire, J.-P., \& Savard, J. (2009). The Economic Burden of Insomnia: Direct and Indirect Costs for Individuals with Insomnia Syndrome, Insomnia Symptoms, and Good Sleepers. Sleep, 32(1), 55-64.

Dawber, T. R., Meadors, G. F., \& Moore, F. E., Jr. (1951). Epidemiological approaches to heart disease: the Framingham Study. American Journal of Public Health and the Nation's Health, 41(3), 279-281.

de Lorgeril, M., Renaud, S., Salen, P., Monjaud, I., Mamelle, N., Martin, J. L., ... Delaye, J. (1994). Mediterranean alpha-linolenic acid-rich diet in secondary prevention of coronary heart disease. The Lancet, 343(8911), 1454-1459. https://doi.org/10.1016/S01406736(94)92580-1

De Zambotti, M., Covassin, N., De Min Tona, G., Sarlo, M., \& Stegagno, L. (2011). Sleep onset and cardiovascular activity in primary insomnia. Journal of Sleep Research, 20(2), 318325. https://doi.org/http://dx.doi.org.ezproxy.lib.ryerson.ca/10.1111/j.13652869.2010.00871.x

DeCaro, J. A. (2016). Beyond catecholamines: Measuring autonomic responses to psychosocial context. American Journal of Human Biology: The Official Journal of the Human Biology Council, 28(3), 309-317. https://doi.org/10.1002/ajhb.22815

Deffenbacher, J. L., Oetting, E. R., Thwaites, G. A., Lynch, R. S., Baker, D. A., Stark, R. S., ... Eiswerth-Cox, L. (1996). State-Trait Anger Theory and the utility of the Trait Anger Scale. Journal of Counseling Psychology, 43(2), 131-148. https://doi.org/10.1037/00220167.43 .2 .131 
Dunbar, A., Gotsis, W., \& Frishman, W. (2013). Second-hand tobacco smoke and cardiovascular disease risk: an epidemiological review. Cardiology in Review, 21(2), 94-100. https://doi.org/10.1097/CRD.0b013e31827362e4

Eckberg, D. L. (1997). Sympathovagal Balance. Circulation, 96(9), 3224-3232. https://doi.org/10.1161/01.CIR.96.9.3224

Edinger, J. D., Bonnet, M. H., Bootzin, R. R., Doghramji, K., Dorsey, C. M., Espie, C. A., ... Stepanski, E. J. (2004). Derivation of research diagnostic criteria for insomnia: report of an American Academy of Sleep Medicine Work Group. Sleep, 27(8), 1567-1596.

Edinger, J. D., Fins, A. I., Glenn, D. M., Sullivan, R. J., Bastian, L. A., Marsh, G. R., ... Vasilas, D. (2000). Insomnia and the eye of the beholder: Are there clinical markers of objective sleep disturbances among adults with and without insomnia complaints? Journal of Consulting and Clinical Psychology, 68(4), 586-593. https://doi.org/10.1037/0022006X.68.4.586

Edinger, J. D., Kirby, A., Lineberger, M., Loiselle, M., Wohlgemuth, W., \& Means, M. (2004). The Duke Structured Interview for Sleep Disorders. Durham, NC: Duke University Medical Centre.

Edinger, J. D., \& Wohlgemuth, W. K. (1999). The significance and management of persistent primary insomnia: the past, present and future of behavioral insomnia therapies. Sleep Medicine Reviews, 3(2), 101-118.

Ekman, P., Friesen, W. V., \& Simons, R. C. (1985). Is the startle reaction an emotion? Journal of Personality and Social Psychology, 49(5), 1416-1426. https://doi.org/http://dx.doi.org.ezproxy.lib.ryerson.ca/10.1037/0022-3514.49.5.1416 
Elsesser, K., Freyth, C., Lohrmann, T., \& Sartory, G. (2008). Startle reactivity and peritraumatic dissociations in acute stress disorder. Journal of Psychophysiology, 22(4), 185-194. https://doi.org/http://dx.doi.org.ezproxy.lib.ryerson.ca/10.1027/0269-8803.22.4.185

Espie, C. A. (2007). Understanding insomnia through cognitive modelling. Sleep Medicine, 8(Supp14), S3-S8. https://doi.org/http://dx.doi.org.ezproxy.lib.ryerson.ca/10.1016/S13899457(08)70002-9

Espie, C. A., Brooks, D. N., \& Lindsay, W. R. (1989). An evaluation of tailored psychological treatment of insomnia. Journal of Behavior Therapy and Experimental Psychiatry, 20(2), 143-153. https://doi.org/http://dx.doi.org.ezproxy.lib.ryerson.ca/10.1016/00057916(89)90047-5

Fang, S., Huang, C., Yang, T., \& Tsai, P. (2008). Heart rate variability and daytime functioning in insomniacs and normal sleepers: Preliminary results 计. Journal of Psychosomatic Research, 65(1), 23-30. https://doi.org/10.1016/j.jpsychores.2008.02.003

Fernandez-Mendoza, J., Calhoun, S. L., Bixler, E. O., Karataraki, M., Liao, D., Vela-Bueno, A., ... Vgontzas, A. N. (2011). Sleep Misperception and Chronic Insomnia in the General Population: The Role of Objective Sleep Duration and Psychological Profiles. Psychosomatic Medicine, 73(1), 88-97. https://doi.org/10.1097/PSY.0b013e3181fe365a

First, M. B., Spitzer, R. L., Gibbon, M., \& Williams, J. B. W. (2002). Structured Clinical Interview for DSM-IV Axis I Disorders, Research Version, Patient Edition (SCID-I/P). New York Psychiatric Institute: New York Biometrics Research.

Ford, D. E., \& Kamerow, D. B. (1989). Epidemiologic study of sleep disturbances and psychiatric disorders. An opportunity for prevention? JAMA: The Journal of the American Medical Association, 262(11), 1479-1484. 
Franzen, P. L., \& Buysse, D. J. (2008). Sleep disturbances and depression: risk relationships for subsequent depression and therapeutic implications. Dialogues in Clinical Neuroscience, 10(4), 473-481.

Freedman, R. R., \& Sattler, H. L. (1982). Physiological and psychological factors in sleep-onset insomnia. Journal of Abnormal Psychology, 91(5), 380-389.

https://doi.org/10.1037/0021-843X.91.5.380

Friedman, B. H., \& Thayer, J. F. (1998). Autonomic balance revisited: Panic anxiety and heart rate variability. Journal of Psychosomatic Research, 44(1), 133-151. https://doi.org/10.1016/S0022-3999(97)00202-X

Fung, T. T., Rimm, E. B., Spiegelman, D., Rifai, N., Tofler, G. H., Willett, W. C., \& Hu, F. B. (2001). Association between dietary patterns and plasma biomarkers of obesity and cardiovascular disease risk. The American Journal of Clinical Nutrition, 73(1), 61-67.

GISSI-Prevenzione Investigators. (2000). Dietary Supplementation With n-3 Polyunsaturated Fatty Acids. Journal of Cardiopulmonary Rehabilitation and Prevention, 20(2), 131.

Glassman, A. H., Helzer, J. E., Covey, L. S., Cottler, L. B., Stetner, F., Tipp, J. E., \& Johnson, J. (1990). Smoking, smoking cessation, and major depression. JAMA: The Journal of the American Medical Association, 264(12), 1546-1549.

Gold, P. W., Calabrese, J. R., Kling, M. A., Avgerinos, P., Khan, I., Gallucci, W. T., ... Chrousos, G. P. (1986). Abnormal ACTH and cortisol responses to ovine corticotropin releasing factor in patients with primary affective disorder. Progress in NeuroPsychopharmacology \& Biological Psychiatry, 10(1), 57-65.

Goldstein, D. S., Bentho, O., Park, M.-Y., \& Sharabi, Y. (2011). Low-frequency power of heart rate variability is not a measure of cardiac sympathetic tone but may be a measure of 
modulation of cardiac autonomic outflows by baroreflexes. Experimental Physiology, 96(12), 1255-1261. https://doi.org/10.1113/expphysiol.2010.056259

Gorka, S. M., Nelson, B. D., Sarapas, C., Campbell, M., Lewis, G. F., Bishop, J. R., ... Shankman, S. A. (2013). Relation between respiratory sinus arrythymia and startle response during predictable and unpredictable threat. Journal of Psychophysiology, 27(2), 95-104. https://doi.org/http://dx.doi.org.ezproxy.lib.ryerson.ca/10.1027/0269$8803 / \mathrm{a} 000091$

Government of Canada. (2005). Physically Active Canadians. Retrieved November 13, 2016, from http://www.statcan.gc.ca/pub/82-003-x/2006008/article/phys/10307-eng.htm\#a2

Government of Canada, S. C. (2014a, January 27). The 10 leading causes of death, 2011. Retrieved August 24, 2016, from http://www.statcan.gc.ca/pub/82-625x/2014001/article/11896-eng.htm

Government of Canada, S. C. (2014b, June 12). Heavy drinking, 2013. Retrieved November 13, 2016, from http://www.statcan.gc.ca/pub/82-625-x/2014001/article/14019-eng.htm

Grillon, C., Morgan, C. A., 3rd, Davis, M., \& Southwick, S. M. (1998). Effect of darkness on acoustic startle in Vietnam veterans with PTSD. The American Journal of Psychiatry, 155(6), 812-817.

Grillon, C., Pellowski, M., Merikangas, K. R., \& Davis, M. (1997). Darkness facilitates the acoustic startle reflex in humans. Biological Psychiatry, 42(6), 453-460. https://doi.org/10.1016/S0006-3223(96)00466-0

Gross, R. T., \& Borkovec, T. D. (1982). Effects of a cognitive intrusion manipulation on the sleep-onset latency of good sleepers. Behavior Therapy, 13(1), 112-116. https://doi.org/10.1016/S0005-7894(82)80054-3 
Hall, M., Buysse, D. J., Reynolds, C. F., Kupfer, D. J., \& Baum, A. (1996). Stress-related intrusive thoughts disrupt sleep onset and continuity. Sleep Research, 25(163).

Hall, M., Vasko, R., Buysse, D., Ombao, H., Chen, Q., Cashmere, J. D., ... Thayer, J. F. (2004). Acute Stress Affects Heart Rate Variability During Sleep. Psychosomatic Medicine, 66(1), 56-62. https://doi.org/10.1097/01.PSY.0000106884.58744.09

Harvey, A. . (2002). A cognitive model of insomnia. Behaviour Research and Therapy, 40(8), 869-893. https://doi.org/10.1016/S0005-7967(01)00061-4

Harvey, A. G. (2000). Pre-sleep cognitive activity: A comparison of sleep-onset insomniacs and good sleepers. British Journal of Clinical Psychology, 39(3), 275-286. https://doi.org/http://dx.doi.org.ezproxy.lib.ryerson.ca/10.1348/014466500163284

Harvey, A. G., \& Greenall, E. (2003). Catastrophic worry in primary insomnia. Journal of Behavior Therapy and Experimental Psychiatry, 34(1), 11-23. https://doi.org/10.1016/S0005-7916(03)00003-X

Heathers, J. A. J. (2012). Sympathovagal balance from heart rate variability: an obituary. Experimental Physiology, 97(4), 556. https://doi.org/10.1113/expphysiol.2011.063867

Heathers, J. A. J. (2014). Everything Hertz: methodological issues in short-term frequencydomain HRV. Frontiers in Physiology, 5, 177. https://doi.org/10.3389/fphys.2014.00177

Henry, J. D., \& Crawford, J. R. (2005). The short-form version of the Depression Anxiety Stress Scales (DASS-21): Construct validity and normative data in a large non-clinical sample. British Journal of Clinical Psychology, 44(2), 227-239. https://doi.org/10.1348/014466505X29657 
Hjemdahl, P., Freyschuss, U., Juhlin-Dannfelt, A., \& Linde, B. (1984). Differentiated sympathetic activation during mental stress evoked by the Stroop test. Acta Physiologica Scandinavica. Supplementum, 527, 25-29.

Holmes, M. V., Dale, C. E., Zuccolo, L., Silverwood, R. J., Guo, Y., Ye, Z., ... Casas, J. P. (2014). Association between alcohol and cardiovascular disease: Mendelian randomisation analysis based on individual participant data. BMJ, 349, g4164. https://doi.org/10.1136/bmj.g4164

Hubert, H. B., Feinleib, M., McNamara, P. M., \& Castelli, W. P. (1983). Obesity as an independent risk factor for cardiovascular disease: a 26-year follow-up of participants in the Framingham Heart Study. Circulation, 67(5), 968-977. https://doi.org/10.1161/01.CIR.67.5.968

Ignarro, L. J., Balestrieri, M. L., \& Napoli, C. (2007). Nutrition, physical activity, and cardiovascular disease: An update. Cardiovascular Research, 73(2), 326-340. https://doi.org/10.1016/j.cardiores.2006.06.030

Irwin, J. R., \& McClelland, G. H. (2003). Negative Consequences of Dichotomizing Continuous Predictor Variables. Journal of Marketing Research, 40(3), 366-371. https://doi.org/10.1509/jmkr.40.3.366.19237

Jacobs, G. A., Latham, L. E., \& Brown, M. S. (1988). Test-retest reliability of the state-trait personality inventory and the anger expression scale. Anxiety Research, 1(3), 263-265. https://doi.org/10.1080/08917778808248724

Jansson-Fröjmark, M., \& Linton, S. J. (2008). The role of psychological mechanisms to insomnia in its early phase: A focus on arousal, distress, and sleep-related beliefs. Psychology \& Health, 23(6), 691-705. https://doi.org/10.1080/14768320701302791 
Jarrin, D. C., Chen, I. Y., Ivers, H., Lamy, M., Vallières, A., \& Morin, C. M. (2016). Nocturnal heart rate variability in patients treated with cognitive-behavioral therapy for insomnia. Health Psychology, 35(6), 638-641.

https://doi.org/http://dx.doi.org.ezproxy.lib.ryerson.ca/10.1037/hea0000347

Jones, F. P., \& Kennedy, J. L. (1951). An electromyographic technique for recording the startle pattern. Journal of Psychology, 32, 63-68.

Jurysta, F., Lanquart, J.-P., Sputaels, V., Dumont, M., Migeotte, P.-F., Leistedt, S., ... van de Borne, P. (2009). The impact of chronic primary insomnia on the heart rate - EEG variability link. Clinical Neurophysiology, 120(6), 1054-1060. https://doi.org/10.1016/j.clinph.2009.03.019

Jurysta, F., van de Borne, P., Migeotte, P.-F., Dumont, M., Lanquart, J.-P., Degaute, J.-P., \& Linkowski, P. (2003). A study of the dynamic interactions between sleep EEG and heart rate variability in healthy young men. Clinical Neurophysiology: Official Journal of the International Federation of Clinical Neurophysiology, 114(11), 2146-2155.

Kannel, W. B. (1967). Habitual level of physical activity and risk of coronary heart disease: the Framingham study. Canadian Medical Association Journal, 96(12), 811-812.

Kannel, W. B., Dawber, T. R., Kagan, A., Revotskie, N., \& Stokes, J., 3rd. (1961). Factors of risk in the development of coronary heart disease--six year follow-up experience. The Framingham Study. Annals of Internal Medicine, 55, 33-50.

Karim, N., Hasan, J. A., \& Sanowar, S. (2011). Heart rate variability - A review. Journal of Basic Applied Science, 7, 71-77. 
Kawachi, I., Sparrow, D., Vokonas, P. S., \& Weiss, S. T. (1995). Decreased heart rate variability in men with phobic anxiety (data from the Normative Aging Study). The American Journal of Cardiology, 75(14), 882-885.

Kelsey, R. M. (2012). Beta-adrenergic cardiovascular reactivity and adaptation to stress: The cardiac pre-ejection period as an index of effort. In R. A. Wright \& G. H. E. Gendolla (Eds.), How motivation affects cardiovascular response: Mechanisms and applications (pp. 43-60). Washington, DC, US: American Psychological Association.

Kelsey, R. M., Blascovich, J., Leitten, C. L., Schneider, T. R., Tomaka, J., \& Wiens, S. (2000). Cardiovascular reactivity and adaptation to recurrent psychological stress: The moderating effects of evaluative observation. Psychophysiology, 37(6), 748-756. https://doi.org/http://dx.doi.org.ezproxy.lib.ryerson.ca/10.1017/S004857720098209X

Kelsey, R. M., Blascovich, J., Tomaka, J., Leitten, C. L., Schneider, T. R., \& Wiens, S. (1999). Cardiovascular reactivity and adaptation to recurrent psychological stress: Effects of prior task exposure. Psychophysiology, 36(6), 818-831. https://doi.org/http://dx.doi.org.ezproxy.lib.ryerson.ca/10.1017/S0048577299981672

Kelsey, R. M., Soderlund, K., \& Arthur, C. M. (2004). Cardiovascular reactivity and adaptation to recurrent psychological stress: Replication and extension. Psychophysiology, 41(6), 924-934. https://doi.org/http://dx.doi.org.ezproxy.lib.ryerson.ca/10.1111/j.14698986.2004.00245.x

Kleiger, R. E., Miller, J. P., Bigger Jr., J. T., \& Moss, A. J. (1987). Decreased heart rate variability and its association with increased mortality after acute myocardial infarction. The American Journal of Cardiology, 59(4), 256-262. https://doi.org/10.1016/00029149(87)90795-8 
Kripke, D. F., Garfinkel, L., Wingard, D. L., Klauber, M. R., \& Marler, M. R. (2002). Mortality Associated With Sleep Duration and Insomnia. Arch Gen Psychiatry, 59(2), 131-136. https://doi.org/<p>10.1001/archpsyc.59.2.131</p >

Krystal, A. D., Edinger, J. D., Wohlgemuth, W. K., \& Marsh, G. R. (2002). NREM sleep EEG frequency spectral correlates of sleep complaints in primary insomnia subtypes. Sleep, 25(6), 630-640.

Kubzansky, L. D., Kawachi, I., Spiro, A., Weiss, S. T., Vokonas, P. S., \& Sparrow, D. (1997). Is Worrying Bad for Your Heart?: A Prospective Study of Worry and Coronary Heart Disease in the Normative Aging Study. Circulation, 95(4), 818-824. https://doi.org/10.1161/01.CIR.95.4.818

Lachowski, A. M. (2012). Predicting heart rate variability in individuals with insomnia. Unpublished Master's Thesis, Ryerson University, Toronto, ON.

Laviolle, B., Froger-Bompas, C., Guillo, P., Sevestre, A., Letellier, C., Pouchard, M., ... Paillard, F. (2005). Relative validity and reproducibility of a 14-item semi-quantitative food frequency questionnaire for cardiovascular prevention. European Journal of Cardiovascular Prevention \& Rehabilitation, 12(6), 587-595. https://doi.org/10.1097/01.hjr.0000186625.98604.5d

Leaf, A., Kang, J. X., Xiao, Y.-F., \& Billman, G. E. (2003). Clinical Prevention of Sudden Cardiac Death by n-3 Polyunsaturated Fatty Acids and Mechanism of Prevention of Arrhythmias by n-3 Fish Oils. Circulation, 107(21), 2646-2652. https://doi.org/10.1161/01.CIR.0000069566.78305.33 
Lichstein, K. L., \& Rosenthal, T. L. (1980). Insomniacs' perceptions of cognitive versus somatic determinants of sleep disturbance. Journal of Abnormal Psychology, 89(1), 105-107. https://doi.org/http://dx.doi.org.ezproxy.lib.ryerson.ca/10.1037/0021-843X.89.1.105

Licht, C. M. M., Penninx, B. W. J. H., \& de Geus, E. J. C. (2012). Effects of antidepressants, but not psychopathology, on cardiac sympathetic control: a longitudinal study. Neuropsychopharmacology: Official Publication of the American College of Neuropsychopharmacology, 37(11), 2487-2495. https://doi.org/10.1038/npp.2012.107

Lobbestael, J., Leurgans, M., \& Arntz, A. (2011). Inter-rater reliability of the Structured Clinical Interview for DSM-IV Axis I Disorders (SCID I) and Axis II Disorders (SCID II). Clinical Psychology \& Psychotherapy, 18(1), 75-79. https://doi.org/10.1002/cpp.693

Lovibond, S. H., \& Lovibond, P. F. (1995). Manuel fot the Depression Anxiety Stress Scale (2nd Ed.). Sydney: Psychology Foundation.

MacCallum, R. C., Zhang, S., Preacher, K. J., \& Rucker, D. D. (2002). On the practice of dichotomization of quantitative variables. Psychological Methods, 7(1), 19-40.

Manber, R., Edinger, J. D., Gress, J. L., Pedro-Salcedo, M. G. S., Kuo, T. F., \& Kalista, T. (2008). Cognitive Behavioral Therapy for Insomnia Enhances Depression Outcome in Patients with Comorbid Major Depressive Disorder and Insomnia. Sleep, 31(4), 489.

Masters Steedman, S., Middaugh, S. J., Kee, W. G., Carson, D. S., Harden, R. N., \& Miller, M. C. (1992). Chronic-pain medications: equivalence levels and method of quantifying usage. The Clinical Journal of Pain, 8(3), 204-214.

McMullan, M. (2006). Patients using the Internet to obtain health information: How this affects the patient-health professional relationship. Patient Education and Counseling, 63(1-2), 24-28. https://doi.org/10.1016/j.pec.2005.10.006 
Mendis, S., Puska, P., \& Norrving, B. (2011). Global atlas on cardiovascular disease prevention and control., vi $+55 \mathrm{pp}$.

Meng, L., Zheng, Y., \& Hui, R. (2013). The relationship of sleep duration and insomnia to risk of hypertension incidence: a meta-analysis of prospective cohort studies. Hypertension Research, 36(11), 985-995. https://doi.org/10.1038/hr.2013.70

Mills, P. J., Schneider, R. H., \& Dimsdale, J. E. (1989). Anger assessment and reactivity to stress. Journal of Psychosomatic Research, 33(3), 379-382. https://doi.org/10.1016/0022-3999(89)90028-7

Monroe, L. J. (1967). Psychological and physiological differences between good and poor sleepers. Journal of Abnormal Psychology, 72(3), 255-264. https://doi.org/10.1037/h0024563

Morin, C. M. (1993). Insomnia: psychological assessment and management. New York: Guilford.

Morin, C. M., LeBlanc, M., Bélanger, L., Ivers, H., Mérette, C., \& Savard, J. (2011). Prevalence of Insomnia and Its Treatment in Canada. Canadian Journal of Psychiatry, 56(9), 540-8.

Morin, C. M., LeBlanc, M., Daley, M., Gregoire, J. P., \& Mérette, C. (2006). Epidemiology of insomnia: Prevalence, self-help treatments, consultations, and determinants of helpseeking behaviors. Sleep Medicine, 7(2), 123-130. https://doi.org/10.1016/j.sleep.2005.08.008

Morin, C. M., Rodrigue, S., \& Ivers, H. (2003). Role of Stress, Arousal, and Coping Skills in Primary Insomnia. Psychosomatic Medicine, 65(2), 259-267. https://doi.org/10.1097/01.PSY.0000030391.09558.A3 
Morin, C. M., Vallières, A., \& Ivers, H. (2007). Dysfunctional beliefs and attitudes about sleep (DBAS): validation of a brief version (DBAS-16). Sleep, 30(11), 1547-1554.

Murray, E., Lo, B., Pollack, L., Donelan, K., Catania, J., Lee, K., ... Turner, R. (2003). The Impact of Health Information on the Internet on Health Care and the Physician-Patient Relationship: National U.S. Survey among 1.050 U.S. Physicians. https://doi.org/10.2196/jmir.5.3.e17

Musselman, D. L., Tomer, A., Manatunga, A. K., Knight, B. T., Porter, M. R., Kasey, S., ... Nemeroff, C. B. (1996). Exaggerated platelet reactivity in major depression. The American Journal of Psychiatry, 153(10), 1313-1317.

Nedeltcheva, A. V., Kilkus, J. M., Imperial, J., Kasza, K., Schoeller, D. A., \& Penev, P. D. (2009). Sleep curtailment is accompanied by increased intake of calories from snacks. The American Journal of Clinical Nutrition, 89(1), 126-133. https://doi.org/10.3945/ajen.2008.26574

Newlin, D. B., \& Levenson, R. W. (1979). Pre-ejection Period: Measuring Beta-adrenergic Influences Upon the Heart. Psychophysiology, 16(6), 546-552. https://doi.org/10.1111/j.1469-8986.1979.tb01519.x

Nofzinger, E. A., Buysse, D. J., Germain, A., Price, J. C., Miewald, J. M., \& Kupfer, D. J. (n.d.). Functional neuroimaging evidence for hyperarousal in insomnia. The American Journal of Psychiatry, 161(11), 2126-2129.

Nunan, D., Sandercock, G. R. H., \& Brodie, D. A. (2010). A quantitative systematic review of normal values for short-term heart rate variability in healthy adults. Pacing and Clinical Electrophysiology: PACE, 33(11), 1407-1417. https://doi.org/10.1111/j.15408159.2010.02841.x 
Ogoh, S., Brothers, R. M., Barnes, Q., Eubank, W. L., Hawkins, M. N., Purkayastha, S., ... Raven, P. B. (2005). The effect of changes in cardiac output on middle cerebral artery mean blood velocity at rest and during exercise. The Journal of Physiology, 569(2), 697704. https://doi.org/10.1113/jphysiol.2005.095836

Ohayon, M. M. (2002). Epidemiology of insomnia: what we know and what we still need to learn. Sleep Medicine Reviews, 6(2), 97-111.

Omisade, A., Buxton, O. M., \& Rusak, B. (2010). Impact of acute sleep restriction on cortisol and leptin levels in young women. Physiology \& Behavior, 99(5), 651-656. https://doi.org/http://dx.doi.org.ezproxy.lib.ryerson.ca/10.1016/j.physbeh.2010.01.028

Ong, J. C., Ulmer, C. S., \& Manber, R. (2012). Improving sleep with mindfulness and acceptance: a metacognitive model of insomnia. Behaviour Research and Therapy, 50(11), 651-660. https://doi.org/10.1016/j.brat.2012.08.001

Parthasarathy, S., Vasquez, M. M., Halonen, M., Bootzin, R., Quan, S. F., Martinez, F. D., \& Guerra, S. (2015). Persistent Insomnia is Associated with Mortality Risk. The American Journal of Medicine, 128(3), 268-275.e2. https://doi.org/10.1016/j.amjmed.2014.10.015

Pejovic, S., Vgontzas, A. N., Basta, M., Tsaoussoglou, M., Zoumakis, E., Vgontzas, A., ... Chrousos, G. P. (2010). Leptin and hunger levels in young healthy adults after one night of sleep loss. Journal of Sleep Research, 19(4), 552-558. https://doi.org/http://dx.doi.org.ezproxy.lib.ryerson.ca/10.1111/j.1365-2869.2010.00844.x

Perlis, M. L., Smith, M. T., Andrews, P. J., Orff, H., \& Giles, D. E. (2001). Beta/Gamma EEG activity in patients with primary and secondary insomnia and good sleeper controls. Sleep, 24(1), 110-117.

Phillips, B., \& Mannino, D. M. (2005). Does insomnia kill? Sleep, 28(8), 965-971. 
Phillips, B., \& Mannino, D. M. (2007). Do Insomnia Complaints Cause Hypertension or Cardiovascular Disease? Journal of Clinical Sleep Medicine : JCSM : Official Publication of the American Academy of Sleep Medicine, 3(5), 489-494.

Pigeon, W. R., Hegel, M., Unützer, J., Fan, M.-Y., Sateia, M. J., Lyness, J. M., ... Perlis, M. L. (2008). Is Insomnia a Perpetuating Factor for Late-Life Depression in the IMPACT Cohort? Sleep, 31(4), 481.

Pratt, L. A., Ford, D. E., Crum, R. M., Armenian, H. K., Gallo, J. J., \& Eaton, W. W. (1996). Depression, psychotropic medication, and risk of myocardial infarction. Prospective data from the Baltimore ECA follow-up. Circulation, 94(12), 3123-3129.

PsychCentral. (2014, March 10). Heart Failure Tied to Insomnia Symptoms. Retrieved January 22, 2017, from https://psychcentral.com/news/2014/03/10/heart-failure-tied-to-insomniasymptoms/66929.html

Quigley, K. S., \& Stifter, C. A. (2006). A comparative validation of sympathetic reactivity in children and adults. Psychophysiology, 43(4), 357-365. https://doi.org/http://dx.doi.org.ezproxy.lib.ryerson.ca/10.1111/j.1469-8986.2006.00405.x

Ramsawh, H. J., Stein, M. B., Belik, S.-L., Jacobi, F., \& Sareen, J. (2009). Relationship of anxiety disorders, sleep quality, and functional impairment in a community sample. Journal of Psychiatric Research, 43(10), 926-933. https://doi.org/10.1016/j.jpsychires.2009.01.009

Rehm, J., Mathers, C., Popova, S., Thavorncharoensap, M., Teerawattananon, Y., \& Patra, J. (2009). Global burden of disease and injury and economic cost attributable to alcohol use and alcohol-use disorders. The Lancet, 373(9682), 2223-2233. https://doi.org/10.1016/S0140-6736(09)60746-7 
Riedel, B. W., \& Lichstein, K. L. (2000). Insomnia and daytime functioning. Sleep Medicine Reviews, 4(3), 277-298. https://doi.org/10.1053/smrv.1999.0074

Riemann, D., Klein, T., Rodenbeck, A., Feige, B., Horny, A., Hummel, R., ... Voderholzer, U. (2002). Nocturnal cortisol and melatonin secretion in primary insomnia. Psychiatry Research, 113(1), 17-27.

Rodenbeck, A., Huether, G., Rüther, E., \& Hajak, G. (2002). Interactions between evening and nocturnal cortisol secretion and sleep parameters in patients with severe chronic primary insomnia. Neuroscience Letters, 324(2), 159-163.

Ronksley, P. E., Brien, S. E., Turner, B. J., Mukamal, K. J., \& Ghali, W. A. (2011). Association of alcohol consumption with selected cardiovascular disease outcomes: a systematic review and meta-analysis. BMJ : British Medical Journal, 342. https://doi.org/10.1136/bmj.d671

Rosenman, R. H., Brand, R. J., Sholtz, R. I., \& Friedman, M. (1976). Multivariate prediction of coronary heart disease during 8.5 year follow-up in the western collaborative group study. The American Journal of Cardiology, 37(6), 903-910. https://doi.org/10.1016/0002-9149(76)90117-X

Roth, T. (2007). Insomnia: Definition, Prevalence, Etiology, and Consequences. Journal of Clinical Sleep Medicine : JCSM : Official Publication of the American Academy of Sleep Medicine, 3(5 Suppl), S7.

Rozanski, A., Blumenthal, J. A., \& Kaplan, J. (1999). Impact of Psychological Factors on the Pathogenesis of Cardiovascular Disease and Implications for Therapy. Circulation, 99(16), 2192-2217. https://doi.org/10.1161/01.CIR.99.16.2192 
Sarsour, K., Morin, C. M., Foley, K., Kalsekar, A., \& Walsh, J. K. (2010). Association of insomnia severity and comorbid medical and psychiatric disorders in a health plan-based sample: Insomnia severity and comorbidities. Sleep Medicine, 11(1), 69-74. https://doi.org/http://dx.doi.org.ezproxy.lib.ryerson.ca/10.1016/j.sleep.2009.02.008

Schächinger, H., Weinbacher, M., Kiss, A., Ritz, R., \& Langewitz, W. (2001). Cardiovascular indices of peripheral and central sympathetic activation. Psychosomatic Medicine, 63(5), $788-796$.

Schwartz, S., Anderson, W. M., Cole, S. R., Cornoni-Huntley, J., Hays, J. C., \& Blazer, D. (1999). Insomnia and heart disease: A review of epidemiologic studies. Journal of Psychosomatic Research, 47(4), 313-333. https://doi.org/10.1016/S0022-3999(99)00029$\mathrm{X}$

Shechter, A., O'Keeffe, M., Roberts, A. L., Zammit, G. K., RoyChoudhury, A., \& St-Onge, M.P. (2012). Alterations in sleep architecture in response to experimental sleep curtailment are associated with signs of positive energy balance. American Journal of Physiology. Regulatory, Integrative and Comparative Physiology, 303(9), R883-889. https://doi.org/10.1152/ajpregu.00222.2012

Sherwood, A., Allen, M. T., Fahrenberg, J., Kelsey, R. M., Lovallo, W. R., \& van Doornen, L. J. P. (1990). Methodological Guidelines for Impedance Cardiography. Psychophysiology, 27(1), 1-23. https://doi.org/10.1111/j.1469-8986.1990.tb02171.x

Shin, C., Kim, J., Yi, H., Lee, H., Lee, J., \& Shin, K. (2005). Relationship between trait-anger and sleep disturbances in middle-aged men and women. Journal of Psychosomatic Research, 58(2), 183-189. https://doi.org/10.1016/j.jpsychores.2004.07.002 
Simpson, N. S., Banks, S., \& Dinges, D. F. (2010). Sleep restriction is associated with increased morning plasma leptin concentrations, especially in women. Biological Research for Nursing, 12(1), 47-53. https://doi.org/10.1177/1099800410366301

Smith, S. C., Collins, A., Ferrari, R., Holmes, D. R., Logstrup, S., McGhie, D. V., ... Zoghbi, W. A. (2012). Our Time: A Call to Save Preventable Death From Cardiovascular Disease (Heart Disease and Stroke). Journal of the American College of Cardiology, 60(22), 2343-2348. https://doi.org/10.1016/j.jacc.2012.08.962

Smith, T. W., \& Ruiz, J. M. (2002). Psychosocial influences on the development and course of coronary heart disease: Current status and implications for research and practice. Journal of Consulting and Clinical Psychology, 70(3), 548-568. https://doi.org/10.1037/0022006X.70.3.548

Sodolski, T., \& Kutarski, A. (2007). Impedance cardiography: A valuable method of evaluating haemodynamic parameters. Cardiology Journal, 14(2), 115-126.

Sofi, F., Cesari, F., Casini, A., Macchi, C., Abbate, R., \& Gensini, G. F. (2014). Insomnia and risk of cardiovascular disease: a meta-analysis. European Journal of Preventive Cardiology, 21(1), 57-64. https://doi.org/10.1177/2047487312460020

Somers, V. K., Dyken, M. E., Mark, A. L., \& Abboud, F. M. (1993). Sympathetic-nerve activity during sleep in normal subjects. The New England Journal of Medicine, 328(5), 303-307.

Spaeth, A. M., Dinges, D. F., \& Goel, N. (2013). Effects of Experimental Sleep Restriction on Weight Gain, Caloric Intake, and Meal Timing in Healthy Adults. Sleep, 36(7), 981-990. https://doi.org/10.5665/sleep.2792 
Spiegel, K., Leproult, R., \& Van Cauter, E. (1999). Impact of sleep debt on metabolic and endocrine function. The Lancet, 354(9188), 1435-1439. https://doi.org/10.1016/S01406736(99)01376-8

Spiegelhalder, K., Fuchs, L., Ladwig, J., Kyle, S. D., Nissen, C., Voderholzer, U., ... Riemann, D. (2011). Heart rate and heart rate variability in subjectively reported insomnia. Journal of Sleep Research, 20(1 Pt 2), 137-145. https://doi.org/10.1111/j.13652869.2010.00863.x

Spielberger, C. D., Sydeman, S. J., Owen, A. E., \& Marsh, B. J. (1999). Measuring anxiety and anger with the State-Trait Anxiety Inventory (STAI) and the State-Trait Anger Expression Inventory (STAXI). In The use of psychological testing for treatment planning and outcomes assessment (2nd ed.) (pp. 993-1021). Mahwah, NJ, US: Lawrence Erlbaum Associates Publishers.

Spielman, A. J., Saskin, P., \& Thorpy, M. J. (1987). Treatment of chronic insomnia by restriction of time in bed. Sleep, 10(1), 45-56.

Statistics Canada. (2015). Current smoking trends. Retrieved November 13, 2016, from http://www.statcan.gc.ca/pub/82-624-x/2012001/article/11676-eng.htm

St-Onge, M.-P., Roberts, A. L., Chen, J., Kelleman, M., O’Keeffe, M., RoyChoudhury, A., \& Jones, P. J. H. (2011). Short sleep duration increases energy intakes but does not change energy expenditure in normal-weight individuals. The American Journal of Clinical Nutrition, 94(2), 410-416. https://doi.org/10.3945/ajcn.111.013904

Stormo, K. J., Kee, W. G., Steedham, S., \& Middaugh, S. (1998). Medication quantification scores and evaluation of patient pharmacology profiles. Current Review of Pain, 2(3), 171-174. https://doi.org/10.1007/s11916-998-0015-4 
Suls, J., \& Bunde, J. (2005). Anger, Anxiety, and Depression as Risk Factors for Cardiovascular Disease: The Problems and Implications of Overlapping Affective Dispositions. Psychological Bulletin, 131(2), 260-300. https://doi.org/10.1037/0033-2909.131.2.260

Szelenberger, W., \& Niemcewicz, S. (2000). Severity of insomnia correlates with cognitive impairment. Acta Neurobiologiae Experimentalis, 60(3), 373.

Tagawa, H., Shimokawa, H., Tagawa, T., Kuroiwa-Matsumoto, M., Hirooka, Y., \& Takeshita, A. (1999). Long-Term Treatment with Eicosapentaenoic Acid Augments Both Nitric Oxide-Mediated and Non-Nitric Oxide-Mediated Endothelium-Dependent Forearm Vasodilatation in Patients with Coronary Artery Disease: Journal of Cardiovascular Pharmacology, 33(4), 633-640. https://doi.org/10.1097/00005344-199904000-00017

Talbot, L. S., McGlinchey, E. L., Kaplan, K. A., Dahl, R. E., \& Harvey, A. G. (2010). Sleep deprivation in adolescents and adults: Changes in affect. Emotion, 10(6), 831-841. https://doi.org/10.1037/a0020138

Talbot, L. S., Stone, S., Gruber, J., Hairston, I. S., Eidelman, P., \& Harvey, A. G. (2012). A test of the bidirectional association between sleep and mood in bipolar disorder and insomnia. Journal of Abnormal Psychology, 121(1), 39-50. https://doi.org/10.1037/a0024946

Task Force of the European Society of Cardiology and The North American Society of Pacing and Electrophysiology. (1996). Heart rate variability. European Heart Journal, 17(3), $354-381$.

Taylor, B., Irving, H. M., Baliunas, D., Roerecke, M., Patra, J., Mohapatra, S., \& Rehm, J. (2009). Alcohol and hypertension: gender differences in dose-response relationships determined through systematic review and meta-analysis. Addiction, 104(12), 19811990. https://doi.org/10.1111/j.1360-0443.2009.02694.x 
Thayer, J. F., \& Brosschot, J. F. (2005). Psychosomatics and psychopathology: looking up and down from the brain. Psychoneuroendocrinology, 30(10), 1050-1058. https://doi.org/10.1016/j.psyneuen.2005.04.014

Thayer, J. F., Smith, M., Rossy, L. A., Sollers, J. J., \& Friedman, B. H. (1998). Heart period variability and depressive symptoms: gender differences. Biological Psychiatry, 44(4), 304-306. https://doi.org/10.1016/S0006-3223(98)00008-0

Thayer, J., Hansen, A., Saus-Rose, E., \& Johnsen, B. (2009). Heart Rate Variability, Prefrontal Neural Function, and Cognitive Performance: The Neurovisceral Integration Perspective on Self-regulation, Adaptation, and Health. Annals of Behavioral Medicine, 37(2), 141153. https://doi.org/10.1007/s12160-009-9101-z

The Link Between Insomnia \& Heart Failure. (n.d.). Retrieved February 4, 2017, from https://www.verywell.com/heart-failure-and-insomnia-1746195

Troxler, R. G., Sprague, E. A., Albanese, R. A., Fuchs, R., \& Thompson, A. J. (1977). The association of elevated plasma cortisol and early atherosclerosis as demonstrated by coronary angiography. Atherosclerosis, 26(2), 151-162. https://doi.org/10.1016/00219150(77)90098-3

Uhde, T. W., Cortese, B. M., \& Vedeniapin, A. (2009). Anxiety and sleep problems: Emerging concepts and theoretical treatment implications. Current Psychiatry Reports, 11(4), 269276. https://doi.org/10.1007/s11920-009-0039-4

Vgontzas, A. N., Fernandez-Mendoza, J., Liao, D., \& Bixler, E. O. (2013). Insomnia with objective short sleep duration: The most biologically severe phenotype of the disorder. Sleep Medicine Reviews, 17(4), 241-254. https://doi.org/10.1016/j.smrv.2012.09.005 
Vgontzas, A. N., Liao, D., Pejovic, S., Calhoun, S., Karataraki, M., Basta, M., ... Bixler, E. O. (2010). Insomnia with short sleep duration and mortality: The Penn State cohort. Sleep: Journal of Sleep and Sleep Disorders Research, 33(9), 1159-1164.

Waters, W. F., Adams, S. G., Binks, P., \& Varnado, P. (1993). Attention, stress and negative emotion in persistent sleep-onset and sleep maintenance insomnia. Sleep: Journal of Sleep Research \& Sleep Medicine, 16(2), 128-136.

West, S. G., Finch, J. F., \& Curran, P. J. (1995). Structural equation models with nonnormal variables: Problems and remedies. In Structural equation modeling: Concepts, issues, and applications (pp. 56-75). Thousand Oaks, CA, US: Sage Publications, Inc.

World Health Organization. (2009). Global Health Risks: Mortality and Burden of Disease Attributable to Selected Major Risks. World Health Organization.

World Health Organization. (2014). Global statys report on alcohol and health - 2014 ed. WHO Library Cataloguing-in-Publication Data, 1-100.

Wu, J. C., \& Bunney, W. E. (1990). The biological basis of an antidepressant response to sleep deprivation and relapse: Review and hypothesis. The American Journal of Psychiatry, $147(1), 14-21$.

Yeragani, V. K., Rao, K. A. R. K., Smitha, M. R., Pohl, R. B., Balon, R., \& Srinivasan, K. (2002). Diminished chaos of heart rate time series in patients with major depression. Biological Psychiatry, 51(9), 733-744. https://doi.org/10.1016/S0006-3223(01)01347-6

Young, M. E. (2016). The problem with categorical thinking by psychologists. Behavioural Processes, 123, 43-53. https://doi.org/10.1016/j.beproc.2015.09.009

Yusuf, S., Reddy, S., Ôunpuu, S., \& Anand, S. (2001). Global Burden of Cardiovascular Diseases Part I: General Considerations, the Epidemiologic Transition, Risk Factors, and 
Impact of Urbanization. Circulation, 104(22), 2746-2753.

https://doi.org/10.1161/hc4601.099487

Zambotti, M. de, Covassin, N., Sarlo, M., Tona, G. D. M., Trinder, J., \& Stegagno, L. (2012). Nighttime cardiac sympathetic hyper-activation in young primary insomniacs. Clinical Autonomic Research, 23(1), 49-56. https://doi.org/10.1007/s10286-012-0178-2

Zhang, B., \& Wing, Y.-K. (2006). Sex differences in insomnia: a meta-analysis. Sleep, 29(1), $85-93$. 
Appendix A

\section{Demographics and Duke Structured Interview for Sleep Disorders DEMOGRAPHIC INFORMATION [SCREENING VISIT]}

ID:

AGE:

ETHNIC BACKGROUND (check one):

Aboriginal Canadian

African Canadian

Caribbean Canadian

East/Southeast Canadian

European Canadian

Latin/Central/South Canadian

Oceanic Canadian

South Asian Canadian

West Asian/Arab Canadian

Pacific Islander Canadian

Other:

MARITAL STATUS (check one):

Single

Married/common-law

Live-in Partner (less than 2 years)

Divorced

Separated

Widowed

\section{LIVING ARRANGEMENT (check one):}

Living Alone

With Spouse/Partner and Children

With Friend(s)/Roommate(s)
Date:

$\operatorname{SEX}$ (check one): _ $\mathrm{F} \_\mathrm{M}$

\section{EMPLOYMENT STATUS}

Full-Time

Part-Time

Not Working

If employed, what kind of work are you involved in? 


\section{CHECKLIST OF MEDICAL CONDITIONS \& SYMPTOMS}

Have you ever had or do you currently have (i.e. past month) any of the following disorders or medical symptoms? Please check the appropriate box (current or past) for all that apply

\begin{tabular}{|c|c|c|}
\hline $\begin{array}{l}\text { CURRENT } \\
\text { (past month) }\end{array}$ & PAST & DISORDER/SYMPTOMS \\
\hline & & $\begin{array}{l}\text { Heart Disease: } \\
\text { Examples: Angina; Cardiac Arrhythmias (irregular heart beats); Congestive } \\
\text { Heart Failure; Myocardial Infarction (heart attack) }\end{array}$ \\
\hline & & $\begin{array}{l}\text { Pulmonary Disease: } \\
\text { Examples: COPD; Emphysema; Cystic Fibrosis; Asthma }\end{array}$ \\
\hline & & $\begin{array}{l}\text { Gastrointestinal Disorders: } \\
\text { Examples: Stomach or Duodenal Ulcers; Reflux Disease (GERD) }\end{array}$ \\
\hline & & $\begin{array}{l}\text { Neurologic Disorders: } \\
\text { Examples: Huntington's Disease; Seizures; Spastic Torticollis; Blepharospasm; } \\
\text { Dystonias; Parkinson's Disease; Alzheimer's Disease; Dementia; Sleep- } \\
\text { disruptive Headaches }\end{array}$ \\
\hline & & $\begin{array}{l}\text { Head Trauma: } \\
\text { Examples: Blow to the head with loss of consciousness; Concussion }\end{array}$ \\
\hline & & $\begin{array}{l}\text { Chronic Pain Disorders: } \\
\text { Examples: Fibrositis/Fibromyalgia; Arthritis; Muscle Cramps; Chronic Low } \\
\text { Back Pain }\end{array}$ \\
\hline & & Endocrine Disorders such as Thyroid Disease \\
\hline & & Metabolic Disorders such as Diabetes \\
\hline & & $\begin{array}{l}\text { Kidney Disease: } \\
\text { Examples: Kidney Failure with Dialysis; Kidney Stones }\end{array}$ \\
\hline & & Autoimmune Disorders such as Lupus \\
\hline & & Cancer \\
\hline & & HIV/AIDS \\
\hline & & Headaches \\
\hline & & Other. Please specify: \\
\hline
\end{tabular}




\section{EXERCISE}

How often do you exercise (break a sweat)?

$\square$ Never

$\square$ 1-2 times per week

$\square$ 3-4 times per week

$\square$ 5-7 times per week

CHECKLIST OF MEDICATION, DRUGS, AND OTHER SUBSTANCES

Have you ever used or do you currently use (i.e. past month) any of the following medications or substances? Please check the appropriate box (current or past) for all that apply.

\section{PRESCRIPTION MEDICATIONS}

\begin{tabular}{|l|l|l|}
\hline $\begin{array}{c}\text { CURRENT } \\
\text { (past } \\
\text { month) }\end{array}$ & PAST & \multicolumn{1}{|c|}{ MEDICATIONS/SUBSTANCES } \\
\hline & & $\begin{array}{l}\text { Antidepressants } \\
\text { Examples - Elavil, Trazodone, Prozac, Zoloft }\end{array}$ \\
\hline & $\begin{array}{l}\text { Anti-anxiety drugs } \\
\text { Examples - Valium, Xanax, Buspar }\end{array}$ \\
\hline & $\begin{array}{l}\text { Anti-psychotics } \\
\text { Examples - Thorazine, Haldol, Risperidone }\end{array}$ \\
\hline & $\begin{array}{l}\text { Antihypertensives } \\
\text { Examples - beta blockers, Clonidin }\end{array}$ \\
\hline & $\begin{array}{l}\text { Thyroid medication } \\
\text { Examples - Thyroxin }\end{array}$ \\
\hline & $\begin{array}{l}\text { Antiasthmatics } \\
\text { Examples - Theophyllin, Clebuterol }\end{array}$ \\
\hline & $\begin{array}{l}\text { Anti-Parkinson drugs } \\
\text { Examples - L-Dopa, Sinemet, Requip }\end{array}$ \\
\hline Anticonvulsants \\
Examples - Dilantin, Tegretol, Phenobarbital \\
\hline
\end{tabular}




\begin{tabular}{|l|l|}
\hline & $\begin{array}{l}\text { Sleep medicines } \\
\text { Examples - Ambien, Trazodone, Amitriptyline, Benadryl }\end{array}$ \\
\hline & $\begin{array}{l}\text { Lipid lowering or antihypertensive medications } \\
\text { Examples - Lipitor, ACE inhibitors, lisinopril }\end{array}$ \\
\hline & Other - Specify \\
\hline
\end{tabular}

CHECKLIST OF MEDICATION, DRUGS, AND OTHER SUBSTANCES, continued

OTHER DRUGS AND SUBSTANCES

\begin{tabular}{|l|l|l|l|}
\hline $\begin{array}{c}\text { CURRENT } \\
\text { (past month) }\end{array}$ & PAST & AMOUNT & \multicolumn{1}{c|}{ DRUGS/SUBSTANCES } \\
\hline & & & Nicotine \\
\hline & & Cannabis \\
\hline & & Marijuana \\
\hline & & Hashish \\
\hline & & Cocaine/Crack \\
\hline & & Heroin \\
\hline & & LSD \\
\hline & & Amphetamines \\
\hline & & & Glue \\
\hline
\end{tabular}

COMMON BEVERAGES

\begin{tabular}{|c|c|c|}
\hline $\begin{array}{c}\text { CURRENT } \\
\text { (past } \\
\text { month) }\end{array}$ & PAST & \multicolumn{1}{c|}{ DRUGS/SUBSTANCES } \\
\hline & & Alcohol (used in large quantities or on a daily basis) \\
\hline & & $\begin{array}{l}\text { Caffeinated beverages (coffee, tea, soft drinks) } \\
\text { 4 or more cups per day or 2 or more cups after 6:00 p.m. }\end{array}$ \\
\hline
\end{tabular}




\section{CHECKLIST OF UNUSUAL EVENTS AND BEHAVIORS OCCURRING DURING}

SLEEP

Have you ever had or do you currently have (i.e. past month) any of the following symptoms? Please check the appropriate box (current or past) for all that apply.

\begin{tabular}{|c|c|c|}
\hline $\begin{array}{c}\text { CURRENT } \\
\text { (past } \\
\text { month) } \\
\end{array}$ & PAST & SYMPTOMS \\
\hline & & Recurrent disturbing dreams \\
\hline & & $\begin{array}{l}\text { Night terrors (abrupt awakening with feelings of fright } \\
\text { and confusion) }\end{array}$ \\
\hline & & Sleepwalking \\
\hline & & $\begin{array}{l}\text { Strange sensory experiences upon awakening or falling } \\
\text { asleep }\end{array}$ \\
\hline & & Memory changes or bizarre behaviors during the night \\
\hline & & $\begin{array}{l}\text { Confusion and difficulty coming to your senses when } \\
\text { awakened from sleep }\end{array}$ \\
\hline & & Painful leg cramps during sleep \\
\hline & & Paralysis or inability to move while in bed \\
\hline & & $\begin{array}{l}\text { Behaviors that are aggressive to others or dangerous to } \\
\text { yourself during sleep }\end{array}$ \\
\hline & & Acting out your dreams \\
\hline & & Grinding your teeth during sleep \\
\hline & & Eating/drinking during sleep \\
\hline & & Groaning during sleep \\
\hline & & $\begin{array}{l}\text { Loud noises in your head upon awakening or falling } \\
\text { asleep }\end{array}$ \\
\hline & & Bedwetting \\
\hline
\end{tabular}




\section{Appendix B}

\section{Insomnia Severity Index}

1. Please rate the current severity of your insomnia problem(s):

Difficulty falling asleep

Difficulty staying asleep

Problem waking up too early

$\begin{array}{lllll}\text { None } & \text { Mild } & \text { Mod. } & \text { Severe } & \text { Sery } \\ 0 & 1 & 2 & 3 & 4 \\ 0 & 1 & 2 & 3 & 4 \\ 0 & 1 & 2 & 3 & 4\end{array}$

2. How satisfied/dissatisfied are you with your current sleep pattern?

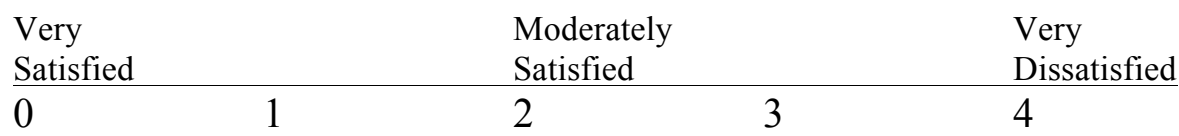

3. To what extent do you consider your sleep problem to INTERFERE with your daily functioning (e.g., daytime functioning, ability to function at work/daily chores, concentration, memory, mood, etc.)?

\begin{tabular}{llccc}
$\begin{array}{l}\text { Not at } \\
\text { All }\end{array}$ & A little & Somewhat & Much & $\begin{array}{c}\text { Very } \\
\text { much }\end{array}$ \\
\hline 0 & 1 & 2 & 3 & 4
\end{tabular}

4. How NOTICEABLE to others do you think your sleeping problem is in terms of impairing the quality of your life?

\begin{tabular}{llccc}
$\begin{array}{l}\text { Not at } \\
\text { All }\end{array}$ & A little & Somewhat & Much & $\begin{array}{c}\text { Very } \\
\text { much }\end{array}$ \\
\hline 0 & 1 & 2 & 3 & 4
\end{tabular}

5. How WORRIED/distressed are you about your current sleep problem?

\begin{tabular}{llccc}
$\begin{array}{l}\text { Not at } \\
\text { All }\end{array}$ & A little & Somewhat & Much & $\begin{array}{c}\text { Very } \\
\text { much }\end{array}$ \\
\hline 0 & 1 & 2 & 3 & 4
\end{tabular}

6. After a poor night's sleep, which of the following problems do you experience the next day?

Circle all those that apply.

a. Daytime fatigue: tired, exhausted, washed out, sleepy.

b. Difficulty functioning: performance impairment at work/daily chores, difficulty concentrating, memory problems.

c. Mood problems: irritable, tense, nervous, groggy, depressed, anxious, grouchy, hostile, angry, confused. 
d. Physical symptoms: muscle aches/pain, light-headed, headache, nausea, heartburn, muscle tension.

e. None. 


\section{Appendix C}

\section{Depression Anxiety Stress Scale - 21}

Please read each statement and circle a number $0,1,2$ or 3 which indicates how much the statement applied to you over the past week. There are no right or wrong answers. Do not spend too much time on any statement.

The rating scale is as follows:

0 Did not apply to me at all

1 Applied to me to some degree, or some of the time

2 Applied to me to a considerable degree, or a good part of time

3 Applied to me very much, or most of the time

1 I found it hard to wind down

2 I was aware of dryness of my mouth

3 I couldn't seem to experience any positive feeling at all

$4 \quad$ I experienced breathing difficulty (e.g., excessively rapid breathing, $\begin{array}{lllll}0 & 1 & 2 & 3\end{array}$ breathlessness in the absence of physical exertion)

5 I found it difficult to work up the initiative to do things

$6 \quad$ I tended to over-react to situations

7 I experienced trembling (e.g., in the hands)

8 I felt that I was using a lot of nervous energy

$\begin{array}{lllllll}9 & \text { I was worried about situations in which I might panic and make a } & 0 & 1 & 2 & 3\end{array}$ fool of myself

10 I felt that I had nothing to look forward to

11 I found myself getting agitated

12 I found it difficult to relax

13 I felt down-hearted and blue

$\begin{array}{llllll}14 & \text { I was intolerant of anything that kept me from getting on with what } & 0 & 1 & 2 & 3\end{array}$ I was doing

15 I felt I was close to panic

16 I was unable to become enthusiastic about anything

17 I felt I wasn't worth much as a person

18 I felt that I was rather touchy

19 I was aware of the action of my heart in the absence of physical

$\begin{array}{llll}0 & 1 & 2 & 3 \\ 0 & 1 & 2 & 3 \\ 0 & 1 & 2 & 3 \\ 0 & 1 & 2 & 3 \\ 0 & 1 & 2 & 3\end{array}$


exertion (e.g., sense of heart rate increase, heart missing a beat)

20 I felt scared without any good reason

$\begin{array}{llll}0 & 1 & 2 & 3\end{array}$

21 I felt that life was meaningless

$\begin{array}{llll}0 & 1 & 2 & 3\end{array}$




\section{Appendix D}

\section{Daytime Insomnia Symptom Rumination Scale}

People think and do many different things when they feel tired. Please read each of the items below and indicate whether you almost never, sometimes, often, or almost always think or do each one when you feel tired. Please select only one answer. Please indicate what you generally do, not what you think you should do.

$$
\begin{aligned}
& 1=\text { Almost Never } \\
& 2=\text { Sometimes } \\
& 3=\text { Often } \\
& 4=\text { Almost Always }
\end{aligned}
$$

1234 1. Think, "I won't be able to do work because I feel so bad"

$\begin{array}{lllll}1 & 2 & 3 & 4 & 2 \text { 2. Think about your feelings of fatigue }\end{array}$

$\begin{array}{lllll}1 & 2 & 3 & 4 & 3 \text {. Think about how hard it is to concentrate }\end{array}$

$\begin{array}{lllll}1 & 2 & 3 & 4 & 4 \text {. Think about how unmotivated you feel }\end{array}$

$\begin{array}{lllll}1 & 2 & 3 & 4 & 5 \text {. Think about how your thoughts are cloudy/muddled }\end{array}$

$\begin{array}{lllll}1 & 2 & 3 & 4 & 6 \text {. Think about how everything requires more effort than usual }\end{array}$

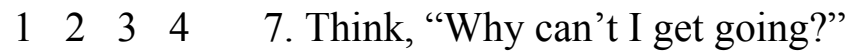

$\begin{array}{lllll}1 & 2 & 3 & 4 & \text { 8. Think about how sad you feel }\end{array}$

$\begin{array}{lllll}1 & 2 & 3 & 4 & 9\end{array}$. Think about how you don't feel up to doing anything

$\begin{array}{lllll}1 & 2 & 3 & 4 & 10 . \text { Think about your feelings of achiness }\end{array}$

$\begin{array}{lllll}1 & 2 & 3 & 4 & 11 \text {. Think about how bad you feel }\end{array}$

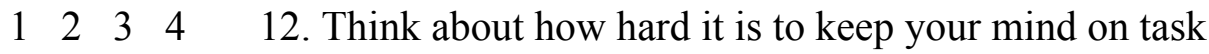

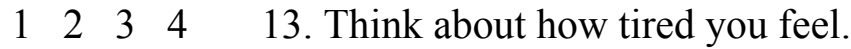

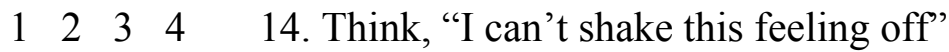

$\begin{array}{lllll}1 & 2 & 3 & 4 & 15 \text {. Think about how irritable you feel }\end{array}$

$\begin{array}{lllll}1 & 2 & 3 & 4 & 16 \text {. Think about how sleepy you feel }\end{array}$ 


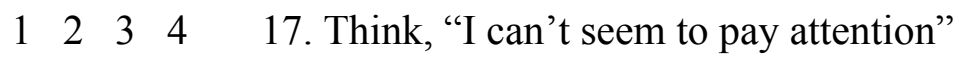

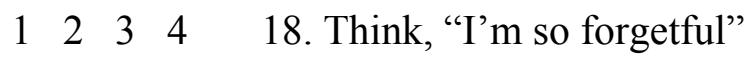

$\begin{array}{lllll}1 & 2 & 3 & 4 & 19\end{array}$. Think, "I can't be around people when I'm feeling this way"

$\begin{array}{lllll}1 & 2 & 3 & 4 & 20 \text {. Think about how you don't have the energy to get through the day }\end{array}$ 
Appendix E

\section{Semi-Quantitative Food Frequency Questionnaire}

Instructions: Please choose the best response for the questions below.

1) Do you eat cheese $(1$ portion $=1 / 8$ of a camembert $=30 \mathrm{~g})$ ?

Less than 2 portions a week

3 to 6 portions a week

2 portions a day

3 or more portions a day

2) Do you eat red meat (apart from poultry) or variety of meats (e.g. liver, kidneys...)?

Less than 3 times a week

3 to 6 times a week

7 or more times a week

3) Do you eat fresh or canned fish (such as canned sardines or tuna)?

Less than once a week

Once a week

2 to 3 times a week

4 or more times a week

4) Do you eat deli foods (including sausages, cassoulet, and sauerkraut with its trimmings) except lean ham?

Less than twice a week

2 to 3 times a week

4 to 6 times a week

7 or more times a week

5) Do you eat salted pies, pizzas, rolls, or commercial sandwiches?

Less than twice a week

2 to 3 times a week

4 or more times a week

6) Do you eat French fries?

Frequency $=$ times/week

Homemade French fries cooked with vegetable oil, kind of oil:

Homemade French fries cooked with solid fat (e.g. Vegetaline)

Oven cooked frozen French fries

Restaurant or fast food French fries

7) Do you eat cakes and pastries?

Less than twice a week

2 to 4 times a week

5 or more times a week

8) Do you eat fruit or drink fruit juice ( 1 portion $=1$ average fruit $=1$ glass of $200 \mathrm{~mL}$ fruit juice)? 
Less than 3 portions a week

3 to 6 portions a week

7 to 13 portions a week (at least 1 fruit a day)

14 or more portions a week (at least 2 fruits a day)

9) At present, do you eat nuts?

Yes, daily consumption:

No

10) Do you eat cooked vegetables or vegetable soup $(1$ portion $=1$ plate or 1 bowl)?

Less than 3 portions a week

3 to 7 portions a week

8 or more portions a week

11) Do you eat raw vegetables or salads?

Less than 3 portions a week

3 to 7 portions a week

8 or more portions a week

12) Do you eat butter or cream ( 1 portion $=1$ individual block of $10-15 \mathrm{~g})$ ?

Never

1 portion a day

2 portions a day

3 portions a day

More than three portions a day (e.g., used for cooking)

13) Apart from butter, do you use other kids of fat (like margarine) to spread or to season cooked dishes?

No

Yes, kind of fat:

1 meal a day (1 individual block)

2 meals a day ( 2 individual blocks)

3 or more portions a day (more than 3 individual blocks)

For cooking?

No

Yes, kind of fat:

1 meal a day (about 1 tablespoon)

2 meals a day (about 2 tablespoons)

14) Do you eat oil for cooking?

No

Yes, kind of oil:

1 meal a day (about 1 tablespoon)

2 meals a day (about 2 tablespoons)

Do you eat oil for salad dressing?

No

Yes, kind of oil: 
Once a day (about 1 tablespoon)

Twice a day (about 2 tablespoons)

3 or more times a day (more than 2 tablespoons) 
Appendix F

Medication Quantification Scale

Patient Worksheet

\begin{tabular}{|c|c|c|c|c|c|c|}
\hline \multirow[b]{2}{*}{ Drug } & \multirow[b]{2}{*}{$\begin{array}{l}\text { Dosage } \\
\text { Mg/day }\end{array}$} & \multicolumn{5}{|c|}{ For Office Use Only: } \\
\hline & & $\begin{array}{l}\text { Detriment } \\
\text { Weight } \\
\text { (Table 1) }\end{array}$ & (X) & $\begin{array}{l}\text { Dosage } \\
\text { Level } \\
\text { (Table 2) }\end{array}$ & $(=)$ & $\begin{array}{l}\text { MOS } \\
\text { Score }\end{array}$ \\
\hline & & & $\mathrm{X}$ & & $=$ & \\
\hline & & & $\mathrm{X}$ & & $=$ & \\
\hline & & & $\mathrm{X}$ & & $=$ & \\
\hline & & & $\mathrm{X}$ & & $=$ & \\
\hline & & & $\mathrm{X}$ & & $=$ & \\
\hline & & & $\mathrm{X}$ & & $=$ & \\
\hline & & & $\mathrm{X}$ & & $=$ & \\
\hline & & & $\mathrm{X}$ & & $=$ & \\
\hline & & & $X$ & & $=$ & \\
\hline & & & & Total Sc & & \\
\hline
\end{tabular}


Appendix G

\section{General Instructions}

\section{Consensus Sleep Diary}

What is a Sleep Diary? A sleep diary is designed to gather information about your daily sleep pattern.

How often and when do I fill out the sleep diary? It is necessary for you to complete your sleep diary every day. If possible, the sleep diary should be completed within one hour of getting out of bed in the morning.

What should I do if I miss a day? If you forget to fill in the diary or are unable to finish it, leave the diary blank for that day.

What if something unusual affects my sleep or how I feel in the daytime? If your sleep or daytime functioning is affected by some unusual event (such as an illness, or an emergency) you may make brief notes on your diary.

What do the words "bed" and "day" mean on the diary? This diary can be used for people who are awake or asleep at unusual times. In the sleep diary, the word "day" is the time when you choose or are required to be awake. The term "bed" means the place where you usually sleep.

Will answering these questions about my sleep keep me awake? This is not usually a problem. You should not worry about giving exact times, and you should not watch the clock. Just give your best estimate.

\section{Item Instructions}

Use the guide below to clarify what is being asked for each item of the Sleep Diary.

Date: Write the date of the morning you are filling out the diary.

1. What time did you get into bed? Write the time that you got into bed. This may not be the time that you began "trying" to fall asleep.

2. What time did you try to go to sleep? Record the time that you began "trying" to fall asleep.

3. How long did it take you to fall asleep? Beginning at the time you wrote in question 2, how long did it take you to fall asleep.

4. How many times did you wake up, not counting your final awakening? How many times did you wake up between the time you first fell asleep and your final awakening?

5. In total, how long did these awakenings last? What was the total time you were awake between the time you first fell asleep and your final awakening. For example, if you woke 3 times for 20 minutes, 35 minutes, and 15 minutes, add them all up $(20+35+15=70 \mathrm{~min}$ or $1 \mathrm{hr}$ and $10 \mathrm{~min}$ ).

6. What time was your final awakening? Record the last time you woke up in the morning.

7. What time did you get out of bed for the day? What time did you get out of bed with no 
further attempt at sleeping? This may be different from your final awakening time (e.g. you may have woken up at 6:35 a.m. but did not get out of bed to start your day until 7:20 a.m.)

8. How would you rate the quality of your sleep? "Sleep Quality" is your sense of whether your sleep was good or poor.

9. Comments If you have anything that you would like to say that is relevant to your sleep feel free to write it here. 


\begin{tabular}{|c|c|c|c|c|c|c|c|c|}
\hline Today's date & $4 / 5 / 11$ & & & & & & & \\
\hline $\begin{array}{l}\text { 1. What time } \\
\text { did you get } \\
\text { into bed? }\end{array}$ & $10: 15 \mathrm{p} .1$ & & & & & & & \\
\hline $\begin{array}{l}\text { 2. What time } \\
\text { did you try to } \\
\text { go to sleep? }\end{array}$ & $11: 30$ p.1 & & & & & & & \\
\hline $\begin{array}{l}\text { 3. How long } \\
\text { did it take } \\
\text { you to fall } \\
\text { asleep? }\end{array}$ & $55 \mathrm{~min}$. & & & & & & & \\
\hline $\begin{array}{l}\text { 4. How many } \\
\text { times did you } \\
\text { wake up, not } \\
\text { counting your } \\
\text { final } \\
\text { awakening? }\end{array}$ & 3 times & & & & & & & \\
\hline $\begin{array}{l}\text { 5. In total, } \\
\text { how long did } \\
\text { these } \\
\text { awakenings } \\
\text { last? }\end{array}$ & $\begin{array}{l}1 \text { hour } \\
10 \mathrm{~min} \text {. }\end{array}$ & & & & & & & \\
\hline $\begin{array}{l}\text { 6. What time } \\
\text { was your } \\
\text { final } \\
\text { awakening? }\end{array}$ & $6: 35$ a.r & & & & & & & \\
\hline $\begin{array}{l}\text { 7. What time } \\
\text { did you get } \\
\text { out of bed for } \\
\text { the day? }\end{array}$ & $7: 20 \mathrm{a}$. & & & & & & & \\
\hline $\begin{array}{l}8 . \text { How } \\
\text { would you } \\
\text { rate the } \\
\text { quality of } \\
\text { your sleep? }\end{array}$ & $\begin{array}{l}\square \text { Very } \\
\text { poor } \\
\square \text { Poor } \\
\square \text { Fair } \\
\square \text { Good } \\
\square \text { Very } \\
\text { good }\end{array}$ & $\begin{array}{l}\square \text { Very } \\
\text { poor } \\
\square \text { Poor } \\
\square \text { Fair } \\
\square \text { Good } \\
\square \text { Very } \\
\text { good }\end{array}$ & $\begin{array}{l}\square \text { Very } \\
\text { poor } \\
\square \text { Poor } \\
\square \text { Fair } \\
\square \text { Good } \\
\square \text { Very } \\
\text { good }\end{array}$ & $\begin{array}{l}\square \text { Very } \\
\text { poor } \\
\square \text { Poor } \\
\square \text { Fair } \\
\square \text { Good } \\
\square \text { Very } \\
\text { good }\end{array}$ & $\begin{array}{l}\square \text { Very } \\
\text { poor } \\
\square \text { Poor } \\
\square \text { Fair } \\
\square \text { Good } \\
\square \text { Very } \\
\text { good }\end{array}$ & $\begin{array}{l}\square \text { Very } \\
\text { poor } \\
\square \text { Poor } \\
\square \text { Fair } \\
\square \text { Good } \\
\square \text { Very } \\
\text { good }\end{array}$ & $\begin{array}{l}\square \text { Very } \\
\text { poor } \\
\square \text { Poor } \\
\square \text { Fair } \\
\square \text { Good } \\
\square \text { Very } \\
\text { good }\end{array}$ & $\begin{array}{l}\text { Very } \\
\text { poor } \\
\square \text { Poor } \\
\square \text { Fair } \\
\square \text { Good } \\
\square \text { Very } \\
\text { good }\end{array}$ \\
\hline $\begin{array}{l}\text { 9. Comments } \\
\text { (if applicable) }\end{array}$ & $\begin{array}{l}\text { I have a } \\
\text { cold }\end{array}$ & & & & & & & \\
\hline
\end{tabular}




\section{Glossary}

BMI - Body Mass Index

CBT-I - Cognitive Behavioural Therapy for Insomnia

$\mathrm{CO}-$ Cardiac Output

CNS - Central Nervous System

CSD - Consensus Sleep Diary

CVD - Cardiovascular Disease

$\mathrm{CV}$ - Cardiovascular

DASS-21 - Depression Anxiety Stress Scales

DASS-A - Anxiety subscale of the DASS-21

DASS-D - Depression subscale of the DASS-21

DASS-S - Stress subscale of the DASS-21

DP1 - Dark Phase 1

DP2 - Dark Phase 2

DISRS - Daytime Insomnia Symptom Response Scale

HLM - Hierarchical Linear Modeling

HRV - Heart Rate Variability

HF HRV - High Frequency HRV

ICC - Intraclass Correlation Coefficient

ISI - Insomnia Severity Index

LF HRV - Low Frequency HRV

MLM - Multilevel Modeling

MQS - Medication Quantification Scale

PEP - Pre-ejection Period

PNS - Parasympathetic Nervous System

RDC - Research Diagnostic Criteria

SE - Sleep Efficiency

SFFQ - Semi-Quantitative Food Frequency Questionnaire

SNS - Sympathetic Nervous System

SOL - Sleep Onset Latency 
STAXI - State-Trait Anger Expression Inventory

Trait Anger-R - Angry Reaction subscale of the STAXI

Trait Anger-T - Angry Temperament subscale of the STAXI

TST - Total Sleep Time

TWT - Total Wake Time

WASO - Wakefulness After Sleep Onset 